Cochrane Database of Systematic Reviews

\title{
Negative pressure wound therapy for treating foot wounds in people with diabetes mellitus (Review)
}

Liu Z, Dumville JC, Hinchliffe RJ, Cullum N, Game F, Stubbs N, Sweeting M, Peinemann F

Liu Z, Dumville JC, Hinchliffe RJ, Cullum N, Game F, Stubbs N, Sweeting M, Peinemann F.

Negative pressure wound therapy for treating foot wounds in people with diabetes mellitus.

Cochrane Database of Systematic Reviews 2018, Issue 10. Art. No.: CD010318.

DOI: 10.1002/14651858.CD010318.pub3.

www.cochranelibrary.com 
TABLE OF CONTENTS

HEADER 1

ABSTRACT

PLAIN LANGUAGE SUMMARY

SUMMARY OF FINDINGS

BACKGROUND

OBJECTIVES

METHODS

RESULTS

Figure 1.

Figure 2.

Figure 3.

DISCUSSION

AUTHORS' CONCLUSIONS

ACKNOWLEDGEMENTS

REFERENCES

CHARACTERISTICS OF STUDIES

DATA AND ANALYSES

Analysis 1.1. Comparison 1 Negative pressure wound therapy (NPWT) compared with dressings in postoperative wounds, Outcome 1 Proportion of wounds healed.

Analysis 1.2. Comparison 1 Negative pressure wound therapy (NPWT) compared with dressings in postoperative wounds, Outcome 2 Time to healing.

Analysis 1.3. Comparison 1 Negative pressure wound therapy (NPWT) compared with dressings in postoperative wounds, Outcome 3 Amputations.

Analysis 1.4. Comparison 1 Negative pressure wound therapy (NPWT) compared with dressings in postoperative wounds, Outcome 4 Number of wounds closed or covered with surgery.

Analysis 1.5. Comparison 1 Negative pressure wound therapy (NPWT) compared with dressings in postoperative wounds, Outcome 5 Adverse events.

Analysis 2.1. Comparison 2 NPWT compared with dressings in diabetic foot ulcers, Outcome 1 Proportion of wounds healed. .. Analysis 2.2. Comparison 2 NPWT compared with dressings in diabetic foot ulcers, Outcome 2 Amputations.

Analysis 2.3. Comparison 2 NPWT compared with dressings in diabetic foot ulcers, Outcome 3 Number of wounds closed or covered with surgery.

Analysis 2.4. Comparison 2 NPWT compared with dressings in diabetic foot ulcers, Outcome 4 Wound recurrence. ................. Analysis 3.1. Comparison 3 Low compared with high pressure of NPWT in diabetic foot ulcers, Outcome 1 Number of wounds closed or covered with surgery.

Analysis 3.2. Comparison 3 Low compared with high pressure of NPWT in diabetic foot ulcers, Outcome 2 Adverse events. ..... ADDITIONAL TABLES

APPENDICES

WHAT'S NEW

HISTORY

CONTRIBUTIONS OF AUTHORS

DECLARATIONS OF INTEREST

SOURCES OF SUPPORT

DIFFERENCES BETWEEN PROTOCOL AND REVIEW

INDEX TERMS 
[Intervention Review]

\section{Negative pressure wound therapy for treating foot wounds in people with diabetes mellitus}

Zhenmi Liu1,2, Jo C Dumville², Robert J Hinchliffe ${ }^{3}$, Nicky Cullum², Fran Game ${ }^{4}$, Nikki Stubbs ${ }^{5}$, Michael Sweeting6, Frank Peinemann 7

1West China School of Public Health, West China Hospital, Sichuan University, Chengdu, China. 2Division of Nursing, Midwifery and Social Work, School of Health Sciences, Faculty of Biology, Medicine and Health, University of Manchester, Manchester Academic Health Science Centre, Manchester, UK. ${ }^{3}$ St George's Vascular Institute, St George's Healthcare NHS Trust, London, UK. ${ }^{4}$ Department of Diabetes and Endocrinology, Derby Hospitals NHS Foundation Trust, Derby, UK. 5Leeds Community Healthcare NHS Trust, St Mary's Hospital, Leeds, UK. ${ }^{6}$ Department of Health Sciences, College of Life Sciences, University of Leicester, Leicester, UK. ${ }^{7}$ Pediatric Oncology and Hematology, Children's Hospital, University of Cologne, Cologne, Germany

Contact address: Zhenmi Liu, West China School of Public Health, West China Hospital, Sichuan University, Chengdu, Sichuan, 610041, China.zhenmiliu@scu.edu.cn.

Editorial group: Cochrane Wounds Group.

Publication status and date: New search for studies and content updated (conclusions changed), published in Issue 10, 2018.

Citation: Liu Z, Dumville JC, Hinchliffe RJ, Cullum N, Game F, Stubbs N, Sweeting M, Peinemann F. Negative pressure wound therapy for treating foot wounds in people with diabetes mellitus. Cochrane Database of Systematic Reviews 2018, Issue 10. Art. No.: CD010318. DOI: 10.1002/14651858.CD010318.pub3.

Copyright @ 2018 The Cochrane Collaboration. Published by John Wiley \& Sons, Ltd.

\section{A B S T R A C T}

\section{Background}

Foot wounds in people with diabetes mellitus (DM) are a common and serious global health issue. People with DM are prone to developing foot ulcers and, if these do not heal, they may also undergo foot amputation surgery resulting in postoperative wounds. Negative pressure wound therapy (NPWT) is a technology that is currently used widely in wound care. NPWT involves the application of a wound dressing attached to a vacuum suction machine. A carefully controlled negative pressure (or vacuum) sucks wound and tissue fluid away from the treated area into a canister. A clear and current overview of current evidence is required to facilitate decision-making regarding its use.

\section{Objectives}

To assess the effects of negative pressure wound therapy compared with standard care or other therapies in the treatment of foot wounds in people with DM in any care setting.

\section{Search methods}

In January 2018, for this first update of this review, we searched the Cochrane Wounds Specialised Register; the Cochrane Central Register of Controlled Trials (CENTRAL); Ovid MEDLINE (including In-Process \& Other Non-Indexed Citations); Ovid Embase and EBSCO CINAHL Plus. We also searched clinical trials registries for ongoing and unpublished studies, and scanned reference lists of relevant included studies, reviews, meta-analyses and health technology reports to identify additional studies. There were no restrictions with respect to language, date of publication or study setting. We identified six additional studies for inclusion in the review.

\section{Selection criteria}

Published or unpublished randomised controlled trials (RCTs) that evaluated the effects of any brand of NPWT in the treatment of foot wounds in people with DM, irrespective of date or language of publication. Particular effort was made to identify unpublished studies. 


\section{Data collection and analysis}

Two review authors independently performed study selection, risk of bias assessment and data extraction. Initial disagreements were resolved by discussion, or by including a third review author when necessary. We presented and analysed data separately for foot ulcers and postoperative wounds.

\section{Main results}

Eleven RCTs (972 participants) met the inclusion criteria. Study sample sizes ranged from 15 to 341 participants. One study had three arms, which were all included in the review. The remaining 10 studies had two arms. Two studies focused on postamputation wounds and all other studies included foot ulcers in people with DM. Ten studies compared NPWT with dressings; and one study compared NPWT delivered at $75 \mathrm{mmHg}$ with NPWT delivered at $125 \mathrm{mmHg}$. Our primary outcome measures were the number of wounds healed and time to wound healing.

\section{NPWT compared with dressings for postoperative wounds}

Two studies (292 participants) compared NPWT with moist wound dressings in postoperative wounds (postamputation wounds). Only one study specified a follow-up time, which was 16 weeks. This study (162 participants) reported an increased number of healed wounds in the NPWT group compared with the dressings group (risk ratio (RR) 1.44, 95\% confidence interval (Cl) 1.03 to 2.01 ; low-certainty evidence, downgraded for risk of bias and imprecision). This study also reported that median time to healing was 21 days shorter with NPWT compared with moist dressings (hazard ratio (HR) calculated by review authors $1.91,95 \% \mathrm{Cl} 1.21$ to 2.99 ; low-certainty evidence, downgraded for risk of bias and imprecision). Data from the two studies suggest that it is uncertain whether there is a difference between groups in amputation risk (RR 0.38, 95\% Cl 0.14 to 1.02; 292 participants; very low-certainty evidence, downgraded once for risk of bias and twice for imprecision).

\section{NPWT compared with dressings for foot ulcers}

There were eight studies (640 participants) in this analysis and follow-up times varied between studies. Six studies (513 participants) reported the proportion of wounds healed and data could be pooled for five studies. Pooled data (486 participants) suggest that NPWT may increase the number of healed wounds compared with dressings (RR $1.40,95 \% \mathrm{Cl} 1.14$ to $1.72 ; I^{2}=0 \%$; low-certainty evidence, downgraded once for risk of bias and once for imprecision). Three studies assessed time to healing, but only one study reported usable data. This study reported that NPWT reduced the time to healing compared with dressings (hazard ratio (HR) calculated by review authors $1.82,95 \% \mathrm{Cl} 1.27$ to $2.60 ; 341$ participants; low-certainty evidence, downgraded once for risk of bias and once for imprecision).

Data from three studies (441 participants) suggest that people allocated to NPWT may be at reduced risk of amputation compared with people allocated to dressings (RR $0.33,95 \% \mathrm{Cl} 0.15$ to $0.70 ; \mathrm{I}^{2}=0 \%$; low-certainty evidence; downgraded once for risk of bias and once for imprecision).

\section{Low-pressure compared with high-pressure NPWT for foot ulcers}

One study (40 participants) compared NPWT $75 \mathrm{mmHg}$ and NPWT $125 \mathrm{mmHg}$. Follow-up time was four weeks. There were no data on primary outcomes. There was no clear difference in the number of wounds closed or covered with surgery between groups (RR $0.83,95 \%$ $\mathrm{Cl} 0.47$ to 1.47; very low-certainty evidence, downgraded once for risk of bias and twice for serious imprecision) and adverse events (RR $1.50,95 \% \mathrm{Cl} 0.28$ to 8.04 ; very low-certainty evidence, downgraded once for risk of bias and twice for serious imprecision).

\section{Authors' conclusions}

There is low-certainty evidence to suggest that NPWT, when compared with wound dressings, may increase the proportion of wounds healed and reduce the time to healing for postoperative foot wounds and ulcers of the foot in people with DM. For the comparisons of different pressures of NPWT for treating foot ulcers in people with DM, it is uncertain whether there is a difference in the number of wounds closed or covered with surgery, and adverse events. None of the included studies provided evidence on time to closure or coverage surgery, health-related quality of life or cost-effectiveness. The limitations in current RCT evidence suggest that further trials are required to reduce uncertainty around decision-making regarding the use of NPWT to treat foot wounds in people with DM.

\section{PLAIN LANGUAGE SUMMARY}

\section{Negative pressure wound therapy for treating foot wounds in people with diabetes mellitus}

\section{What was the aim of this review?}

We reviewed the evidence about whether or not negative pressure wound therapy (NPWT) is effective in treating foot wounds in people with diabetes. Researchers from Cochrane collected and analysed all relevant studies (randomised controlled trials; clinical studies where people are randomly put into one of two or more treatment groups) to answer this question and found 11 relevant studies.

\section{Key messages}


We cannot be certain whether NPWT is effective for treating foot wounds in people with diabetes. There is some low-certainty evidence that NPWT increases the number of wounds healed compared with dressings, and may reduce the time it takes wounds to heal. We are uncertain about the effectiveness of different pressures of NPWT on wound healing. Overall, the reliability of the evidence provided by the trials is too low for us to be certain of the benefits and harms of NPWT for treating foot wounds in people with diabetes.

\section{What did the review study?}

Diabetes mellitus is a common condition that leads to high blood glucose (blood sugar) concentrations, with around 2.8 million people affected in the UK (approximately $4.3 \%$ of the population). Some people with diabetes can develop ulcers on their feet. These wounds can take a long time to heal, they can be painful and become infected. Ulceration of the foot in people with diabetes can also lead to a higher risk of amputation of parts of the foot or leg. Generally, people with diabetes are at a higher risk of lower-limb amputation than people without diabetes.

NPWT is a treatment currently being used for wounds including leg ulcers. NPWT involves the application of a wound dressing attached to a vacuum suction machine which sucks any wound and tissue fluid away from the treated area into a canister. Worldwide, the use of NPWT is increasing. However, it is expensive compared with wound treatments such as dressings.

We wanted to find out if NPWT could help foot wounds in people with diabetes to heal more quickly and effectively. We wanted to know if people treated with NPWT experienced any side effects. We were also interested in the impact of NPWT on people's quality of life.

\section{What were the main results of the review?}

In January 2018, we searched for randomised controlled trials that compared NPWT with other treatments for foot ulcers or other open wounds of the foot in people with diabetes. We found 11 trials involving 972 adults. Participant numbers in each trial ranged from 15 to 341 and trial follow-up (observation) times ranged from four weeks to 16 weeks where specified. Not all the studies stated how they were funded. Two were funded by an NPWT manufacturer.

There is low-certainty evidence to suggest that NPWT may be effective in healing postoperative foot wounds and ulcers of the foot in people with diabetes compared with wound dressings, in terms of the proportion of wounds healed and time to healing. For the comparison of different pressures of NPWT for foot ulcers in people with diabetes, we are uncertain whether there is a difference in the number of wounds closed or covered with surgery, and side effects. There was no evidence available on time to closure or coverage surgery, health-related quality of life and cost-effectiveness.

\section{How up to date was this review?}

We searched for studies that had been published up to January 2018. 


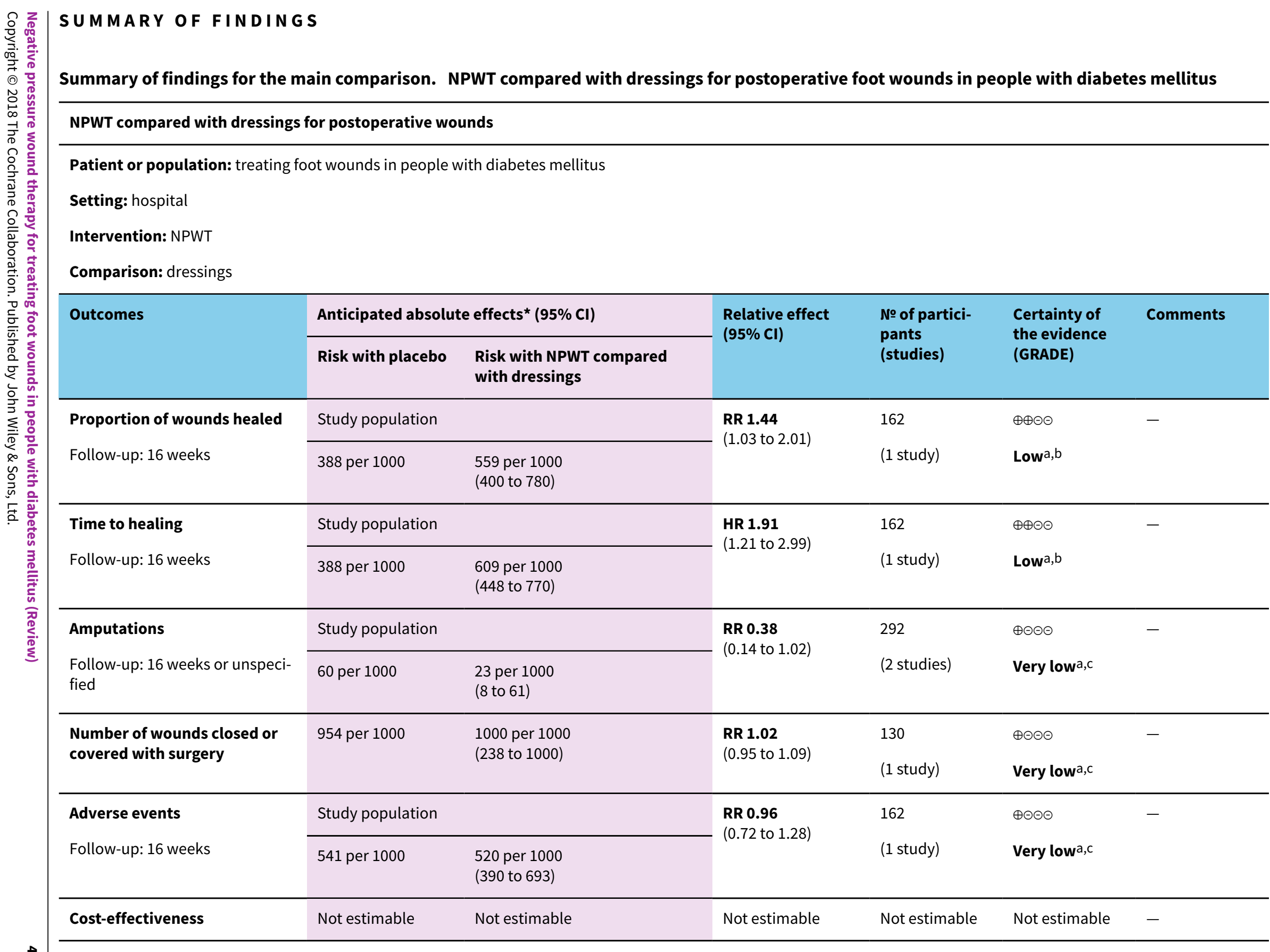




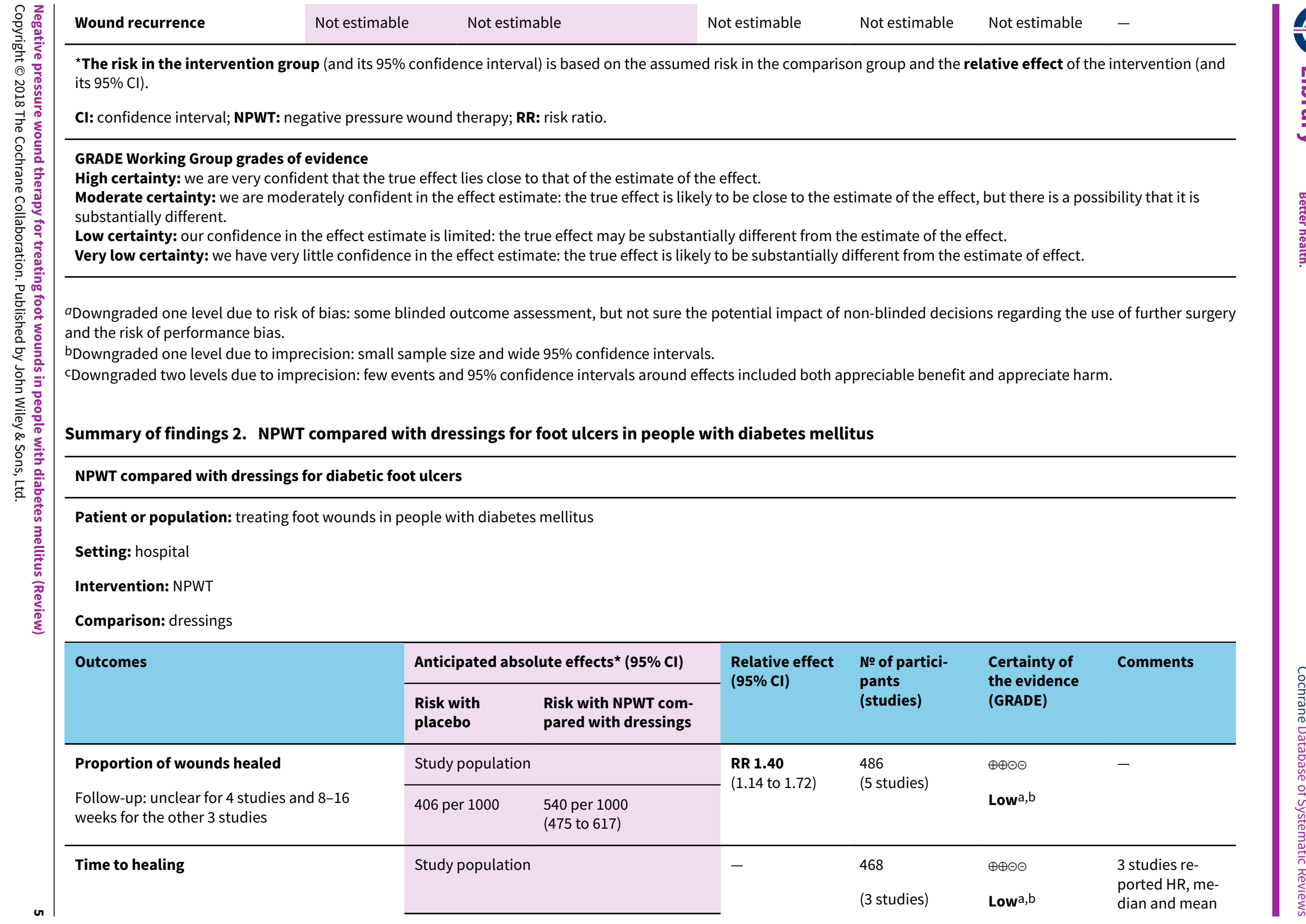




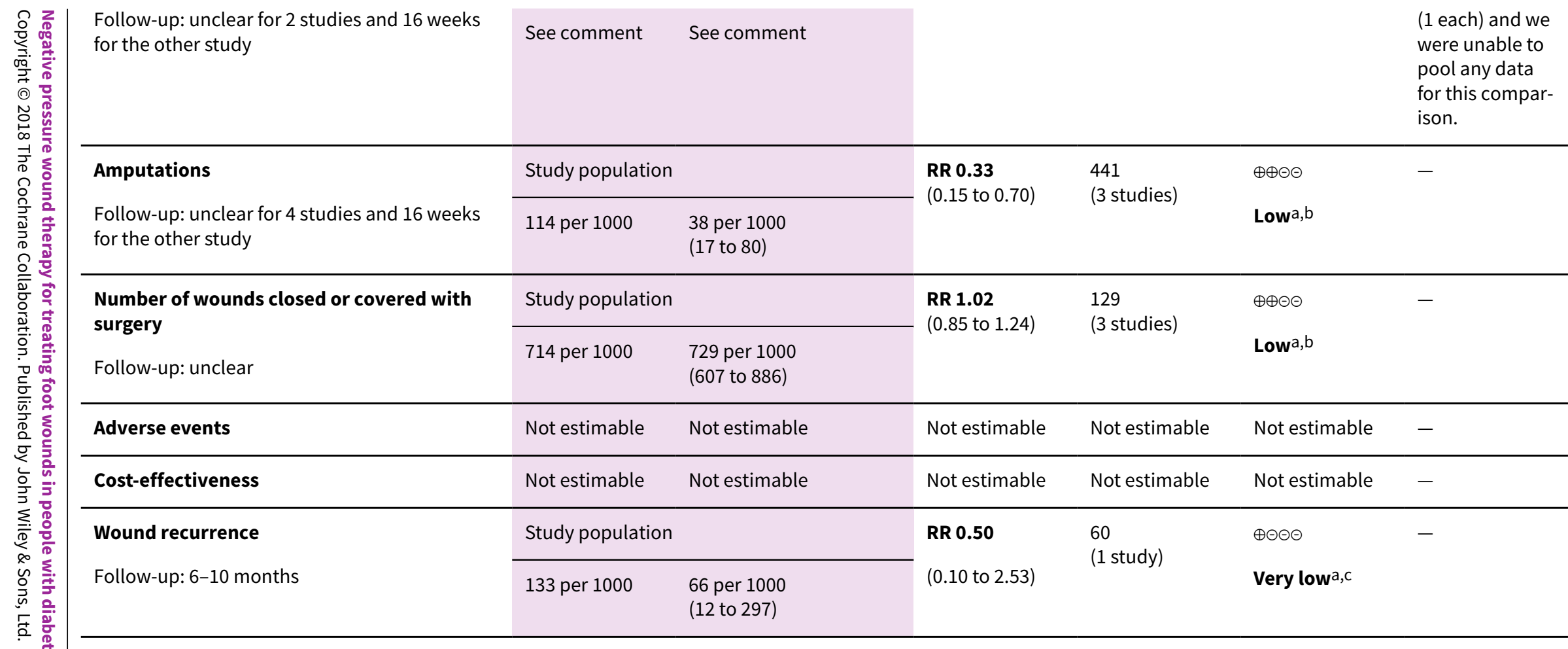

${ }^{\star}$ The risk in the intervention group (and its $95 \%$ confidence interval) is based on the assumed risk in the comparison group and the relative effect of the intervention (and its $95 \% \mathrm{Cl})$.

Cl: confidence interval; NPWT: negative pressure wound therapy; HR: hazard ratio; RR: risk ratio.

\section{GRADE Working Group grades of evidence}

High certainty: we are very confident that the true effect lies close to that of the estimate of the effect.

Moderate certainty: we are moderately confident in the effect estimate: the true effect is likely to be close to the estimate of the effect, but there is a possibility that it is substantially different.

Low certainty: our confidence in the effect estimate is limited: the true effect may be substantially different from the estimate of the effect.

Very low certainty: we have very little confidence in the effect estimate: the true effect is likely to be substantially different from the estimate of effect.

aDowngraded one level due to risk of bias (no blind outcome assessment).

bDowngraded one level due to imprecision: small sample size and wide $95 \%$ confidence intervals.

cDowngraded two levels due to very serious Imprecision. 


\begin{tabular}{|c|c|c|c|c|c|c|}
\hline \multicolumn{7}{|c|}{ Low-pressure compared with high-pressure NPWT for diabetic foot ulcers } \\
\hline \multicolumn{7}{|c|}{ Patient or population: treating foot wounds in people with diabetes mellitus } \\
\hline \multicolumn{7}{|l|}{ Setting: hospital } \\
\hline \multicolumn{7}{|c|}{ Intervention: low-pressure NPWT (75 mmHg) } \\
\hline \multicolumn{7}{|c|}{ Comparison: high-pressure NPWT (125 mmHg) } \\
\hline \multirow[t]{2}{*}{ Outcomes } & \multicolumn{2}{|c|}{ Anticipated absolute effects ${ }^{\star}(95 \% \mathrm{Cl})$} & \multirow{2}{*}{$\begin{array}{l}\text { Relative effect } \\
(95 \% \mathrm{Cl})\end{array}$} & \multirow{2}{*}{$\begin{array}{l}\text { № of partici- } \\
\text { pants } \\
\text { (studies) }\end{array}$} & \multirow{2}{*}{$\begin{array}{l}\text { Certainty of the } \\
\text { evidence } \\
\text { (GRADE) }\end{array}$} & \multirow[t]{2}{*}{ Comments } \\
\hline & Risk with placebo & $\begin{array}{l}\text { Risk with low compared } \\
\text { with high pressure of NPWT }\end{array}$ & & & & \\
\hline $\begin{array}{l}\text { Proportion of wounds } \\
\text { healed }\end{array}$ & Not estimable & Not estimable & Not estimable & Not estimable & Not estimable & - \\
\hline Time to ulcer healing & Not estimable & Not estimable & Not estimable & Not estimable & Not estimable & - \\
\hline Amputation & Not estimable & Not estimable & Not estimable & Not estimable & Not estimable & - \\
\hline $\begin{array}{l}\text { Number of wounds closed or } \\
\text { covered with surgery }\end{array}$ & \multicolumn{2}{|l|}{ Study population } & \multirow{2}{*}{$\begin{array}{l}\text { RR } \mathbf{0 . 8 3} \\
(0.47 \text { to } 1.47)\end{array}$} & \multirow{2}{*}{$\begin{array}{l}40 \\
\text { (1 study) }\end{array}$} & \multirow{2}{*}{$\begin{array}{l}\oplus \odot \odot \ominus \\
\text { Very low }\end{array}$} & \multirow[t]{2}{*}{ - } \\
\hline Follow-up: 4 weeks & 600 per 1000 & $\begin{array}{l}498 \text { per } 1000 \\
\text { (282 to } 882)\end{array}$ & & & & \\
\hline \multirow{2}{*}{$\begin{array}{l}\text { Adverse events } \\
\text { Follow-up: } 4 \text { weeks }\end{array}$} & \multicolumn{2}{|l|}{ Study population } & \multirow{2}{*}{$\begin{array}{l}\text { RR } 1.50 \\
(0.28 \text { to } 8.04)\end{array}$} & \multirow{2}{*}{$\begin{array}{l}40 \\
\text { (1 study) }\end{array}$} & \multirow{2}{*}{$\begin{array}{l}\oplus \odot \Theta \odot \\
\text { Very low }\end{array}$} & \multirow[t]{2}{*}{ - } \\
\hline & 100 per 1000 & $\begin{array}{l}150 \text { per } 1000 \\
(28 \text { to } 804)\end{array}$ & & & & \\
\hline Cost-effectiveness & Not estimable & Not estimable & Not estimable & Not estimable & Not estimable & - \\
\hline Wound recurrence & Not estimable & Not estimable & Not estimable & Not estimable & Not estimable & - \\
\hline
\end{tabular}

${ }^{*}$ The risk in the intervention group (and its $95 \%$ confidence interval) is based on the assumed risk in the comparison group and the relative effect of the intervention (and its $95 \% \mathrm{Cl})$.

Cl: confidence interval; NPWT: negative pressure wound therapy; RR: risk ratio.

GRADE Working Group grades of evidence

High certainty: we are very confident that the true effect lies close to that of the estimate of the effect. 
Moderate certainty: we are moderately confident in the effect estimate: the true effect is likely to be close to the estimate of the effect, but there is a possibility that it is substantially different.

Low certainty: our confidence in the effect estimate is limited: the true effect may be substantially different from the estimate of the effect.

Very low certainty: we have very little confidence in the effect estimate: the true effect is likely to be substantially different from the estimate of effect.

${ }^{a}$ Downgraded three levels: once for risk of bias (some blinded outcome assessment, but not sure the potential impact of non-blinded decisions regarding the use of further surgery and the risk of performance bias); twice for very serious imprecision with a small sample size and limited reported information to quantify imprecision. 


\section{B A C K G R O U N D}

\section{Description of the condition}

Diabetes mellitus (DM) is a chronic condition caused by impaired regulation of blood glucose levels. Normally the hormone insulin regulates blood glucose, but in people with type 1 DM production of insulin no longer occurs. Type $2 \mathrm{DM}$ is characterised by cellular insensitivity to insulin and reduced insulin secretion. In the UK approximately $90 \%$ of people with DM have type 2 (Diabetes UK 2010).

Worldwide in 2017, there were over 425 million adults with DM (five million of whom die of the disease annually), and the prevalence of diabetes is expected to reach over 640 million (1 in 10) by 2040 (IDF 2017). In the UK adult population, the prevalence of diagnosed DM is approximately 3.7 million people (Diabetes UK 2017a). In the USA, the 2015 prevalence of diagnosed DM (all ages) was approximately 9\% (CDC 2015), and in Canada in 2008/2009, for those over one year of age, it was $6.8 \%$ (Public Health Agency of Canada 2011). However, many cases of DM are undiagnosed and when these are included, the adjusted 2010 prevalence estimates increase to $10.3 \%$ for the USA, $9.2 \%$ for Canada, $7.8 \%$ for India and $10.8 \%$ for Mexico. The global prevalence of DM is projected to rise further up to the late 2030s, largely driven by ageing populations, obesity and increasingly sedentary lifestyles (Shaw 2010). Almost half of all deaths attributable to high blood glucose occur before the age of 70 years and the World Health Organization (WHO) projects that diabetes will be the seventh leading cause of death in 2030 (WHO 2016).

DM is a serious health problem because of its associated complications including microvascular complications such as retinopathy, nephropathy and neuropathy (damage to the retina, kidney and nerves); and macrovascular complications including cardiovascular, cerebrovascular and peripheral arterial disease (PAD). The particular combination of peripheral neuropathy (nerve damage) and peripheral vascular disease (damaged veins) contributes to the development of foot ulceration, which may lead to surgical debridement or amputation of the foot or lower limb.

\section{Foot wounds in people with diabetes mellitus}

There are two main types of foot wounds that can affect people with DM, foot ulcers and surgical wounds to the foot; these are summarised below.

\section{Foot ulcers}

Both PAD and neuropathy are risk factors for the development of chronic foot ulceration in people with DM (Pecoraro 1990; Reiber 1999). PAD and neuropathy can occur separately (the ischaemic foot (PAD) or the neuropathic foot (neuropathy)), or in combination (the neuroischaemic foot). Foot ulceration is reported to affect 15\% or more of people with DM at some time in their lives (Reiber 1996; Singh 2005). Estimates of the prevalence of foot ulceration vary, but around $1 \%$ to $4 \%$ of people with DM have foot ulcers at any given time (Abbott 2002; Kumar 1994). Figures for 2008 showed that, for those people with DM in receipt of US Medicare, the prevalence of the presence of least one foot ulcer was $8 \%$ (Margolis 2011).

An ulcer forms as a result of damage to the epidermis (outermost layer of skin) and subsequent loss of underlying tissue. A foot ulcer is specifically defined by the International Consensus on the
Diabetic Foot as a wound that extends through the full thickness of the skin below the level of the ankle (Apelqvist 2000a). This definition is not concerned with duration of the ulcer (although some definitions of chronic ulceration require a duration of six weeks or more), and includes ulcers that extend to muscle, tendon and bone.

The severity of foot ulcers in people with DM can be graded using a number of systems. The Wagner wound classification system was one of the first described and has, historically, been widely used, although it is now rarely used in clinical practice. This system assesses ulcer depth and the presence of osteomyelitis (bone infection) or gangrene and grades ulcers as: grade 0 (pre- or post-ulcerative lesion), grade 1 (partial/full-thickness ulcer), grade 2 (probing to tendon or capsule), grade 3 (deep with osteitis (inflammation of the bone)), grade 4 (partial foot gangrene) and grade 5 (whole foot gangrene) (Wagner 1981). Newer grading systems, such as the PEDIS system (Schaper 2004), the University of Texas Wound Classification System (Oyibo 2001), and SINBAD (Ince 2008), have been developed since, with the SINBAD system being the best validated (Karthikesalingam 2010).

Foot ulcers in people with DM have a serious impact on healthrelated quality of life, particularly with respect to physical functioning and role-limitations due to physical and emotional issues (Nabuurs-Franssen 2005; Ribu 2006). They also represent a major use of health resources, incurring costs not only for dressings, but also staff costs (for podiatrists, nurses, doctors), costs for tests and investigations, antibiotics and specialist footwear. In 2010 to 2011 the estimated National Health Service (NHS) spend on foot ulceration and amputation in people with DM in England was GBP 639 million to GBP 662 million (Diabetes UK 2017b). The economic impact is also high in terms of the personal costs to patients and carers, for example, costs associated with lost work time and productivity while the patient is unable to bear weight or is hospitalised. As many as $85 \%$ of foot-related amputations are preceded by ulceration (Apelqvist 2000b; Pecoraro 1990).

In terms of ulcer healing, one meta-analysis of trials in which people with neuropathic ulcers received good wound care, reported that $24 \%$ of ulcers completely healed by 12 weeks and $31 \%$ by 20 weeks (Margolis 1999). Reasons for delayed healing can include: infection (especially osteomyelitis (bone infection)), comorbidities such as peripheral vascular disease and end-stage renal disease, and the size and depth of an ulcer at presentation. Even when ulcers do heal, the risk of recurrence is high. Pound 2005 reported that $62 \%$ of people with ulcers (from a sample of 231 people) became ulcer-free at some stage over a 31-month observation period, however, $40 \%$ of the ulcer-free group went on to develop a new, or recurrent, ulcer after a median of 126 days. Indeed, the ulcer recurrence rate over five years can be as high as 70\% (Dorresteijn 2010; Van Gils 1999). Failure of ulcers to heal may result in amputation, and people with DM have a 10- to 20-fold higher risk of losing a lower limb, or part of a lower limb, to non-traumatic amputation than people without DM (Morris 1998; Wrobel 2001).

\section{Surgical wounds to the foot}

The risk of lower limb amputation is much greater for people with DM than for those without. The major underlying pathophysiological conditions associated with amputation are neuropathy and ischaemia. Lower limb amputation can have devastating consequences for people's health status and health- 
related quality of life (Tennvall 2000), as well as having a large financial impact on healthcare providers and users. In the UK, from 1 April 2007 to 31 March 2010, a total of 16,693 lower limb amputations were recorded in people with DM (Holman 2012). Of these 10,216 were classed as minor amputations (usually defined as below the ankle joint), and 6477 as major amputations (usually defined as above the ankle joint). The cost of diabetic foot care in 2010 to 2011 was estimated at GBP 580 million, almost $0.6 \%$ of NHS expenditure in England. Of hospital admissions with recorded diabetes, $8.8 \%$ included ulcer care (GBP 219 million) or amputation (GBP 55 million) (Kerr 2014). In the US, the 2008 prevalence of lower extremity amputation in Medicare recipients was $1.8 \%$, with a total mean annual Medicare reimbursement cost for each person with DM and a lower extremity amputation estimated at USD 54,000 . Ulcers are often considered to be chronic wounds, while postsurgical amputation sites are considered to be acute wounds, unless they do not heal (Ubbink 2008).

As well as amputation, debridement is regarded as an important component of the treatment of 'chronic' foot wounds, such as ulcers or non-healing surgical wounds, in people with DM, and can sometimes be undertaken as a surgical procedure. Debridement involves removal of dead tissue and callus, along with pressurerelief/off-loading, treatment of infection and revascularisation, where necessary. As in other areas of wound care, sharp (surgical) debridement of diabetic foot wounds is recommended in guidelines in order to promote wound healing by 'converting' a chronic wound to an acute wound via removal of dead tissue and slough (Steed 2006). While this practice is common, there is little evidence that surgical debridement promotes healing of diabetic foot wounds (Eneroth 2008; Lebrun 2010), but debridement of necrotic tissue with eschar from wounds, including diabetic foot wounds, can sometimes be a requirement prior to the use of wound treatments such as negative pressure wound therapy (NPWT) (KCl 2018).

\section{Description of the intervention}

Any intervention that promotes healing, or reduces amputation rates, or both, in foot wounds in people with DM would make an important difference, and a number of health technologies are marketed as impacting on these outcomes. However, the evidence for the clinical- and cost-effectiveness of these technologies is frequently lacking. A suite of Cochrane Reviews (Dumville 2011a; Dumville 2011b; Dumville 2012a; Dumville 2012b), and an associated mixed treatment comparison (Dumville 2012c), found no robust evidence to suggest that any one dressing was more effective than another in terms of healing foot ulcers in people with DM. A similar conclusion was drawn following a systematic review by the International Working Group of the Diabetic Foot (Game 2012).

NPWT is a technology that is currently used widely in wound care. NPWT is promoted for use on complex wounds, including foot wounds in people with DM, as an adjunct (additional) therapy to standard care (Guy 2012). NPWT involves the application of a wound dressing through which a negative pressure (or vacuum) is applied, with wound and tissue fluid being collected into a canister. The intervention was developed in the 1990s, and the uptake of NPWT in the healthcare systems of high-income countries has been dramatic. One US Department of Health report estimated that between 2001 and 2007 Medicare payments for NPWT pumps and associated equipment increased from USD 24 million to USD
164 million (an increase of almost 600\%) (Department of Health and Human Services 2009). Initially only one NPWT manufacturer supplied NPWT machines (the V.A.C (vacuum-assisted closure) system: Kinetic Concepts Inc (KCI), San Antonio, TX); however, as the NPWT market has grown, several different commercial NPWT systems have been developed, with machines becoming smaller and more portable. Indeed, the most recent introduction to the market is a single use, or 'disposable,' negative pressure product. Ad hoc, homemade, negative pressure devices are also used, especially in resource-poor settings. These devices tend to use simple wound dressings, such as gauze, or transparent occlusive (non-permeable) dressings, with negative pressure generated in hospital by vacuum suction pumps.

Several different healthcare professionals prescribe and apply NPWT, and it is now used both in secondary and primary (community) care, particularly following the introduction of ambulatory systems. While the NPWT systems outlined above differ in a number of respects, such as type of pressure (constant or cyclical) applied to the wound, the material in contact with the surface of the wound and also the type of dressing used, the principle of applying a negative pressure to the wound in a closed environment is the same for all products. The place of NPWT in the treatment pathway and the rationale for its use vary based on different types of wound and local treatment protocols. For open wounds that have been debrided but are still waiting for soft tissue cover, National Institute for Health and Care Excellence (NICE) guidelines recommend that NPWT is considered as an intermediate wound dressing prior to further surgical intervention. Thus, NPWT would be used for a short period of time on an open, postsurgical wound, with a key aim of reducing infection risk.

\section{How the intervention might work}

NPWT ostensibly assists in wound management by collecting high volumes of wound exudate, reducing the frequency of dressing changes by keeping anatomically challenging wounds (such foot wounds) clean, and reducing odour. However, manufacturers also suggest that the application of mechanical force to the wound provides biologically plausible processes by which wound healing is promoted (i.e. the drawing together of wound edges, increased perfusion, and the removal of infectious material and exudate) (KCl 2018; Huang 2014). NPWT might have a beneficial effect by encouraging off-loading (i.e. reducing the weight taken on the foot, as some NPWT systems make ambulation difficult) and preventing unnecessary dressing changes and repeated exposures to the environment. The molecular effects of negative pressure on the wound bed are still being investigated (Glass 2014).

There are some potentially negative aspects associated with NPWT; these include wound maceration (softening due to exposure to liquid), retention of dressings, and wound infection as well as other injuries (FDA 2011). NPWT devices are usually worn continually by patients during treatment, they can interfere with mobility, and, anecdotally, are often noisy, which prevents some people from sleeping.

\section{Why it is important to do this review}

NPWT is an expensive, yet widely used, health technology for the management of complex wounds, and there is potential for its use to increase. In the UK, NPWT can now be prescribed by primary care physicians (who may not have specific training in wound 
care). A Cochrane Review that examined the clinical effectiveness of NPWT for treating chronic wounds had been previously published, but was withdrawn from publication in acknowledgment of the fact that the topic area was too broad, and that separate reviews addressing a single wound type (pressure ulcers, venous leg ulcers and foot ulcers in people with DM) would provide a more focused summary of evidence. There is a great deal of focus on the use of NPWT, and it is an area of high research activity and so is a priority area for review. This updated review includes all foot wounds in people with DM (both surgical and non-surgical): this scope means that, for people with DM, we present evidence from foot wounds caused by surgical debridement and recent amputation, in addition to evidence for the effects of NPWT on non-surgically treated foot ulcers or other non-healing foot wounds. This approach provides an up-to-date and comprehensive overview of evidence for NPWT for all types of foot wound in people with DM, with a focus on considering the type of diabetic foot wound to which current evidence relates.

A Cochrane review that comprehensively identifies, interrogates, presents and synthesises evidence of the effects of NPWT on the outcomes of foot wounds in people with DM is a valuable piece of research. The review is relevant to clinical policy and consumer decision-makers in providing a robust overview of current evidence, and to researchers and funders in highlighting areas of uncertainty that may be addressed by future research. This is relevant, since the draft NICE clinical guideline, Diabetic foot problems: prevention and management (NICE 2016), recommends that NPWT is considered as a treatment after surgical debridement for diabetic foot ulcers on the advice of the multidisciplinary foot care service.

This is the first update of this review: the update is required since there are new trials to be added to the review which previously reported inconclusive findings.

\section{OB JECTIVES}

To assess the effects of negative pressure wound therapy compared with standard care or other therapies in the treatment of foot wounds in people with DM in any care setting.

\section{METHODS}

\section{Criteria for considering studies for this review}

\section{Types of studies}

Published or unpublished randomised controlled trials (RCTs) that evaluated the effects of any brand of NPWT in the treatment of foot wounds in people with DM, irrespective of publication status or language of publication.

\section{Types of participants}

Trials recruiting people with type 1 or type 2 DM (as defined by the study authors), with foot wounds below the ankle, regardless of underlying aetiology (i.e. ischaemic, neuropathic or neuroischaemic). This included diabetic foot ulcers, or wounds resulting from amputation or other surgical treatment, or both. We included trials involving people of any age and from any setting.

Where trials with broad inclusion criteria recruited people with DM with foot wounds as part of a larger chronic wound study population (e.g. alongside participants with pressure ulcers or leg ulcers), we excluded these trials unless the results for the subgroup of people with DM with foot wounds were reported separately or were available from authors on request.

\section{Types of interventions}

Any brand of NPWT (including studies that investigated homemade or ad hoc negative pressure devices) compared with standard care (such as advanced wound dressings and gauze) or other treatments, so that the primary intervention of interest was NPWT (both commercial and non-commercial treatments). We included RCTs in which the use of a specific NPWT intervention during the treatment period was the only systematic difference between treatment groups. We anticipated that likely comparisons would include the use of NPWT during the care pathway compared with no use of NPWT or comparison of different types/brands of NPWT used during the care pathway.

\section{Types of outcome measures}

We listed primary and secondary outcomes below. If a study was otherwise eligible (i.e. correct study design, population and intervention/comparator) but did not report a listed outcome, then we contacted the study authors where possible to establish whether an outcome of interest here was measured but not reported. If we remained unsure whether an outcome was measured or not, the study was included. We reported outcome measures at the latest time point available (assumed to be length of follow-up if not specified) and the time point specified in the methods as being of primary interest (if this was different from latest time point available). For all outcomes, we planned to class assessment of outcome measures from:

- one week or less to eight weeks as short term;

- eight weeks to 16 weeks as medium term;

- more than 16 weeks as long term.

\section{Primary outcomes}

- Complete wound healing

* Time to wound healing within a specific time period, correctly analysed using survival, time-to-event, approaches, ideally with adjustment for relevant covariates such as size of wound at baseline (start of trial). We assumed that the period of time in which healing could occur was the duration of the trial, unless otherwise stated.

* Number of wounds completely healed during follow-up (frequency of complete healing).

Where studies reported both of these outcomes, our plan was to present all data in a summary outcome table for reference, but give 'time to healing' primacy. As planned, when time was analysed as a continuous measure but it was not clear whether all ulcers had healed, we documented the use of this outcome in the study but did not summarise, or otherwise use, the data in any meta-analysis. We accepted study authors' definitions of what constituted a healed wound.

\footnotetext{
- Amputation

* Major amputation (defined as any amputation above the ankle joint).

* Minor amputation (defined as any amputation below the level of the ankle joint).
} 


\section{Secondary outcomes}

- Proportion of wounds closed or covered with surgery: complete wound closure as the result of delayed surgical closure but without subsequent wound healing (i.e. the wounds were surgically closed but not yet healed). The inclusion of this outcome represents a change from the protocol; see Differences between protocol and review for more details.

- Time to closure or coverage surgery: NPWT is often not used until complete wound healing but until a point where the wound is ready for further treatment such as closure surgery. The inclusion of this outcome represents a change from the protocol; see Differences between protocol and review for more details.

- Participant health-related quality of life/health status (measured using a standardised generic questionnaire such as EQ-5D, 36-item Short Form (SF-36), 12-item Short Form (SF-12) or six-item Short Form (SF-6) or wound-specific questionnaires such as the Cardiff Wound Impact Schedule at noted time points. These reported data were adjusted for the baseline score. We did not include ad hoc measures of quality of life that were not likely to be validated and would not have been common to multiple trials.

- Other adverse events (measured using survey/questionnaire/ data capture process or visual analogue scale), where a clear methodology for the collection of adverse event data was provided. This would include making it clear whether (i) events were reported at the participant level or if multiple events per person were reported; and (ii) that an appropriate adjustment was made for data clustering. Where available, we extracted data on all serious and all non-serious adverse events. We did not extract individual types of adverse events such as pain or infection, which require specific assessment under this outcome, rather we used the assessment of any event classed as adverse by the participant or health professional, or both, during the trial.

- Within-trial cost-effectiveness analysis comparing mean differences in effects with mean cost differences between the two arms: data extracted were incremental mean cost per incremental gain in benefit (incremental cost-effectiveness ratio (ICER)). The inclusion of this outcome represents a change from the protocol; see Differences between protocol and review for more details.

- Wound recurrence: we accepted study author definitions of wound recurrence unless it was clear that the term had not been used to describe the return of a wound that was previously healed.

\section{Search methods for identification of studies}

\section{Electronic searches}

In January 2018, we searched the following electronic databases to identify reports of relevant clinical trials:

- Cochrane Wounds Group Specialised Register (searched 10 January 2018);

- Cochrane Central Register of Controlled Trials (CENTRAL; 2017, Issue 12) in the Cochrane Library (searched 10 January 2018);

- Ovid MEDLINE including In-Process \& Other Non-Indexed Citations (1946 to 10 January 2018);

- Ovid Embase (1974 to 10 January 2018);
- EBSCO CINAHL Plus (Cumulative Index to Nursing and Allied Health Literature; 1937 to 10 January 2018).

Appendix 1 shows the search strategies for the Cochrane Wounds Specialised Register, CENTRAL, Ovid MEDLINE, Ovid Embase and EBSCO CINAHL Plus. We combined the Ovid MEDLINE search with the Cochrane Highly Sensitive Search Strategy for identifying randomised trials in MEDLINE: sensitivity- and precision-maximising version (2008 revision) (Lefebvre 2011). We combined the Embase search with the Ovid Embase filter developed by the UK Cochrane Centre (Lefebvre 2011). We combined the CINAHL Plus searches with the trial filters developed by the Scottish Intercollegiate Guidelines Network (SIGN 2018). There were no restrictions with respect to language, date of publication or study setting.

We also searched the following clinical trials registries for unpublished and ongoing studies in the area. We searched for trials evaluating NPWT and explored these records for those pertaining to foot wounds in people with DM as defined above:

- ClinicalTrials.gov (www.clinicaltrials.gov) (28 February 2018);

- WHO International Clinical Trials Registry Platform (apps.who.int/trialsearch/Default.aspx) (28 February 2018);

- EU Clinical Trials Register (www.clinicaltrialsregister.eu/ctrsearch/search) (28 February 2018).

Appendix 1 shows the search strategies for clinical trial registries.

\section{Searching other resources}

We aimed to identify other potentially eligible trials or ancillary publications by searching the reference lists of retrieved included trials, as well as relevant systematic reviews, meta-analyses and health technology assessment reports.

When necessary, we contacted authors of key papers and abstracts to request further information about their trials.

We also examined the content of the European Wound Management Association conference proceedings (2012 to 2017) and systematic reviews in the field that might have referred to data we had not found, and contacted key manufacturers $(\mathrm{KCl}$, and Smith \& Nephew) to ask about unpublished (as well as ongoing) work.

\section{Data collection and analysis}

We carried out data collection and analysis according to methods stated in the published protocol (Dumville 2013a), which were based on the Cochrane Handbook for Systematic Reviews of Interventions (Higgins 2011a).

\section{Selection of studies}

Two review authors independently assessed the titles and abstracts of retrieved studies for relevance. After this initial assessment, we obtained full copies of all studies considered to be potentially relevant. Two review authors independently checked the full papers for eligibility; we resolved disagreements by discussion and, where required, the input of a third review author. We recorded all reasons for exclusion of studies for which we had obtained full copies in the Characteristics of excluded studies table. We completed a PRISMA flowchart to summarise this process (Liberati 2009). 


\section{Data extraction and management}

We extracted and summarised details of the eligible studies using a data extraction sheet. Two review authors extracted data independently and resolved disagreements by discussion, drawing on a third review author where required. Where data were missing from reports, we attempted to contact the study authors to obtain this information. We included studies published in duplicate once, but extracted the maximal amount of data. We extracted the following data, where possible:

- country of origin;

- participants' type of DM;

- wound aetiology (e.g. PAD);

- type of wound, including site on foot;

- unit of investigation (per participant) (i.e. single wound, or foot, or patient, or multiple wounds on the same participant);

- care setting;

- number of participants randomised to each trial arm;

- eligibility criteria and key baseline participant data;

- details of the dressing/treatment regimen received by each group;

- details of any co interventions;

- number of postamputation/debridement wounds closed surgically;

- primary and secondary outcome(s) (with definitions);

- outcome data for primary and secondary outcomes (by group);

- duration of follow-up;

- number of withdrawals (by group);

- adverse events;

- publication status of study; and

- source of funding for trial.

\section{Assessment of risk of bias in included studies}

Two review authors independently assessed each included study using the Cochrane tool for assessing risk of bias (Higgins 2011a) (Appendix 2). This tool addresses six specific domains, namely, sequence generation, allocation concealment, blinding, incomplete outcome data, selective outcome reporting and other issues (e.g. extreme baseline imbalance, issues with unit of investigation). We assessed blinding of participants and health professionals, and blinded outcome assessment separately. Blinding to reduce the risk of performance bias is often not possible in device trials but it can be minimised, for example, in some cases using blinded panels to make care decisions. To avoid detection bias, blinded outcome assessment is key in open trials. Hróbjartsson 2012 argued that the estimated effects of experimental interventions in RCTs tended to be considerably more optimistic when they were based on non-blinded assessment of subjective outcomes compared with blinded assessment.

For our assessment, we were aware that blinding of participants and health professionals to treatment received would not be possible, but it was important to understand if, and how, studies had compensated for this where required. We completed a 'Risk of bias' table for each eligible study and resolved disagreements about risk of bias assessment by discussion. Where possible, when a lack of reported information resulted in an unclear decision, we contacted authors for clarification.
We classed studies with an assessment of high risk of bias for the randomisation sequence domain or the allocation concealment domain or the blinded outcome assessment domain (for specified outcome) (or a combination of these) as being at overall high risk of bias. We also considered the potential for performance and measurement bias for each primary and secondary outcome extracted.

\section{Measures of treatment effect}

Where possible, we grouped studies according to wound type. Where possible, we presented the outcome results for each trial with $95 \%$ confidence intervals $(\mathrm{Cl})$. We reported estimates for dichotomous outcomes (e.g. ulcers healed during a particular time period) as risk ratios (RR). We used the RR rather than odds ratio (OR), since, when event rates are high, as is the case for many trials reporting wound healing, ORs (when interpreted as RR) can give an inflated impression of the effect size (Deeks 2002). We planned to report outcomes relating to continuous data (e.g. percentage change in ulcer area) as mean differences (MD) and overall effect size (with $95 \% \mathrm{Cl}$ ). Where a study reported data on time-to-healing (the probability of healing over a consecutive time period) we planned to report and plot these data (where possible) using hazard ratio $(\mathrm{HR})$ estimates. However, where the HR was not reported, but data regarding the number of events and the $P$ value for a log rank test (reported to at least two significant figures) were reported, we employed methods proposed by Parmar 1998 to calculate the $H R$ indirectly. Where log rank test $P$ values were published to only one significant figure, the robustness of the calculated HR for the highest possible $P$ value was investigated to test robustness of estimates. HRs and associated $95 \% \mathrm{Cl}$ s were then calculated using the inverse variance option in Review Manager 5 (Review Manager 2014).

\section{Unit of analysis issues}

We recorded whether trials presented outcomes in relation to a wound, a foot, a participant or as multiple wounds on the same participant. We also recorded occasions where multiple wounds on a participant were (incorrectly) treated as independent within a study, rather than having within-participant analysis methods applied. This was recorded as part of the risk of bias assessment. For wound healing and amputation, unless otherwise stated, where the number of wounds appeared to equal the number of participants, we treated the participant as the unit of analysis. For other adverse event outcomes, in order to facilitate further analyses, we aimed to establish whether data were presented at the level of the participant, because in this area there is potential for data to refer to multiple events occurring to a single person (or wound per person), which means that data cannot be analysed further without violating the assumption of independence.

Where studies randomised at the participant level and measured outcomes at the wound level (e.g. wound healing), we treated the participant as the unit of analysis when the number of wounds assessed appeared equal to the number of participants (e.g. one wound per person).

Where there were instances of clustered data, that is where a proportion of individually randomised trial participants had outcome data collected and reported on multiple wounds, this was not treated as a cluster trial since not all participants would have multiple wounds. Rather this was a trial that incorrectly included a mixture of individual and clustered data. We noted these trials 
and recorded the issue in the risk of bias assessment. Data were extracted and presented but not the subject of any further analyses.

We planned only to incorporate clearly conducted fully clustered trials into meta-analyses if the trial was analysed correctly. Where a cluster trial had been conducted but incorrectly analysed, we recorded this as part of the 'Risk of bias' assessment. If possible we planned to approximate the correct analyses based on Cochrane Handbook for Systematic Reviews of Interventions guidance (Higgins 2011b) using information on:

- the number of clusters (or groups) randomised to each intervention group; or the average (mean) size of each cluster;

- the outcome data ignoring the cluster design for the total number of participants (e.g. number or proportion of participants with events, or means and standard deviations (SD)); and

- an estimate of the intracluster (or intraclass) correlation coefficient (ICC).

Where multiple trial arms were reported in a single trial, we planned to include only the relevant arms. If two interventions or more interventions were compared with control and eligible for the same meta-analysis, we planned to pool the intervention arms and compare them with control. If the study data could not be analysed correctly, we extracted outcome data and presented them but did not analysed them further.

\section{Dealing with missing data}

It is common to have data missing from trial reports. Excluding participants post randomisation from the analysis, or ignoring those participants who are lost to follow-up compromises the randomisation, and potentially introduces bias into the trial. In individual studies, where data on the proportion of ulcers healed were presented, we assumed that if randomised participants were not included in an analysis, their wound did not heal (i.e. they would be considered in the denominator but not the numerator). Where a trial did not specify participant group numbers prior to dropout, we presented only complete-case data. In a time-to-healing analysis using survival analysis methods, dropouts should be accounted for as censored data. Hence all participants contributed to the analysis. Such analysis assumes that dropouts are missing at random (i.e. not associated with time to healing). We presented data for area change, and for all secondary outcomes, as a complete-case analysis.

\section{Assessment of heterogeneity}

We considered both clinical and statistical heterogeneity. Wherever appropriate, that is, where studies appeared similar in terms of wound type, intervention type, duration and outcome type, we pooled data using meta-analysis (conducted using Review Manager 5 (Review Manager 2014)). We planned to assess statistical heterogeneity using the $\mathrm{Chi}^{2}$ test (a significance level of $\mathrm{P}$ less than 0.1 was considered to indicate heterogeneity) and the $I^{2}$ estimate (Higgins 2003). The $\mathrm{I}^{2}$ estimate examines the percentage of total variation across studies due to heterogeneity rather than to chance. Values of $\mathrm{I}^{2}$ higher than $50 \%$ indicate a high level of heterogeneity. In the absence of clinical heterogeneity and in the presence of statistical heterogeneity $\left(I^{2}\right.$ over $50 \%$ ), we envisioned using a random-effects model; however, we did not anticipate pooling studies where heterogeneity was very high (I² over $75 \%$ ) (Deeks
2011). Where there was no clinical or statistical heterogeneity, we used a fixed-effect model.

\section{Assessment of reporting biases}

Reporting biases arise when the dissemination of research findings is influenced by the nature and direction of results. Publication bias is one of a number of possible causes of small-study effects, that is, a tendency for estimates of the intervention effect to be more beneficial in smaller RCTs. Funnel plots allow a visual assessment of whether small-study effects may be present in a meta-analysis. A funnel plot is a simple scatter plot of the intervention effect estimates from individual RCTs against some measure of each trial's size or precision (Sterne 2011). We planned to present funnel plots for meta-analyses comprising 10 RCTs or more using Review Manager 5 (Review Manager 2014).

\section{Data synthesis}

We were unable to pre specify the amount of clinical, methodological and statistical heterogeneity in the included studies. Thus, we used a random-effects approach for metaanalysis. Conducting meta-analysis with a fixed-effect model in the presence of even minor heterogeneity may provide overly narrow Cls. We would only have used a fixed-effect approach when clinical and methodological heterogeneity was assessed to be minimal, and the assumption that a single underlying treatment effect was being estimated held. $\mathrm{Chi}^{2}$ and $\mathrm{I}^{2}$ statistics were used to quantify heterogeneity but were not used to guide choice of model for meta-analysis (Kontopantelis 2012). We would have exercised caution when meta-analysed data were at risk of smallstudy effects because use of a random-effects model may be unsuitable here. In this case, or where there were other reasons to question the selection of a fixed-effect or random-effects model, we planned to assess the impact of the approach using sensitivity analyses to compare results from alternate models, but this was not implemented (Thompson 1999).

We presented data using forest plots where possible. For dichotomous outcomes, we presented the summary estimate as an RR with $95 \% \mathrm{Cl}$. Where continuous outcomes were measured, we presented an MD with $95 \% \mathrm{Cl}$; we planned to pool standardised mean difference (SMD) estimates where studies measured the same outcome using different methods. For time-to-event data, we planned to use the inverse variance method on the estimated HR and standard error, when reported or calculated from available data. Unfortunately, it was not possible for us to plot (and, if appropriate, to pool) estimates of HRs and $95 \% \mathrm{Cls}$ for time-toevent data, as there were insufficient data presented in the study reports. Where time to healing was analysed as a continuous measure, but it was not clear if all wounds had healed, we documented use of the outcome in the study, but did not summarise or use these data in any meta-analysis.

We obtained pooled estimates of the treatment effect using Review Manager 5 (Review Manager 2014).

\section{Subgroup analysis and investigation of heterogeneity}

We considered whether there was potential heterogeneity between wound dressings used in control groups (i.e. advanced dressings (non-antimicrobial), antimicrobial dressings or basic contact dressings) as there is no single dressing to suit all scenarios (Wounds International 2013). Where there was evidence 
of between-trial heterogeneity in trial-level co interventions, especially off-loading, we envisaged a subgroup analysis being conducted based on variations in co interventions (e.g. all trial participants reported to receive adequate off-loading protocol/ advice being compared with trial participants who received unclear advice about off-loading); however, this was not required. Finally, depending on the number and heterogeneity of included studies, we considered using meta-regression to investigate wound aetiology as a possible explanatory variable but this analysis also was not possible.

\section{Sensitivity analysis}

We planned to perform sensitivity analyses to explore the effect of the removal of studies classed at high risk of bias for any domain, but this was not possible due to lack of available data.

\section{'Summary of findings' tables}

We used the principles of the GRADE system to assess the certainty of the body of evidence associated with specific outcomes (Guyatt 2008), and constructed 'Summary of findings' tables using GRADEpro GDT software (GRADEpro GDT 2015).

These tables present key information concerning the certainty of the evidence, the magnitude of the effects of the interventions examined and the sum of available data for the main outcomes (Schünemann 2011a). The 'Summary of findings' tables also includes an overall grading of the evidence related to each of the main outcomes using the GRADE approach, which defines the certainty of a body of evidence as the extent to which one can be confident that an estimate of effect or association is close to the true quantity of specific interest. The certainty of a body of evidence involves consideration of within-trial risk of bias (methodological quality), directness of evidence, heterogeneity, precision of effect estimates and risk of publication bias (Schünemann 2011b). We included the following main outcomes in the 'Summary of findings' tables:

- proportion of wounds healed;

- time to ulcer healing;
- amputation;

- number of wounds closed or covered with surgery;

- adverse events;

- cost-effectiveness;

- wound recurrence.

For relevant outcomes reported for comparisons not listed above, we present a GRADE assessment without a 'Summary of findings' table.

When evaluating the 'Risk of bias' domain, we downgraded the GRADE assessment only when we classified a study as being at high risk of bias for one or more domains, or when the 'Risk of bias' assessment for selection bias was unclear (this was classified as unclear for the generation of the randomisation sequence domain and the allocation concealment domain). We downgraded the GRADE assessment when the 'Risk of bias' assessment for blinding was unclear (this was classified as unclear for the performance bias domain and the detection bias domain) as well as at high risk of bias. We did not downgrade for unclear 'Risk of bias' assessments in other domains.

We selected an informal optimal information size of 300 for binary outcomes, following the GRADE default value (Guyatt 2011). We also followed GRADE guidance and downgraded twice for imprecision when there were very few events and $\mathrm{Cls}$ around effects included both appreciable benefit and appreciable harm.

\section{RES U LTS}

\section{Description of studies}

\section{Results of the search}

The initial version of this review included five studies (Dumville 2013a). This is the first update and six studies have been added (Dalla-Paola 2010; Lavery 2014; Nain 2011; Vaidhya 2015; Zhang 2017; Zhu 2014). We present the results of the search in the PRISMA diagram (Figure 1). 
Figure 1. Study flow diagram (Liberati 2009)

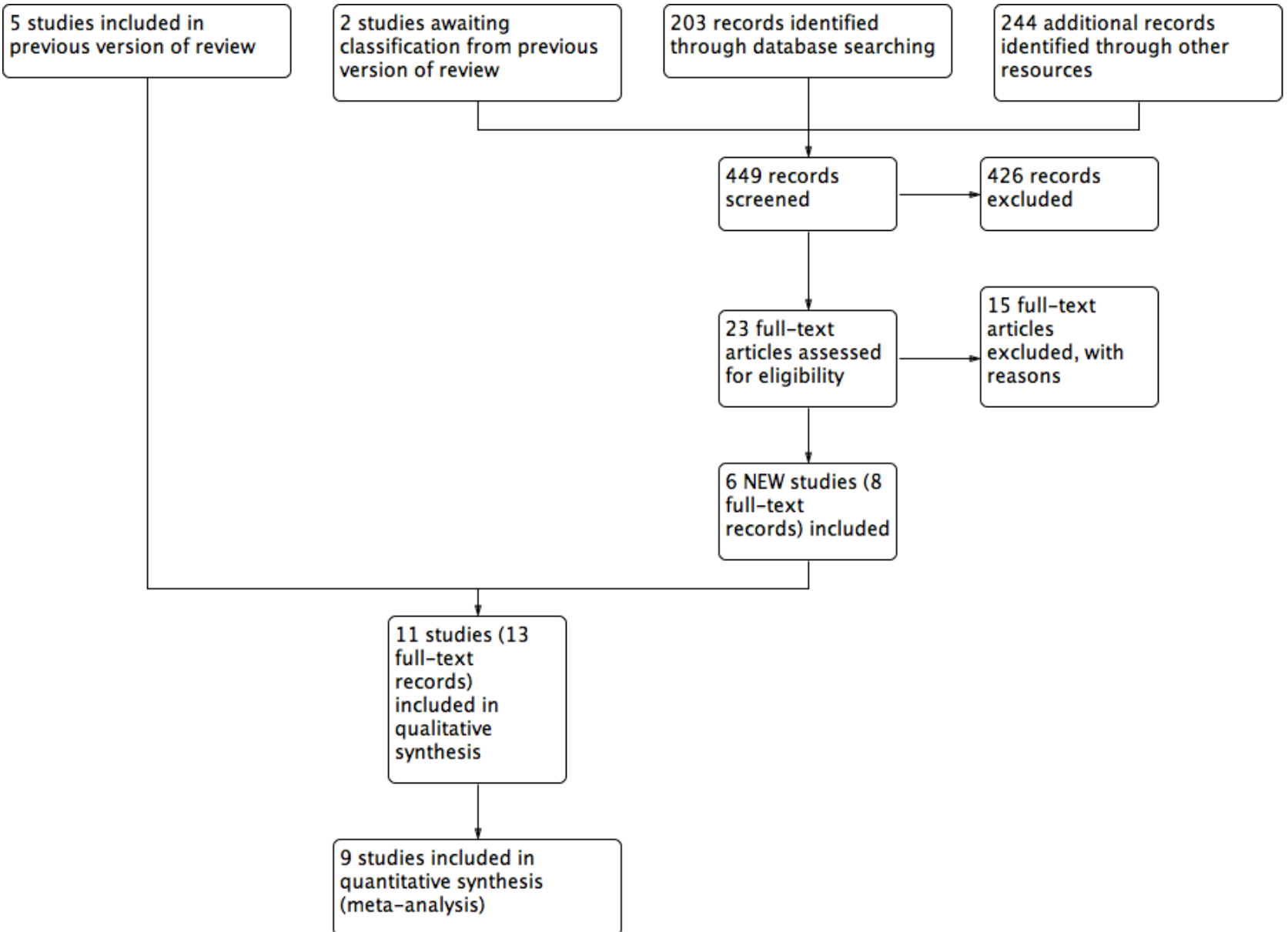

The literature search for this 2018 update yielded 208 abstracts: we sought 23 full-text articles for further scrutiny. From the 23 articles, we included six studies. There are no studies awaiting classification. See Characteristics of included studies and Characteristics of excluded studies tables for full details of the studies identified. We contacted all trial authors for additional information and missing data; any responses are noted in relevant tables. Four studies are ongoing: ACTRN12612000885897; ChiCTRTRC-12002700; DRKS00000059; and ISRCTN64926597. To date, only ISRCTN64926597 has begun to recruit participants (see Ongoing studies).

\section{Included studies}

This review includes 11 studies randomising 972 participants. Ten studies had two arms (Armstrong 2005; Blume 2008; Dalla-Paola 2010; Karatepe 2011; Lavery 2014; Mody 2008; Nain 2011; Vaidhya 2015; Zhang 2017; Zhu 2014), and one had three arms (Novinščak 2010). All studies were parallel studies.

Three studies were undertaken in the USA (Armstrong 2005; Blume 2008; Lavery 2014); two in China (Zhang 2017; Zhu 2014); one in Italy (Dalla-Paola 2010); one in Croatia (Novinščak 2010); three in India (Mody 2008; Nain 2011; Vaidhya 2015); and one in Turkey (Karatepe 2011).

Populations evaluated in the studies were people with DM and foot wounds resulting from amputation in two studies (Armstrong 2005;
Dalla-Paola 2010), and people with DM and foot ulcers in all the other studies (Blume 2008; Karatepe 2011; Lavery 2014; Mody 2008; Nain 2011; Novinščak 2010; Vaidhya 2015; Zhang 2017; Zhu 2014). Two studies reported their funding source: Armstrong 2005 and Blume 2008 received funding from $\mathrm{KCl}$ - manufacturers of the V.A.C. intervention.

Comparison arms received a variety of treatments including:

- dressings:

* advanced moist wound therapy (non-antimicrobial dressing): Armstrong 2005 (moist wound therapy with alginates, hydrocolloid, foam or hydrogel dressings); Dalla-Paola 2010 (alginate, hydrofibre, silver-dressing or polyurethanes); Blume 2008 (advanced moist wound therapy dressings, predominantly hydrogels and alginates);

* antimicrobial dressing: Zhang 2017 (0.5\% dilute iodoform gauze and Vaseline gauze); Zhu 2014 (povidone and lipid dressing);

* basic contact dressing: Karatepe 2011 (sterilised gauze); Mody 2008 (moist gauze); Nain 2011 (saline moistened gauze); Novinščak 2010 (moist dressings and dry gauze); Vaidhya 2015 (saline moistened gauze);

- different pressures of NPWT: Lavery 2014 (75 mmHg and 125 $\mathrm{mmHg}$ ). 
Trials had a range of follow-up periods:

- four weeks (Lavery 2014);

- eight weeks (Nain 2011; Novinščak 2010);

- 16 weeks (Armstrong 2005; Blume 2008); or

- unclear (Dalla-Paola 2010; Karatepe 2011; Mody 2008; Vaidhya 2015; Zhang 2017; Zhu 2014).

In terms of primary outcomes, four studies reported time to healing data (Armstrong 2005; Blume 2008; Karatepe 2011; Zhu 2014), seven reported proportion of wounds healed (Armstrong 2005; Blume 2008; Mody 2008; Nain 2011; Novinščak 2010; Zhang 2017; Zhu 2014); five reported data on amputations recorded during study follow-up (Armstrong 2005; Blume 2008; Vaidhya 2015; Zhang 2017; Zhu 2014); and one reported amputations after the follow-up period (Dalla-Paola 2010). For further details, see Table 1.

In terms of secondary outcomes, five studies reported number of wounds closed or covered with surgery (Dalla-Paola 2010; Lavery 2014; Mody 2008; Vaidhya 2015; Zhu 2014), two reported adverse events (Armstrong 2005; Lavery 2014), and one reported wound recurrence (Zhu 2014).

\section{Excluded studies}

Twenty-eight studies were excluded after investigation of the full text. Eight studies had study populations with multiple wound types and we were unable to obtain separate data on people with DM and foot wounds; nine studies were not considered to be RCTs; nine studies focused on biochemical and related outcomes and, due to the very short follow-up, we considered that relevant outcomes were not measured (they were not reported); and two studies evaluated NPWT as part of a range of treatments, so this intervention was not the only difference between trial groups. See Characteristics of excluded studies for further details.

See Figure 1 for PRISMA diagram.

\section{Risk of bias in included studies}

See Figure 2; Figure 3 risk of bias assessment by study.

Figure 2. Risk of bias graph: review authors' judgements about each risk of bias item presented as percentages across all included studies.

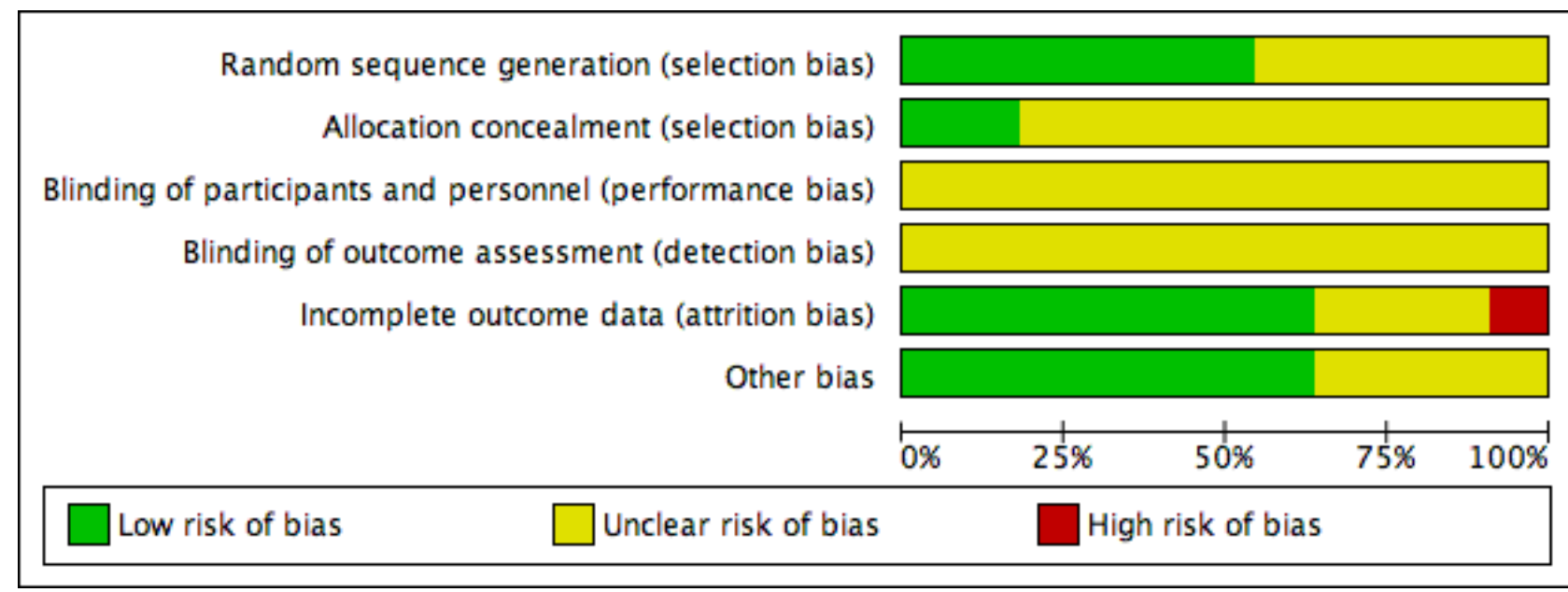


Figure 3. Risk of bias summary: review authors' judgements about each risk of bias item for each included study.

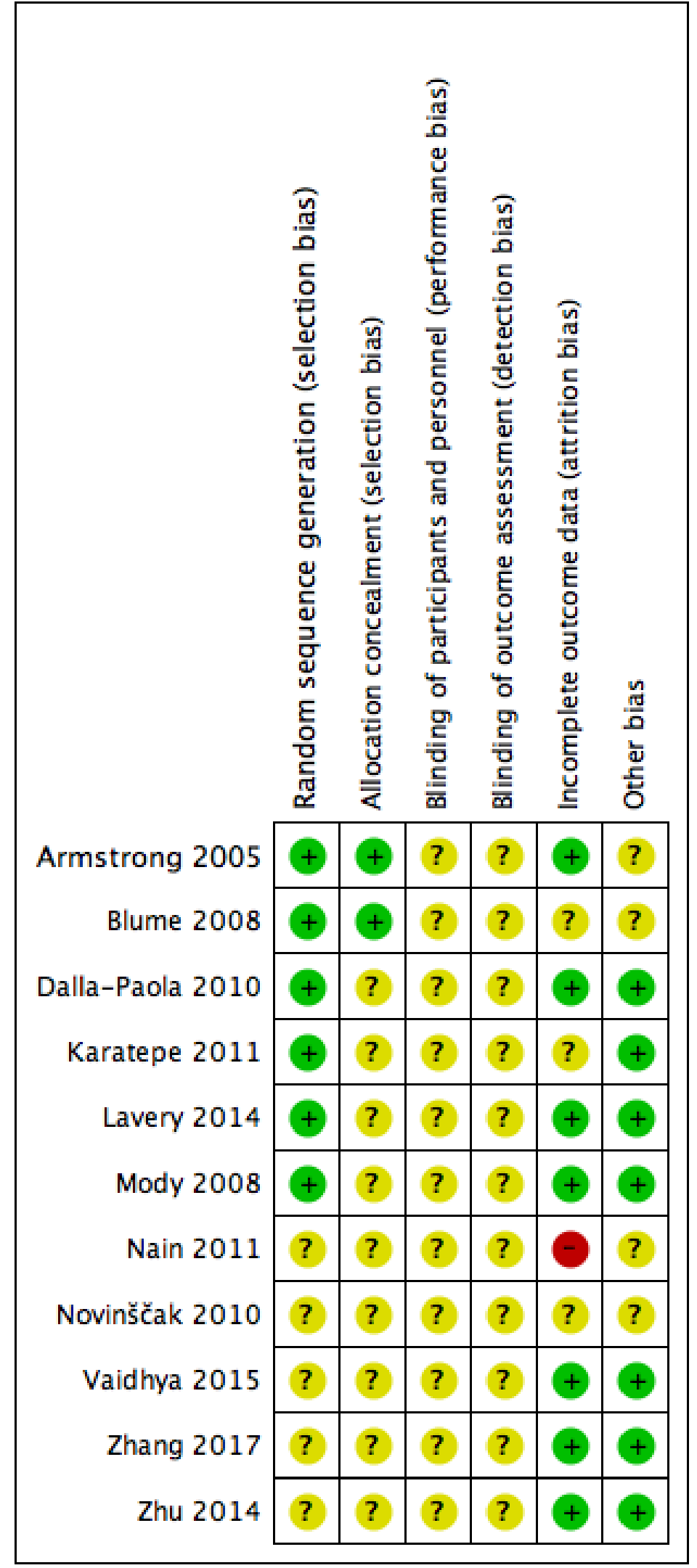




\section{Allocation}

\section{Adequacy of randomisation process}

All included studies were described as 'randomised' with six studies providing information to confirm that adequate sequence generation had taken place (Armstrong 2005; Blume 2008; DallaPaola 2010; Karatepe 2011; Lavery 2014; Mody 2008); these were at low risk of bias for this domain (all studies used computergenerated sequences). The remaining five studies did not describe how randomisation took place, and were at unclear risk of bias for this domain.

\section{Allocation concealment}

Two of the 11 studies were low risk of bias for allocation concealment (Armstrong 2005; Blume 2008). Both studies employed 'sealed envelopes containing opaque, black paper labelled with assigned treatment and participant ID number that were sequentially numbered and provided to each site,' which we deemed to be robust. The remaining studies did not contain enough detail for us to make a judgement for this domain, and so were at unclear risk of bias.

\section{Blinding}

All studies were at unclear risk of blinding bias. We note that while Armstrong 2005, Blume 2008, and Lavery 2014 appeared to undertake some blinded outcome assessment, we questioned the potential impact of non-blinded decisions regarding the use of further surgery and the risk of performance bias. There was no indication that the decision to undertake closure or amputation was guided by the protocol to ensure that there were no differences in performance between groups for reasons other than the treatment received (e.g. surgery was an option only when wounds reached a particular size or condition), or was undertaken by a blinded committee to ensure consistency between groups. Given the non-blinded status of health professionals to treatment received, there may have been the potential for performance bias in promoting surgery (closure or amputation) in one group compared with the other.

\section{Incomplete outcome data}

Seven studies were at low risk of bias for attrition bias (Armstrong 2005; Dalla-Paola 2010; Lavery 2014; Mody 2008; Vaidhya 2015; Zhang 2017; Zhu 2014). Three studies were at unclear risk of bias: Blume 2008 reported a small number of post-randomised exclusions, as well as being unclear about whether there was a large number of early censoring in the analysis; Karatepe 2011 and Novinščak 2010 reported very little information regarding participant flow through the study. Nain 2011 was at high risk of bias as it was unclear how many people underwent amputation.

\section{Other potential sources of bias}

We assessed Nain 2011 and Novinščak 2010 as being at unclear risk of other bias because the data presented in the studies did not consistently match or lacked clarification, which may have resulted in bias. We judged Armstrong 2005 and Blume 2008 to be at unclear risk of bias for this domain as they were funded by an NPWT manufacturer. All other studies were judged as being at low risk of bias for this domain.

\section{Effects of interventions}

See: Summary of findings for the main comparison NPWT compared with dressings for postoperative foot wounds in people with diabetes mellitus; Summary of findings 2 NPWT compared with dressings for foot ulcers in people with diabetes mellitus; Summary of findings 3 Low-pressure compared with highpressure NPWT for foot ulcers in people with diabetes mellitus

Outcome data are summarised in Table 1.

\section{Postoperative wounds}

\section{Comparison 1. Negative pressure wound therapy compared with dressings}

Two studies with 292 participants (medium-term follow-up or unspecified follow-up) compared NPWT with dressing for amputation wounds (Armstrong 2005; Dalla-Paola 2010).

\section{Primary outcome: proportion of wounds healed}

One study reported proportion of wounds healed (Armstrong 2005). The study randomised 162 participants with DM who had previously undergone foot amputation (to the trans-metatarsal level) to receive NPWT (dressing changed every 48 hours) or treatment with alginate, hydrocolloid, foam or hydrogel dressings. Participants were followed for 16 weeks. This study reported an increased number of healed wounds in the NPWT group compared with the dressings group (RR $1.44,95 \% \mathrm{Cl} 1.03$ to 2.01; low-certainty evidence, downgraded once for serious risk of bias and once for serious imprecision) (Analysis 1.1). This means that people in the NPWT group had 1.44 times the 'risk' (likelihood) of healing compared with people in the moist dressing group.

In total, $12 / 77$ (22\%) participants in the NPWT group had wounds classed as healed following closure via surgery compared with $8 / 85$ (9\%) participants in the dressing group. It was not clear from the report when a surgically closed wound was classed as healed. We contacted the trial authors and they replied that "surgically closed wounds were classed as healed based on the same criteria as the open wounds. Epithelialized with no drainage. Typically that was between 2-4 weeks after closure for both groups depending on the surgeon's assessment."

While participants with 'wounds healed' did undergo blinded outcome assessment, health professionals were aware of treatment received during the study and could decide to close wounds via surgery, which risks introducing performance bias into the findings. There was no indication in the study report that this decision to stop NPWT treatment and recommend surgery was guided by specific decision rules (e.g. size of wound), or was made in a blinded fashion. Thus, potentially, different numbers and types of participants within groups may have had wounds 'closed'.

\section{Primary outcome: time to ulcer healing}

One study reported time to healing (complete wound closure) (Armstrong 2005). The study reported a significantly shorter time in the NPWT group (median time to healing of 56 days) compared with the moist dressing group (median time to healing 77 days). We noted that these reported figures did not agree with the KaplanMeier curve reported in the paper, where median values seemed to be higher. 
The authors reported that the results of the time to wound closure analysis were statistically significant $(P=0.005$ : results from a log rank test). Using the observed numbers of events and total numbers in each group together with the reported $P$ value to calculate the log HR and its standard error (Parmar 1998), we calculated the log HR to be 0.645 ( 0.69 where maximum $P$ value of log rank test assumed, as only reported to one significant figure) with a standard error of 0.23 , which gives an HR of 1.91 (95\% Cl 1.21 to 2.99). Thus, our calculations suggest that, at any point during follow-up, the hazard (or chance) of healing in participants allocated to NWPT was 1.9 times that of participants allocated to the moist dressing group; NPWT may decrease the time to healing compared with dressings (low-certainty evidence, downgraded once for serious risk of bias and once for serious imprecision) (Analysis 1.2). There was the potential for the time to healing outcome to be biased by the undertaking of closure surgery in a non-blinded and nonprotocol-driven manner.

\section{Primary outcome: amputations}

Two studies reported amputation (Armstrong 2005; DallaPaola 2010). Only Dalla-Paola 2010 specified major and minor amputations. We decided to carry out meta-analysis without distinguishing between these two subgroups. It is uncertain whether there is a clear difference between NPWT and wounds treated with dressings in number of amputations ((5/142 (3\%) with NPWT versus $14 / 145$ (11\%) with dressings; RR $0.38,95 \% \mathrm{Cl} 0.14$ to 1.02; very low-certainty evidence, downgraded once for serious risk of bias and twice for very serious imprecision) (Analysis 1.3). Ten of the amputations in the dressing group and three in the NPWT group were classed as major. Also, it was not clear whether decisions about amputation were covered by decision rules in the protocol to avoid any potential performance bias.

\section{Secondary outcome: number of wounds closed or covered with surgery}

One study (130 participants) reported data on number of wounds closed or covered with surgery (Dalla-Paola 2010). Based on the findings of this single study it is uncertain whether there is a difference between NPWT or dressings in number of wounds closed or covered with surgery (RR $1.02,95 \% \mathrm{Cl} 0.95$ to 1.09; very lowcertainty evidence, downgraded once for serious risk of bias and twice for very serious imprecision) (Analysis 1.4).

\section{Secondary outcome: adverse events}

One study reported adverse events (Armstrong 2005). From the study report it is uncertain whether there is a difference in the number of participants experiencing one or more adverse events in the NPWT group compared with the moist dressing group (40/77 (52\%) with NPWT versus 46/85 (54\%) with dressings; RR 0.96, 95\% $\mathrm{Cl} 0.72$ to 1.28 ; very low-certainty evidence, downgraded once for serious risk of bias and twice for very serious imprecision) (Analysis 1.5).

\section{Summary of NPWT compared with wound dressings for postoperative wounds}

Low-certainty evidence reporting the hazard or 'chance' of healing over time suggests that there may be a benefit for postoperative foot wounds in participants with DM being treated with NPWT compared with dressings. Low-certainty evidence also shows that NPWT may decrease the time to healing compared with dressings. There is very low-certainty evidence on number of wounds closed or covered with surgery, adverse events and amputations, suggesting that it is uncertain whether there is a clear difference between the treatments (Summary of findings for the main comparison).

\section{Foot ulcers in people with diabetes mellitus}

\section{Comparison 2. Negative pressure wound therapy compared with dressings}

Eight studies with 640 participants (medium-term, long-term or unspecified follow-up) compared NPWT with dressings for foot ulcers.

\section{Primary outcome: proportion of wounds healed}

Six studies (513 participants; medium-term, long-term or unspecified follow-up) reported proportion of wounds healed (Blume 2008; Mody 2008; Nain 2011; Novinščak 2010; Zhang 2017; Zhu 2014). Five studies with 486 participants contributed data to this comparison (Novinščak 2010 was not included as actual numbers of participants healed were not provided) (Analysis 2.1).

Evidence from five pooled studies $(n=486)$ suggests that NPWT may increase the number of completely healed wounds compared with dressings (RR $1.40,95 \% \mathrm{Cl} 1.14$ to $1.72 ; 1^{2}=0 \%$; low-certainty evidence, downgraded once for serious risk of bias and once for serious imprecision).

\section{Subgroup analyses}

Of the prespecified subgroup analyses, we were only able to conduct the comparison based on different wound dressings in control groups. The results of this analysis are shown in Analysis 2.1. There is no evidence of a difference between these subgroups (test for subgroup differences: $P=0.85$ ).

\section{Primary outcome: time to ulcer healing}

Three studies (468 participants; long-term or unspecified followup) reported time to ulcer healing data.

Blume 2008 presented a Kaplan-Meier curve and reported that time to complete wound closure was significantly shorter in the NPWT group, with median time to healing of 96 days ( $95 \% \mathrm{Cl} 75$ to 114), compared with the moist dressing group, in which the median number of participants healed was not reached over the 16-week follow-up.

A log rank test returned a $P$ value of 0.001 . Using the method recommended in Parmar 1998 we calculated the log HR as 0.598 ( 0.581 where maximum $P$ value of log rank test assumed as only reported to one significant figure) with a standard error of 0.182 , which gave an $\mathrm{HR}$ of $1.82(95 \% \mathrm{Cl} 1.27$ to 2.60$)$. These calculations suggest that, at any point during follow-up, the hazard (or chance) of healing for participants allocated to NWPT was 1.8 times that of participants allocated to the moist dressing group.

Using the additional analyses outlined we concluded that NPWT may decrease the time to healing compared with dressings (lowcertainty evidence, downgraded once for serious risk of bias and once for serious imprecision). There was potential for the time to healing outcome to have been affected by the undertaking of closure surgery in a non-blinded and non-protocol-driven way. 
Karatepe 2011 reported that median time to healing was 3.9 weeks in the NPWT group compared with 4.4 weeks in the gauze group ( $P$ $<0.05$, reported by the trial authors) (very low-certainty evidence, downgraded once for serious risk of bias and twice for very serious imprecision). However, limited data were presented and an HR could not be calculated.

Zhu 2014 reported the mean time to healing of the healed wounds (mean: 30.32 (SD 3.80) days in the NPWT group compared with 60.51 (SD 8.22) days in the traditional dressing group; $P<0.05$, reported by the trial authors); however, as not all wounds healed in this study, it was not appropriate to further analyse mean time to healing data (very low-certainty evidence, downgraded once for serious risk of bias and twice for very serious imprecision).

We did not pool data for this comparison as we were unable to convert all results into a single suitable measure with associated variance measures.

\section{Primary outcome: amputations}

Three studies (441 participants; long-term or unspecified followup) reported amputation (without distinguishing between major and minor amputations) (Blume 2008; Zhang 2017; Zhu 2014). The pooled study evidence suggests that NPWT may decrease amputations compared with dressings (RR $0.33,95 \% \mathrm{Cl} 0.15$ to 0.70 ; $\mathrm{I}^{2}=0 \%$; low-certainty evidence, downgraded once for serious risk of bias and once for serious imprecision) (Analysis 2.2).

A fourth study reported data for alternative therapy or amputation (which we reported narratively rather than pooling them into an analysis; $3 / 30$ participants with NPWT versus $7 / 30$ participants with control) (Vaidhya 2015).

The other four studies did not report relevant data about amputation (Karatepe 2011; Mody 2008; Nain 2011; Novinščak 2010).

\section{Secondary outcome: number of wounds closed or covered with surgery}

Three studies (129 participants; unspecified follow-up) reported number of wounds closed or covered with surgery (Mody 2008; Vaidhya 2015; Zhu 2014). The pooled study evidence suggests there is no clear difference between NPWT and dressing-treated wounds in number of wounds closed or covered with surgery (RR 1.02, 95\% $\mathrm{Cl} 0.85$ to $1.24 ;\left.\right|^{2}=28 \%$; low-certainty evidence, downgraded once for serious risk of bias and once for serious imprecision) (Analysis 2.3).

\section{Secondary outcome: wound recurrence}

One study (60 participants; long-term follow-up) reported data on wound recurrence (Zhu 2014). The reported duration of follow-up was six to 10 months. Based on the findings of this single study we are uncertain whether NPWT reduces the risk of wound recurrence compared with dressings (RR $0.50,95 \% \mathrm{Cl} 0.10$ to 2.53; very lowcertainty evidence, downgraded once for serious risk of bias and twice due to very serious imprecision) (Analysis 2.4).

\section{Summary of NPWT compared with wound dressings for foot ulcers}

Available trial evidence from five studies with 486 participants shows that NPWT may increase the number of completely healed wounds compared with dressings (low-certainty evidence). Data from one study (342 participants) suggests that NPWT may decrease the time to healing compared with dressings (lowcertainty evidence). Data from three studies (441 participants) suggests treatment with NPWT may reduce the risk of amputation compared with dressings (low-certainty evidence). Data from three studies (129 participants) shows no clear difference in number of wounds closed or covered with surgery (low-certainty evidence). It is uncertain whether the incidence of wound recurrence differed between groups (very low-certainty evidence from one study with 60 participants) (Summary of findings 2).

\section{Comparison 3. NPWT 75 mmHg versus 125 mmHg}

One study (40 participants, short-term follow-up) compared NPWT $75 \mathrm{mmHg}$ versus $125 \mathrm{mmHg}$ (Lavery 2014). The study randomised 40 people with DM with foot ulcers to receive NPWT $75 \mathrm{mmHg}$ or NPWT $125 \mathrm{mmHg}$. Participants were followed-up for four weeks.

\section{Primary outcome: proportion of wounds healed}

The study did not report proportion of wounds healed.

\section{Primary outcome: time to ulcer healing}

The study did not report time to ulcer healing.

\section{Primary outcome: amputations}

The study did not report amputations.

\section{Secondary outcome: number of wounds closed or covered with surgery}

Based on the findings of this single study we are uncertain whether there is a difference between NPWT $75 \mathrm{mmHg}$ and NPWT 125 $\mathrm{mmHg}$ in terms of the number of wounds closed or covered with surgery (RR $0.83,95 \% \mathrm{Cl} 0.47$ to 1.47 ; very low-certainty evidence, downgraded once for serious risk of bias and twice for very serious imprecision) (Analysis 3.1).

\section{Secondary outcome: adverse events}

Based on the findings of this single study we are uncertain whether there is a difference between NPWT $75 \mathrm{mmHg}$ and NPWT $125 \mathrm{mmHg}$ in terms of number of adverse events (RR $1.50,95 \% \mathrm{Cl} 0.28$ to 8.04 ; very low-certainty evidence, downgraded once for serious risk of bias and twice for very serious imprecision) (Analysis 3.2).

\section{Summary of low compared with high pressure of NPWT for diabetic foot ulcers}

It is uncertain whether there is a difference in the number of wounds closed or covered with surgery and adverse events between NPWT $75 \mathrm{mmHg}$ or NPWT $125 \mathrm{mmHg}$ groups (very low-certainty evidence; Summary of findings 3 ). There were no data on primary outcomes.

\section{I S C U S S I O N}

See: Summary of findings for the main comparison; Summary of findings 2; Summary of findings 3.

\section{Summary of main results}

We included 11 studies with 972 participants in the review. Ten studies compared NPWT with dressings (two for amputation wounds and eight for foot ulcers in people with DM); one study compared NPWT at $75 \mathrm{mmHg}$ and $125 \mathrm{mmHg}$ for the treatment of foot ulcers. 


\section{NPWT compared with dressings in postoperative wounds}

There is low-certainty evidence to suggest that NPWT may be effective in healing postoperative foot wounds compared with wound dressings in terms of the proportion of wounds healed and time to healing. It is uncertain whether there is a difference in number of wounds closed or covered with surgery, adverse events and amputations between the treatment groups (very lowcertainty evidence).

\section{NPWT compared with dressings in diabetic foot ulcers}

There is low-certainty evidence to suggest that NPWT may be effective in healing ulcers compared with wound dressings in terms of the proportion of wounds healed and time to healing. There is low-certainty evidence suggesting NPWT may reduce the risk of amputation, but that there is no clear difference in the number of wounds closed or covered with surgery between the treatment groups. It is uncertain whether the incidence of wound recurrence differs between groups (very low-certainty evidence).

\section{Low compared with high pressure NPWT in diabetic foot ulcers}

It is uncertain whether there is a difference in number of wounds closed or covered with surgery and adverse events between treatment with NPWT $75 \mathrm{mmHg}$ or NPWT $125 \mathrm{mmHg}$ (very lowcertainty evidence). There were no data on primary outcomes.

\section{Overall completeness and applicability of evidence}

The included studies recruited adults with DM with foot wounds involving postoperative amputation wounds and foot ulcers. The included studies compared NPWT with dressings and compared NPWT applied at different pressures for treating multiple wounds.

Although we identified 11 studies, many of these did not report, or did not fully report, the primary outcomes of this review: wound healing and amputation. Therefore, usable data on key outcomes were limited and often unavailable. Only a minority of studies reported enough data to enable us to calculate the most appropriate measure of time-to-event data - an HR. Where this was not available, we were in some cases able to report a mean time to healing or a relative risk of healing for a particular time point. Neither of these measures was ideal and both may have given an impression of either an effect or a lack of effect which was not truly present, particularly where the event rate was high. For the secondary outcomes, apart from the number of wounds closed or covered with surgery and adverse events, the other outcomes were reported in single studies. All evidence is of low or very low certainty because of risk of bias and imprecision.

The included studies took place in a range of settings and countries, including low- to middle-income countries. The geographical distribution of the studies reflected the concentration of disease burden outside of Western high-income countries. The use of NPWT for the treatment of foot wounds in people with DM was similar in that the treatment was used on the most serious wounds that could not be easily covered or closed during initial surgery. The treatment aim in most studies was to close the wounds in the near future, which seemed to reflect common practice in this area. Beyond this, treatment protocol varied across studies in terms of frequency of dressing change and dressing type; however, these variations are common in clinical practice. We grouped all dressing treatments as one control group, which we acknowledge is a broad grouping. The generalisability from such a grouping is unclear and the evidence will need to be considered alongside the results of further studies when these become available.

\section{Quality of the evidence}

The certainty of the available evidence is low or very low. This is due to the risk of bias, small sample size and wide Cls that included both an effect and no effect or even a harm of the intervention. We downgraded the evidence certainty due to the high risk of bias for the randomisation sequence domain or the allocation concealment domain or the blinded outcome assessment domain or a combination of these. We also downgraded the evidence certainty if the randomisation sequence domain and the allocation concealment domain were both at unclear risk of bias; similarly, we downgraded the evidence certainty if the performance bias and detection bias were both assessed as unclear risk of bias.

We noted that while Armstrong 2005, Blume 2008, and Lavery 2014 appeared to undertake some blinded outcome assessment, we questioned the potential impact of non-blinded decisions regarding the use of further surgery and the increased risk of performance bias. Given the non-blinded status of health professionals to treatment received, there may have been the potential for performance bias in promoting surgery (closure or amputation) in one group compared with the other. The two largest studies included in this review, Armstrong 2005 and Blume 2008, were similar in design (both were funded by the manufacturer of V.A.C., i.e. $\mathrm{KCl}$ ) although they evaluated different types of foot wounds. While these studies were deemed to be at low risk of bias for random sequence generation and allocation concealment, the risk of performance and detection bias for both was unclear, since study reports suggested that key decisions regarding the treatment of wounds, such as closure surgery and further amputation, were made by unblinded health professionals and were not guided by a trial protocol in a way that would minimise potential performance bias. This issue has been noted in other reviews (e.g. Medical Advisory Secretariat 2006), and the validity of combining wounds closed by secondary intention and those closed by surgery questioned. For Blume 2008, it was also unclear whether the study's analysis was as close to an intention-to-treat analysis as would be possible with the data collected. The sample sizes of the remaining studies were quite small, leading to imprecision and wide Cls; which in turn led to an overall assessment of very low-certainty evidence.

We also noted that the included studies had limited information about the receipt of important adjunctive therapies such as offloading. While these therapies were often noted as being delivered where required, it would be useful to know whether their delivery was balanced between study groups, as they are such an important part of routine care.

\section{Potential biases in the review process}

Following the upgrade of Review Manager 5 in recent years, new methods which were not previously considered were subsequently included in the review. These changes have been highlighted in the Differences between protocol and review section. These additions only serve to ensure a more robust process and methodology; therefore, we do not consider them to be of concern.

We made a concerted effort to prevent biases during the review process by ensuring an extensive literature search and strict adherence to the published protocol. In this, as in other areas, 
all RCT data should be available in the public domain to enable decision-making to be informed by the most comprehensive evidence base possible. However, previous work highlighted the large number of RCTs of NPWT that have either been terminated, or have been completed but remain unpublished (Peinemann 2008). Extensive searching here did not locate further unpublished studies beyond those previously identified (Peinemann 2008). However, there may well be other studies of which we are not aware. We also noted that some studies were excluded because they evaluated interventions on multiple wound types, and specific data for foot wounds in people with DM were not available.

The protocol was not specific with regard to wound closure by surgery; we made a decision in this update to include the number of wounds closed or covered with surgery and time to closure or coverage surgery as secondary outcomes. Changing the outcomes of a review is often a potential source of bias. However, wound closure by surgery is a clinically important outcome and the fact that it was not included in the protocol represented an oversight on our part. The inclusion of the outcomes in the review was not driven by the data available in the included studies. We also made a decision to include cost effectiveness rather than resource use as a secondary outcome, in view of the importance of this in determining the implementation of relatively high-cost interventions such as NPWT.

\section{Agreements and disagreements with other studies or reviews}

We found one systematic review that evaluated the clinical efficacy of NPWT in treating foot ulcers in people with DM (Liu 2017 - no relation to this Cochrane Review author). There was some overlap between this review and our Cochrane Review. The review included 11 studies that were classed as RCTs, however we excluded two of these studies (McCallon 2000, 10 participants; Sun 2007, 38 participants), as they used alternation and four further studies did not measure relevant outcome data (Eginton 2003; Sajid 2015; and Sun 2007 measured change in size data and Sepulveda 2009 measured granulation data). Liu 2017 highlighted the positive findings in complete ulcer healing from Armstrong 2005; Blume 2008; Karatepe 2011; Nain 2011; Vaidhya 2015; and McCallon 2000. Liu 2017 also highlighted the positive findings in reducing amputation from Armstrong 2005; and Blume 2008. However, Liu 2017 did not conduct a GRADE assessment, so while our review drew similar conclusions, we included an additional six RCTs and used GRADE assessment to highlight the low certainty in many findings due to risk of bias and imprecision. Additionally, there were also differences between reviews in the analytical approaches taken. This Cochrane Review contains HRs derived from reported data to allow evaluation of the 'chance' of healing over time for some of the comparisons; this is a more robust measure of the outcome than mean time to healing or the occurrence of healing events at a single time point.

We found another systematic review with a title suggesting a focus on foot ulcers in people with DM (Noble-Bell 2008). The review included four studies that were classed as RCTs; however, we excluded two of these from our review (Etoz 2007, 24 participants; McCallon 2000, 10 participants), as they used alternation and we considered this a quasi-randomised method of allocation. We excluded the third study from our review as it did not measure relevant outcome data (Eginton 2003). We included the fourth study in our review (Armstrong 2005). The Noble-Bell 2008 review highlighted the positive findings from Armstrong 2005, while recommending further larger RCTs in a wider number of diabetic foot-wound groups. We summarised the same RCT findings, but recommend more cautious interpretation of Armstrong 2005.

Finally, NICE guidelines reviewed the data regarding use of NPWT for treatment of foot wounds in people with DM (NICE 2016). They included three studies: two of which we included here (Armstrong 2005; Blume 2008), and one which we excluded (as above; Etoz 2007). The review conducted within the guideline also found that "two RCTs with a total number of 497 participants showed that participants who received NPWT with standard wound care were significantly less likely to have an amputation, and significantly more likely to have complete wound closure, when compared with participants who received standard wound care alone." However, the GRADE assessment of the evidence in the NICE guideline regarded this as low-quality evidence. The NICE Guideline Development Group recommended that, "a health economic evaluation should be carried out to further assess its [NPWT] cost effectiveness as an adjunctive treatment for diabetic foot problems." The Guideline Development Group also "recommended the use of the intervention in the context of a clinical trial or as a rescue therapy to prevent amputation" (NICE 2016). The findings from our review agreed that further robust RCT research would help to reduce uncertainty regarding the effectiveness of NPWT in the treatment of foot wounds in people with DM. Robust studies should focus on ensuring confidence that differences in outcomes, such as healing and amputations, can be attributed to the intervention, rather than occurring as a result of bias.

\section{AUTHORS' CONCLUSIONS}

\section{Implications for practice}

This review draws together all relevant studies that evaluated negative pressure wound therapy (NPWT) for the treatment of foot wounds in people with diabetes mellitus (DM). The robust review process considered only randomised controlled trials (RCTs), excluding studies that indicated that participants had been allocated using alternation.

Data from several RCTs, including the two largest studies, suggest that NPWT may be an effective treatment (including ulcer healing and amputation) compared with dressings in terms of healing debrided foot ulcers and postoperative amputation wounds in people with DM. However, we graded the evidence for these comparisons as low or very low certainty since the included studies could be at risk of bias. The effect of different NPWT treatments (different pressure and pathways) in many of the comparisons is unclear: it is often uncertain whether there is any difference in healing, wound closure, adverse events or other outcomes. The certainty of the evidence is very low, primarily due to the high levels of imprecision around the estimates of effect. Thus, any potential change in practice regarding the use of NPWT would need to be informed by clinical experience and acknowledge the uncertainty around this decision due to the quality of data.

\section{Implications for research}

There is a lack of high-quality evidence on the effect of NPWT on foot wounds in people with DM. Given that several RCTs of NPWT for foot wounds and other wound types are underway, decision makers and funders need to assess the relative priority of this research 
question compared with others in wound care. There is scope for future research in this area - probably large robust RCTs. Given the importance of wound healing, any future studies should, alongside standard areas of good practice:

- have appropriate follow-up times to capture maximal information about important outcomes such as time-to-healing and amputations (e.g. 12 months);

- collect and report detailed adverse event data;

- collect and report health-related quality of life data using validated measures;

- collect and report cost-effectiveness data;

- ensure protocols are designed to minimise the potential for performance bias.

Additionally, time to event measures (time to healing or time to closure or coverage surgery) are very important in wounds research. When time is analysed as a continuous measure (mean time to healing), this is only a valid time to event measure if it is clear that all wounds have healed/closed by surgery (i.e. had the event of interest) - otherwise by default it is not possible to calculate a mean value. Any future studies should clarify this point when reporting the mean time to healing/closure or coverage surgery or use median measures.

\section{ACKNOWLEDGEMENTS}

The review authors would like to acknowledge the contributions of peer reviewers to the previously published version of this review: Andrew Jull, Janet Gunderson and Gill Worthy, and to thank Kurinchi Gurusamy and Sharon Van Wicklin for their comments on this update. They would also like to thank Elizabeth Royle for copy editing the review and Anne Lawson for copy editing this update. 


\section{R E F E R E N C E S}

\section{References to studies included in this review}

Armstrong 2005 \{published data only\}

Apelqvist J, Armstrong DG, Lavery LA, Boulton AJ. Diabetic foot ulcer and VAC resource utilization and economic cost based on a randomized trial. 20th Annual Symposium on Advanced Wounds Care and the Wound Healing Society Meeting; 2007 April 28 - May 1; Tampa, FL. 2007:C64.

Apelqvist J, Armstrong DG, Lavery LA, Boulton AJ. Resource utilization and economic costs of care based on a randomized trial of vacuum-assisted closure therapy in the treatment of diabetic foot wounds. American Journal of Surgery 2008;195(6):782-8.

* Armstrong DG, Lavery LA. Negative pressure wound therapy after partial diabetic foot amputation: a multicentre, randomised controlled trial. Lancet 2005;366(9498):1704-10.

Armstrong DG, Lavery LA, Boulton AJ. Negative pressure wound therapy via vacuum-assisted closure following partial foot amputation: what is the role of wound chronicity?. International Wound Journal 2007;4(1):79-86.

Armstrong DG, Lavery LA, Frykberg RG, Andros G, Attinger CE, Boulton AJ. VAC therapy appears to heal complex DFU. 2nd World Union of Wound Healing Societies Meeting; 2004 July 8-13; Paris, France. 2004:22.

Driver V, Andersen C, Taneja C, Oster G. Evaluation of healthcare utilization and costs for hospitalizations and surgical procedures in patients with diabetic foot ulcers treated with negative pressure wound therapy using open cell foam versus advanced moist wound therapy. 3rd Congress of the World Union of Wound Healing Societies Meeting; 2008 June 4-8; Toronto, Canada. 2008:0R035.

\section{Blume 2008 \{published data only\}}

Blume PA, Sumpio BE. Interim results of a randomized, controlled multicenter trial of vacuum-assisted closure therapy in the treatment and blinded evaluation of diabetic foot ulcers. 20th Annual Symposium on Advanced Wounds Care and the Wound Healing Society Meeting; 2007 April 28 - May 1; Tampa, FL. 2007:C126.

* Blume PA, Walters J, Payne W, Ayala J, Lantis J. Comparison of negative pressure wound therapy using vacuum-assisted closure with advanced moist wound therapy in the treatment of diabetic foot ulcers: a multicenter randomized controlled trial. Diabetes Care 2008;31(4):631-6.

Driver VR, Anderson C, Oster G, Taneja C. Evaluation of healthcare utilization and costs for hospitalizations and surgical procedures in patients with diabetic foot ulcers treated with V.A.C. therapy versus advanced moist wound therapy. Ostomy Wound Management 2009;55(4):82.

Driver VR, Blume PA. Evaluation of wound care and healthcare use costs in patients with diabetic foot ulcers treated with negative pressure wound therapy versus advanced moist wound therapy [Erratum appears in Journal of the American
Podiatric Medical Association 2014;104(4):374]. Journal of the American Podiatric Medical Association 2014;104(2):147-53.

Dalla-Paola 2010 \{published data only\}

Dalla-Paola L, Carone A, Ricci S, Russo A, Ceccacci T, Ninkovic S. Use of vacuum assisted closure therapy in the treatment of diabetic foot wounds. Journal of Diabetic Foot Complications 2010;2(2):33-44.

\section{Karatepe 2011 \{published data only\}}

Karatepe O, Eken I, Acet E, Unal O, Mert M, Koc B, et al. Vacuum assisted closure improves the quality of life in patients with diabetic foot. Acta Chirurgica Belgica 2011;111(5):298-302.

\section{Lavery 2014 \{published data only\}}

Lavery LA, La Fontaine J, Thakral G, Kim PJ, Bhavan K, Davis KE. Randomized clinical trial to compare negative-pressure wound therapy approaches with low and high pressure, siliconecoated dressing, and polyurethane foam dressing. Plastic and Reconstructive Surgery 2014;133(3):722-6.

\section{Mody 2008 \{published data only\}}

Mody GN, Nirmal IA, Duraisamy S, Perakath B. A blinded, prospective, randomized controlled trial of topical negative pressure wound closure in India. Ostomy Wound Management 2008;54(12):36-46.

\section{Nain 2011 \{published data only\}}

Nain PS, Uppal SK, Garg R, Bajaj K, Garg S. Role of negative pressure wound therapy in healing of diabetic foot ulcers. Journal of Surgical Technique and Case Report 2011;3(1):17-22.

Novinščak 2010 \{published data only\}

Novinščak T, Zvorc M, Trojko S, Jozinovic E, Filipovic M, Grudic R. Comparison of cost-benefit of the three methods of diabetic ulcer treatment: dry, moist and negative pressure [Usporedba troska i koristi (cost-benefit) triju nacina lijecenja dijabetickog vrijeda: suhim prevojem, vlaznim prevojem i negativnim tlakom]. Acta Medica Croatica 2010;64(Suppl 1):113-5.

\section{Vaidhya 2015 \{published data only\}}

Vaidhya N, Panchal A, Anchalia MM. New cost-effective method of NPWT in diabetic foot wound. Indian Journal of Surgery 2015;77(Suppl 2):525-9.

\section{Zhang 2017 \{published data only\}}

Zhang X, Wan L, Yang R, Jin P, Xia W, Ye Y, et al. Expression of connective tissue growth factor and periostin of wound tissue in patients with diabetes who had vacuum sealing drainage. International Journal of Clinical and Experimental Medicine 2017;10(8):12942-50.

\section{Zhu 2014 \{published data only\}}

Zhu XH, Chai YM, Ye JZ, Han P, Wen G, Chen P. Vacuum sealing drainage technique versus traditional repair in treatment of diabetic foot. Chinese Journal of Tissue Engineering Research 2014;18(34):5548-54. 


\section{References to studies excluded from this review}

\section{Armstrong 2012 \{published data only\}}

* Armstrong DG, Marston WA, Reyzelman AM, Kirsner RS. Comparative effectiveness of mechanically and electrically powered negative pressure wound therapy devices: a multicenter randomized controlled trial. Wound Repair and Regeneration 2012;20(3):332-41.

Armstrong DG, Marston WA, Reyzelman AM, Kirsner RS. Comparison of negative pressure wound therapy with an ultraportable mechanically powered device vs. traditional electrically powered device for the treatment of chronic lower extremity ulcers: a multicenter randomized-controlled trial. Wound Repair and Regeneration 2011;19(2):173-80.

Armstrong DG, Marston WA, Reyzelman AM, Kirsner RS. NPWT comparative effectiveness trial. Wound Repair and Regeneration 2012;20(3):332-41.

\section{Braakenburg 2005 \{published data only\}}

Braakenburg A, Obdeijn MC, Feitz R, Van Rooij IA, van Griethuysen AJ, Klinkenbijl JH. The clinical efficacy and cost effectiveness of the vacuum-assisted closure technique in the management of acute and chronic wounds: a randomized controlled trial. Plastic and Reconstructive Surgery 2006;118(2):390-7.

\section{Chong 2011 \{published data only\}}

Chong SJ, Kwan TM, Weihao L, Joang KS, Rick SC. Maintenance of negative-pressure wound therapy while undergoing hyperbaric oxygen therapy. Diving and Hyperbaric Medicine 2011;41(3):147-50.

\section{Eginton 2003 \{published data only\}}

Eginton MT, Brown KR, Seabrook GR, Towne JB, Cambria RA. A prospective randomized evaluation of negative-pressure wound dressings for diabetic foot wounds. Annals of Vascular Surgery 2003;17(6):645-9.

\section{Etoz 2007 \{published data only\}}

Etoz A, Ozgenel Y, Ozcan M. The use of negative pressure wound therapy on diabetic foot ulcers: a preliminary controlled trial. Wounds 2004;16(8):264-9.

\section{Foo 2004 \{published data only\}}

Foo LS, Chua BS, Chia GT, Tan SB, Howe TS. Vacuum assisted closure vs moist gauze dressing in post-operative diabetic foot wounds: early results from a randomised controlled trial. 2nd World Union of Wound Healing Societies Meeting; 2004 July 8-13; Paris, France. 2004:8-9.

\section{Formosa 2015 \{published data only\}}

* Formosa C, Vassallo IM. Comparing calcium alginate dressings to vacuum-assisted closure: a clinical trial. Diabetic Medicine 2015;32:59.

Vassallo IM, Formosa C. Comparing calcium alginate dressings to vacuum-assisted closure: a clinical trial. Wounds 2015;27(7):180-90.
Gonzalez 2017 \{published data only\}

Gonzalez IG, Angel MA, Baez MV, Ruiz Flores B, De Los Angeles Martinez Ferretiz M, Woolf SV, et al. Handcrafted vacuumassisted device for skin ulcers treatment versus traditional therapy, randomized controlled trial. World Journal of Surgery 2017;41(2):386-93.

\section{Lone 2014 \{published data only\}}

Lone AM, Zaroo MI, Laway BA, Pala NA, Bashir SA, Rasool A. Vacuum-assisted closure versus conventional dressings in the management of diabetic foot ulcers: a prospective case-control study. Diabetic Foot and Ankle 2014;5:10.3402/dfa.v5.23345.

\section{Maggio 2010 \{published data only\}}

Maggio G, Armenio A, Pascone M. Bio-engineered tissue and VAC therapy: a new method for the treatment of the wide soft tissue defects in the diabetic foot. European Journal of Clinical Investigation 2010;40:87.

McCallon 2000 \{published data only\}

McCallon SK, Knight CA, Valiulus JP, Cunningham MW, McCulloch JM, Farinas LP. Vacuum-assisted closure versus saline-moistened gauze in the healing of postoperative diabetic foot wounds. Ostomy Wound Management 2000;46(8):28-34.

\section{Moghazy 2015 \{published data only\}}

Moghazy AM, Ellabban MA, Adly OA, Ahmed FY. Evaluation of the use of vacuum-assisted closure (VAC) and platelet-rich plasma gel (PRP) in management of complex wounds. European Journal of Plastic Surgery 2015;38(6):463-70.

Mouës 2004 \{published data only\}

Mouës CM, Van den Bemd GJ, Heule F, Hovius SE. Comparing conventional gauze therapy to vacuum-assisted closure wound therapy: a prospective randomised trial. Journal of Plastic, Reconstructive \& Aesthetic Surgery 2007;60(6):672-81.

* Mouës CM, Vos MC, van den Bemd GJ, Stijnen T, Hovius SE. Bacterial load in relation to vacuum-assisted closure wound therapy: a prospective randomized trial. Wound Repair and Regeneration 2004;12(1):11-7.

Mouës CM, van den Bemd GJ, Meerding WJ, Hovius SE. An economic evaluation of the use of TNP on full-thickness wounds. Journal of Wound Care 2005;14(5):224-7.

Perez 2010 \{published data only\}

Perez D, Bramkamp M, Exe C, Von Ruden C, Ziegler A. Modern wound care for the poor: a randomized clinical trial comparing the vacuum system with conventional saline-soaked gauze dressings. American Journal of Surgery 2010;199(1):14-20.

Rahmanian-Schwarz 2012 \{published data only\}

Rahmanian-Schwarz A, Willkomm LM, Gonser P, Hirt B, Schaller HE. A novel option in negative pressure wound therapy (NPWT) for chronic and acute wound care. Burns 2012;38(4):573-7.

Ravari 2013 \{published data only\}

Ravari H, Modaghegh M-H, Kazemzadeh GH, Johari HG, Vatanchi AM, Sangaki A, et al. Comparison of vacuum-assisted 
closure and moist wound dressing in the treatment of diabetic foot ulcers. Journal of Cutaneous and Aesthetic Surgery 2013;6(1):17-20.

\section{Riaz 2010 \{published data only\}}

Riaz MU, Khan M-U, Akbar A. Comparison of vacuum assisted closure versus normal saline dressing in healing diabetic wounds. Pakistan Journal of Medical and Health Sciences 2010;4(4):308-12.

\section{Sajid 2015 \{published data only\}}

Sajid MT, Mustafa Qu, Shaheen N, Hussain SM, Shukr I, Ahmed M. Comparison of negative pressure wound therapy using vacuum-assisted closure with advanced moist wound therapy in the treatment of diabetic foot ulcers. Journal of the College of Physicians and Surgeons - Pakistan: JCPSP 2015;25(11):789-93.

\section{Sepulveda 2009 \{published data only\}}

Sepulveda G, Espindola M, Maureira M, Sepulveda E, Fernandez JI, Oliva C, et al. Negative-pressure wound therapy versus standard wound dressing in the treatment of diabetic foot amputation. A randomised controlled trial. Cirugia Espanola 2009;86(3):171-7.

\section{Sun 2007 \{published data only\}}

Sun JW, Sun JH, Zhang CC. Vacuum assisted closure technique for repairing diabetic foot ulcers: analysis of variance by using a randomized and double-stage crossover design. Journal of Clinical Rehabilitative Tissue Engineering Research 2007;11(14):8908-11.

\section{Sun 2015 \{published data only\}}

Sun Y, Fan W, Yang W, Wang G, Yu G, Zhang D, et al. Effects of intermittent irrigation of insulin solution combined with continuous drainage of vacuum sealing drainage in chronic diabetic lower limb ulcers. Chinese Journal of Reparative and Reconstructive Surgery 2015;29(7):812-7.

\section{Tuncel 2013 \{published data only\}}

Tuncel U, Erkorkmaz U, Turan A. Clinical evaluation of gauzebased negative pressure wound therapy in challenging wounds. International Wound Journal 2013;10:152-8.

\section{Ugurlar 2017 \{published data only\}}

Ugurlar M, Sonmez MM, Armagan R, Eren OT. Comparison of two different vacuum-assisted closure (VAC) treatments of multiple chronic diabetic foot wounds in the same extremity. Foot and Ankle Surgery 2017;23(3):173-8.

\section{Wang 2016 \{published data only\}}

Wang T, Zhao J, Yu M, Yang WC, Jiang YJ, He R, et al. Negative pressure wound therapy promotes wound healing by alleviating inflammatory reaction in patients with diabetic feet. Journal of Shanghai Jiaotong University (Medical Science) 2016;36(8):1159-64.

\section{Yang 2014 \{published data only\}}

Yang SL, Han R, Liu Y, Hu LY, Li XL, Zhu LY. Negative pressure wound therapy is associated with up-regulation of bFGF and
ERK1/2 in human diabetic foot wounds. Wound Repair and Regeneration 2014;22(4):548-54.

Yang 2017a \{published data only\}

Yang SL, Hu LY, Liu Y, Zhu LY, Dou JT. Effects of negative pressure wound therapy on the expression of EDA + FN in granulation tissues of human diabetic foot wounds. Medical Journal of Chinese People's Liberation Army 2017;42(3):224-9.

\section{Yang 2017b \{published data only\}}

Yang SL, Zhu LY, Han R, Sun LL, Dou JT. Effect of negative pressure wound therapy on cellular fibronectin and transforming growth factor-beta1 expression in diabetic foot wounds. Foot \& Ankle International 2017;38(8):893-900.

\section{Zhang 2014 \{published data only\}}

Zhang M, Li Z, Wang J, Wu Q, Wen $\mathrm{H}$. Effects of vacuum sealing drainage combined with irrigation of oxygen loaded fluid on chronic wounds in diabetic patients. Huangding Zhonghua Shao Shang Za Zhi [Chinese Journal of Burns] 2014;30(2):116-23.

\section{References to ongoing studies}

ACTRN12612000885897 \{published data only\}

ACTRN12612000885897. A pilot randomised controlled trial of Negative Pressure Wound Therapy (NPWT) in Hospital in the Home (HITH) to treat post-operative foot wounds. www.anzctr.org.au/Trial/Registration/TrialReview.aspx? id=362910 (first received 17 August 2012).

\section{ChiCTR-TRC-12002700 \{published data only\}}

ChiCTR-TRC-12002700. A prospective multicenter assessment of for you NPWT security and effectiveness in promoting the healing of diabetic foot ulcer. www.chictr.org.cn/ hvshowproject.aspx?id=4262 (first received 16 December 2015).

DRKS00000059 \{published data only\}

DRKS00000059. Treatment of diabetic foot wounds by vacuumassisted closure. www.drks.de/drks_web/navigate.do? navigationld=trial.HTML\&TRIAL_ID=DRKS00000059 (first received 20 July 2009).

ISRCTN64926597 \{published data only\}

ISRCTN64926597. Comparing treatments for diabetic foot ulcers. www.isrctn.com/ISRCTN64926597 (first received 22 May 2017).

\section{Additional references}

\section{Abbott 2002}

Abbott CA, Carrington AL, Ashe H, Bath S, Every LC, Griffiths J, et al. The North West Diabetes Foot Care Study: incidence of and risk factors for new diabetic foot ulceration in a communitybased patient cohort. Diabetic Medicine 2002;19(5):377-84.

\section{Apelqvist 2000a}

Apelqvist J, Bakker K, Van Houtum WH, Nabuurs-Franssen MH, Schaper NC. International consensus and practical guidelines on the management and the prevention of the diabetic foot. 
International Working Group on the Diabetic Foot. Diabetes Metabolism Research and Reviews 2000;16(Suppl 1):S84-92.

\section{Apelqvist 2000b}

Apelqvist J, Larsson J. What is the most effective way to reduce incidence of amputation in the diabetic foot?. Diabetes Metabolism Research and Reviews 2000;16(Suppl 1):S75-83.

\section{CDC 2015}

Centers for Disease Control and Prevention (CDC), Division of Diabetes Translation. 2015. Diagnosed diabetes. gis.cdc.gov/ grasp/diabetes/DiabetesAtlas.html (accessed 16 May 2018).

\section{Deeks 2002}

Deeks JJ. Issues in the selection of a summary statistic for metaanalysis of clinical trials with binary outcomes. Statistics in Medicine 2002;21(1):575-600.

\section{Deeks 2011}

Deeks JJ, Higgins JP, Altman DG, on behalf of the Cochrane Statistical Methods Group. Chapter 9: Analysing data and undertaking meta-analyses. In: Higgins JP, Green S, editor(s). Cochrane Handbook for Systematic Reviews of Interventions Version 5.1.0 (updated March 2011). The Cochrane Collaboration, 2011. Available from handbook.cochrane.org.

\section{Department of Health and Human Services 2009}

US Department of Health and Human Services, Office of Inspector General. Comparison of prices for negative pressure wound therapy pumps. March 2009. oig.hhs.gov/oei/reports/ oei-02-07-00660.pdf (accessed 16 May 2018).

\section{Diabetes UK 2010}

Diabetes UK. Diabetes in the UK 2010: key statistics on diabetes. March 2010. www.diabetes.org.uk/Documents/Reports/ Diabetes_in_the_UK_2010.pdf (accessed 16 May 2018).

\section{Diabetes UK 2017a}

Diabetes UK. Diabetes Prevalence 2017. November 2017. www.diabetes.org.uk/professionals/position-statementsreports/statistics/diabetes-prevalence-2017 (accessed 16 May 2018).

\section{Diabetes UK 2017b}

Diabetes UK. Improving footcare for people with diabetes and saving money: an economic study in England. January 2017. diabetes-resources-production.s3-euwest-1.amazonaws.com/diabetes-storage/migration/pdf/ Improving\%2520footcare\%2520economic\%2520study \%2520\%28January\%25202017\%29.pdf (accessed 16 May 2018).

\section{Dorresteijn 2010}

Dorresteijn JA, Kriegsman DM, Valk GD. Complex interventions for preventing diabetic foot ulceration. Cochrane Database of Systematic Reviews 2010, Issue 1. [DOI: 10.1002/14651858.CD007610.pub2]

\section{Dumville 2011a}

Dumville JC, O'Meara S, Deshpande S, Speak K. Hydrogel dressings for healing diabetic foot ulcers. Cochrane
Database of Systematic Reviews 2011, Issue 9. [DOI: 10.1002/14651858.CD009101.pub2]

\section{Dumville 2011b}

Dumville JC, Deshpande S, O'Meara S, Speak K. Foam dressings for healing diabetic foot ulcers. Cochrane Database of Systematic Reviews 2011, Issue 9. [DOI: 10.1002/14651858.CD009111.pub2]

\section{Dumville 2012a}

Dumville JC, Deshpande S, O'Meara S, Speak K. Hydrocolloid dressings for healing diabetic foot ulcers. Cochrane Database of Systematic Reviews 2012, Issue 2. [DOI: 10.1002/14651858.CD009099.pub2]

\section{Dumville 2012b}

Dumville JC, O'Meara S, Deshpande S, Speak K. Alginate dressings for healing diabetic foot ulcers. Cochrane Database of Systematic Reviews 2012, Issue 2. [DOI: 10.1002/14651858.CD009110.pub2]

\section{Dumville 2012c}

Dumville JC, Soares MO, O'Meara S, Cullum N. Systematic review and mixed treatment comparison: dressings to heal diabetic foot ulcers. Diabetologia 2012;55(7):1902-10.

\section{Eneroth 2008}

Eneroth M, Van Houtum WH. The value of debridement and Vacuum-Assisted Closure (V.A.C.) Therapy in diabetic foot ulcers. Diabetes Metabolism Research and Review 2008;24(Suppl 1):S76-80

\section{FDA 2011}

US Food, Drug Administration (FDA). FDA Safety Communication: update on serious complications associated with negative pressure wound therapy systems. wayback.archive-it.org/7993/20170406071858/https:// www.fda.gov/MedicalDevices/Safety/AlertsandNotices/ ucm244211.htm (accessed 29 August 2018).

\section{Game 2012}

Game FL, Hinchliffe RJ, Apelqvist J, Armstrong DG, Bakker K, Hartemann A, et al. A systematic review of interventions to enhance the healing of chronic ulcers of the foot in diabetes. Diabetes Metabolism Research and Review 2012;Suppl 1:119-41.

\section{Glass 2014}

Glass GE, Murphy GF, Esmaeili A, Lai LM, Nachahal J. Systematic review of molecular mechanism of action of negative-pressure wound therapy. British Journal of Surgery 2014;101:1627-36.

\section{GRADEpro GDT 2015 [Computer program]}

McMaster University (developed by Evidence Prime). GRADEpro Guideline Development Tool. Version accessed 16 May 2018. Hamilton (ON): McMaster University (developed by Evidence Prime), 2015.

\section{Guy 2012}

Guy H. Pressure ulcer risk assessment. Nursing Times 2012;108(4):16-20. 


\section{Guyatt 2008}

Guyatt GH, Oxman AD, Kunz R, Vist GE, Falck-Ytter Y, Schünemann HJ. What is 'quality of evidence' and why is it important to clinicians?. BMJ 2008;336(7651):995-8.

\section{Higgins 2003}

Higgins JP, Thompson SG, Deeks JJ, Altman DG. Measuring inconsistency in meta-analyses. BMJ 2003;327(7414):557-60.

\section{Higgins 2011a}

Higgins JP, Altman DG. Chapter 8: Assessing risk of bias in included studies. In: Higgins JP, Green S, editor(s). Cochrane Handbook for Systematic Reviews of Interventions Version 5.1.0 (updated March 2011). The Cochrane Collaboration, 2011. Available from handbook.cochrane.org.

\section{Higgins 2011b}

Higgins JP, Deeks JJ. Chapter 7: Selecting studies and collecting data. In: Higgins JP, Green S, editor(s). Cochrane Handbook for Systematic Reviews of Interventions Version 5.1.0 (updated March 2011). The Cochrane Collaboration, 2011. Available from handbook.cochrane.org.

\section{Holman 2012}

Holman N, Young RJ, Jeffcoate WJ. Variation in the recorded incidence of amputation of the lower limb in England. Diabetologia 2012;55(7):1919-25.

\section{Hróbjartsson 2012}

Hróbjartsson A, Thomsen AS, Emanuelsson F, Tendal B, Hilden J, Boutron I, et al. Observer bias in randomised clinical trials with binary outcomes: systematic review of trials with both blinded and non-blinded outcome assessors. BMJ 2012;344:e1119.

\section{Huang 2014}

Huang C, Leavitt T, Bayer LR, Orgill DP. Effect of negative pressure wound therapy on wound healing. Current Problems in Surgery 2014;51:301-31.

\section{IDF 2017}

International Diabetes Foundation (IDF). IDF Diabetes Atlas. 8th edition. www.diabetesatlas.org (accessed 29 August 2018).

\section{Ince 2008}

Ince P, Abbas ZG, Lutale JK, Basit A, Ali SM, Chohan F, et al. Use of the SINBAD classification system and score in comparing outcome of foot ulcer management on three continents. Diabetes Care 2008;31(5):964-7.

\section{Karthikesalingam 2010}

Karthikesalingam A, Holt PJ, Moxey P, Jones KG, Thompson MM, Hinchliffe RJ. A systematic review of scoring systems for diabetic foot ulcers. Diabetic Medicine 2010;27(5):544-9.

\section{KCI 2018}

$\mathrm{KCl}$ (Acelity). Infected wounds. www.acelity.com/products/ wound-management/infected-wounds (accessed 16 May 2018).

\section{Kerr 2014}

Kerr M, Rayman G, Jeffcoate WJ. Cost of diabetic foot disease to the National Health Service in England. Diabetic Medicine 2014;31(12):1498-504.

\section{Kontopantelis 2012}

Kontopantelis E, Springate DA, Reeves D. A re-analysis of the Cochrane Library data: the dangers of unobserved heterogeneity in meta-analyses. PloS One 2013;26:e69930.

\section{Kumar 1994}

Kumar S, Ashe HA, Parnell LN, Fernando DJ, Tsigos C, Young RJ, et al. The prevalence of foot ulceration and its correlates in type 2 diabetic patients: a population-based study. Diabetic Medicine 1994;11(5):480-4.

\section{Lebrun 2010}

Lebrun E, Tomic-Canic M, Kirsner RS. The role of surgical debridement in healing of diabetic foot ulcers. Wound Repair and Regeneration 2010;18(5):433-8.

\section{Liberati 2009}

Liberati A, Altman DG, Tetzlaff J, Mulrow C, Gøtzsche PC, loannidis JP, et al. The PRISMA statement for reporting systematic reviews and meta-analyses of studies that evaluate health care interventions: explanation and elaboration. PLOS Medicine 2009;6(7):e1000100.

\section{Liu 2017}

Liu S, He CZ, Cai YT, Xing QP, Guo YZ, Chen ZL, et al. Evaluation of negative-pressure wound therapy for patients with diabetic foot ulcers: systematic review and meta-analysis. Therapeutics and Clinical Risk Management 2017;13:533-44.

\section{Margolis 1999}

Margolis D, Kantor J, Berlin J. Healing of diabetic neuropathic foot ulcers receiving standard treatment. A meta-analysis. Diabetes Care 1999;22(5):692-5.

\section{Margolis 2011}

Margolis D, Malay DS, Hoffstad OJ, Leonard CE, MaCurdy T, Lopez de Nava K, et al. Prevalence of diabetes, diabetic foot ulcer, and lower extremity amputation among Medicare beneficiaries, 2006 to 2008. Diabetic foot ulcers. Data Points \#1 (prepared by the University of Pennsylvania DEcIDE Center, under Contract No. HHSA29020050041I). Agency for Healthcare Research and Quality. AHRQ Publication No. 10(11)-EHC009-EF. 2011.

\section{Medical Advisory Secretariat 2006}

Medical Advisory Secretariat. Negative pressure wound therapy: an evidence-based analysis. Negative pressure wound therapy Ontario Health Technology Assessment Series 2006 2006; Vol. 6, issue 14:1-38.

\section{Morris 1998}

Morris AD, McAlpine R, Steinke D, Boyle DI, Ebrahim AR, Vasudev N, et al. Diabetes and lower limb amputations in the community. A retrospective cohort study. DARTS/ MEMO Collaboration. Diabetes Audit and Research in 
Tayside Scotland/Medicines Monitoring Unit. Diabetes Care 1998;21(5):738-43.

\section{Nabuurs-Franssen 2005}

Nabuurs-Franssen MH, Huijberts MS, Nieuwenhuijzen Kruseman AC, Willems J, Schaper NC. Health-related quality of life of diabetic foot ulcer patients and their caregivers. Diabetologia 2005;48(9):1906-10.

\section{NICE 2016}

National Institute for Health and Care Excellence. Diabetic foot problems: prevention and management. NICE guideline [NH19]. Last updated: January 2016. www.nice.org.uk/guidance/ng19 (accessed 16 May 2018).

\section{Noble-Bell 2008}

Noble-Bell G, Forbes A. A systematic review of the effectiveness of negative pressure wound therapy in the management of diabetes foot ulcers. International Wound Journal 2008;5(2):233-42.

\section{Oyibo 2001}

Oyibo SO, Jude EB, Tarawneh I, Nguyen HC, Harkless LB, Boulton AJ. A comparison of two diabetic foot ulcer classification systems: the Wagner and the University of Texas wound classification systems. Diabetes Care 2001;24(1):84-8.

\section{Parmar 1998}

Parmar MK, Torri V, Stewart L. Extracting summary statistics to perform meta-analysis of the published literature for survival endpoints. Statistics in Medicine 1998;17(24):2815-34.

\section{Pecoraro 1990}

Pecoraro RE, Reiber GE, Burgess EM. Pathways to diabetic limb amputation: basis for prevention. Diabetes Care 1990;13(5):513-21.

\section{Peinemann 2008}

Peinemann F, McGauran N, Sauerland S, Lange S. Negative pressure wound therapy: potential publication bias caused by lack of access to unpublished study results data. BMC Medical Research Methodology 2008;8:4.

\section{Pound 2005}

Pound N, Chipchase S, Treece K, Game F, Jeffcoate W. Ulcerfree survival following management of foot ulcers in diabetes. Diabetic Medicine 2005;22(10):1306-9.

\section{Public Health Agency of Canada 2011}

Public Health Agency of Canada. Diabetes in Canada: facts and figures from a public health perspective. www.phac-aspc.gc.ca/ cd-mc/publications/diabetes-diabete/facts-figures-faitschiffres-2011/highlights-saillants-eng.php (accessed 16 May 2018).

\section{Reiber 1996}

Reiber G. The epidemiology of diabetic foot problems. Diabetic Medicine 1996;13S:S6-11.

\section{Reiber 1999}

Reiber GE, Vileikyte L, Boyko EJ, Del Aguila M, Smith DG, Lavery LA, et al. Causal pathways for incident lower extremity ulcers in patients with diabetes from two settings. Diabetes Care 1999;22(1):157-62

\section{Review Manager 2014 [Computer program]}

Nordic Cochrane Centre, The Cochrane Collaboration. Review Manager 5 (RevMan 5). Version 5.3. Copenhagen: Nordic Cochrane Centre, The Cochrane Collaboration, 2011.

\section{Ribu 2006}

Ribu L, Hanestad BR, Moum T, Birkeland K, Rustoen T. A comparison of the health-related quality of life in patients with diabetic foot ulcers, with a diabetes group and a non diabetes group from the general population. Quality of Life Research 2007;16(2):179-89.

\section{Schaper 2004}

Schaper NC. Diabetic foot ulcer classification system for research purposes: a progress report on criteria for including patients in research studies. Diabetes/metabolism Research and Reviews 2004;20(S1):S90-5.

\section{Schünemann 2011a}

Schünemann HJ, Oxman AD, Higgins JP, Vist GE, Glasziou P, Guyatt GH. Chapter 11: Presenting results and 'Summary of findings' tables. In: Higgins JP, Green S, editor(s). Cochrane Handbook for Systematic Reviews of Interventions Version 5.1.0 (updated March 2011). The Cochrane Collaboration, 2011. Available from handbook.cochrane.org.

\section{Schünemann 2011b}

Schünemann HJ, Oxman AD, Vist GE, Higgins JP, Deeks JJ, Glasziou P, et al. Chapter 12: Interpreting results and drawing conclusions. In: Higgins JP, Green S, editor(s). Cochrane Handbook for Systematic Reviews of Interventions Version 5.1.0 (updated March 2011). The Cochrane Collaboration, 2011. Available from handbook.cochrane.org.

\section{Shaw 2010}

Shaw JE, Sicree RA, Zimmet PZ. Global estimates of the prevalence of diabetes. Diabetes Research and Clinical Practice 2010;87(1):4-14.

\section{SIGN 2018}

Scottish Intercollegiate Guidelines Network (SIGN). Search filters. www.sign.ac.uk/search-filters.html (accessed 14 May 2018).

\section{Singh 2005}

Singh N, Armstrong DG, Lipsky BA. Preventing foot ulcers in patients with diabetes. JAMA 2005;293(2):217-28

\section{Steed 2006}

Steed DL, Attinger C, Colaizzi T, Crossland M, Franz M, Harkless L, et al. Guidelines for the treatment of diabetic ulcers. Wound Repair and Regeneration 2006;14(6):680-92. 


\section{Sterne 2011}

Sterne JA, Egger M, Moher D. Chapter 10: Addressing reporting biases. In: Higgins JP, Green S, editor(s). Cochrane Handbook for Systematic Reviews of Interventions Version 5.1.0 (updated March 2011). The Cochrane Collaboration, 2011. Available from handbook.cochrane.org.

\section{Tennvall 2000}

Tennvall GR, Apelqvist J. Health related quality of life in patients with diabetes mellitus and foot ulcers. Journal of Diabetes and its Complications 2000;14(5):235-41.

\section{Ubbink 2008}

Ubbink DT, Westerbos SJ, Nelson EA, Vermeulen H. A systematic review of topical negative pressure therapy for acute and chronic wounds. British Journal of Surgery 2008;95(6):685-92.

\section{Van Gils 1999}

Van Gils C, Wheeler LA, Mellsrom M, Brinton EA, Mason S, Wheeler CG. Amputation prevention by vascular surgery and podiatry collaboration in high risk diabetic and non-diabetic patients - the operation desert foot experience. Diabetes Care 1999;22(5):678-83.

\section{Wagner 1981}

Wagner FW. The dysvascular foot: a system of diagnosis and treatment. Foot \& Ankle 1981;2(2):64-122.

\section{WHO 2016}

World Health Organization (WHO). Global report on diabetes. www.who.int/diabetes/global-report/en/ (accessed prior to 19 August 2018).

\section{CHARACTERISTICS OF STUDIES}

Characteristics of included studies [ordered by study ID]

\section{Wounds International 2013}

Wounds International. International Best Practice Guidelines: wound management in diabetic foot ulcers. www.woundsinternational.com/media/best-practices/_/673/ files/dfubestpracticeforweb.pdf (accessed 16 May 2018).

\section{Wrobel 2001}

Wrobel JS, Mayfield JA, Reiber GE. Geographic variation of lower limb extremity major amputation in individuals with and without diabetes in the Medicare population. Diabetes Care 2001;24(5):860-4.

\section{References to other published versions of this review}

\section{Dumville 2013a}

Dumville JC, Hinchliffe RJ, Cullum N, Game F, Stubbs N, Sweeting M. Negative pressure wound therapy for treating foot wounds in people with diabetes mellitus. Cochrane Database of Systematic Reviews 2013, Issue 1. [DOI: 10.1002/14651858.CD010318]

\section{Dumville 2013b}

Dumville JC, Hinchliffe RJ, Cullum N, Game F, Stubbs N, Sweeting M, et al. Negative pressure wound therapy for treating foot wounds in people with diabetes mellitus. Cochrane Database of Systematic Reviews 2013, Issue 10. [DOI: 10.1002/14651858.CD010318.pub2]

* Indicates the major publication for the study

Armstrong 2005

Methods 2-arm RCT undertaken in the USA (in wound and academic centres)

Participants 162 adults

Inclusion criteria: presence of: wound from a diabetic foot amputation to the transmetatarsal level of the foot; adequate perfusion; University of Texas grade 2 or 3

Exclusion criteria: people presenting with: active Charcot arthropathy of the foot, wounds resulting from burns, venous insufficiency, untreated cellulitis or osteomyelitis (after amputation), collagen vascular disease, malignant disease in the wound; or people treated with: corticosteroids, immunosuppressive drugs or chemotherapy, NPWT (in the last 30 days), growth factors, normothermic therapy; hyperbaric medicine, bioengineered tissue products (in the last 30 days)

Key baselines covariates:

Wound area $\left(\mathrm{cm}^{2}\right)$ :

Group A: 22.3 (SD 23.4)

Group B: 19.2 (SD 17.6)

Wound duration (months):

Group A: 1.2 (SD 3.9) 
Armstrong 2005 (Continued)

Group B: 1.8 (SD 5.9)

$75.3 \%$ of the study population had wounds that were $<30$ days' duration (classed as acute wounds by the author) and $24.7 \%$ had wounds that were $>30$ days' duration (classed as chronic wounds by authors).

Interventions Group A $(\mathrm{n}=77)$ : NPWT (V.A.C. system). No information provided regarding the pressure applied or the cycle (e.g. constant/cyclical etc); dressing changes every $48 \mathrm{~h}$. Treatment conducted until wound closure or completion of 112 day assessment.

Group B $(n=85)$ : moist wound therapy with alginates, hydrocolloid, foam or hydrogel dressings - adhering to standardised guidelines at the discretion of attending clinician. Dressings changed every other day unless recommended by treating clinician.

All participants received: off-loading therapy, preventatively and therapeutically as indicated - a pressure relief sandal or walker was provided for all participants; sharp debridement within 2 days of randomisation and as deemed necessary by treating clinician; and measurement of prealbumin, albumin and glycosylated haemoglobin levels in 7 days before entering the study. Low pre study albumin levels resulted in consultation with nutritionist, and dietary supplement initiated if needed.

Outcomes

Primary review outcomes: number of wounds completely healed (defined as $100 \%$ re-epithelialisation without drainage and INCLUDED closure via surgery where the decision for surgical closure was made by treating clinician); time to wound healing; amputation

Secondary review outcomes: other adverse events (serious and non-serious); resource use

Notes Follow-up: 112 days (16 weeks)

Outcome assessment: based on data from wound assessments and digital photographs taken by treatment clinicians at days $0,7,14,28,42,56,84$ and 112

A secondary analysis of trial data reported that $75 \%$ of wounds were $\leq 1$ month in duration (classed by authors as acute) and 25\% were $>1$ month in duration (classed by authors as chronic). We noted that mean baseline values for ulcer duration were obviously very skewed.

Funding: study funded by $\mathrm{KCl}$ - manufacturers of the V.A.C. intervention.

\section{Risk of bias}

\section{Bias \\ Authors' judgement Support for judgement}

Random sequence genera- Low risk tion (selection bias)
Quote: "randomisation was accomplished by using www.randomizer.org to generate 15 blocks of 10 random numbers each."

Comment: adequate methodology
Quote: "numbers were systematically assigned to each treatment group, and sealed envelopes containing opaque, black paper labelled with assigned treatment and patient ID number were sequentially numbered and provided to each site. The black paper was added to ensure that the contents of the envelopes were not visible prior to opening."

Comment: adequate methodology

\begin{tabular}{|c|c|c|}
\hline $\begin{array}{l}\text { Blinding of participants } \\
\text { and personnel (perfor- } \\
\text { mance bias) }\end{array}$ & Unclear risk & $\begin{array}{l}\text { Quote: "the decision for surgical closure of amputation wounds was decided } \\
\text { individually by the physician investigator." }\end{array}$ \\
\hline $\begin{array}{l}\text { mance bias) } \\
\text { All outcomes }\end{array}$ & & $\begin{array}{l}\text { Comment: it is understandably not possible to blind participants or investi- } \\
\text { gators to whether or not they received NPWT. However, given this, it is impor- } \\
\text { tant that any decision-making that might be affected by performance bias is } \\
\text { recognised and blinding is introduced where possible. We noted that unblind- } \\
\text { ed health professionals were able to make decisions about closure surgery }\end{array}$ \\
\hline
\end{tabular}

Negative pressure wound therapy for treating foot wounds in people with diabetes mellitus (Review) Copyright $\odot 2018$ The Cochrane Collaboration. Published by John Wiley \& Sons, Ltd. 
Armstrong 2005 (Continued)

that could then have resulted in more wounds being closed (and classed as healed) or amputated in 1 group compared with the other. As a result of this, we classed the risk of bias for this domain as unclear.

Blinding of outcome as-
$\begin{aligned} & \text { sessment (detection bias) } \\ & \text { All outcomes }\end{aligned}$$\quad \begin{aligned} & \text { Quote: "neither patients nor investigators were masked to the randomised } \\ & \text { treatment assignment... However, notes that the masking component of } \\ & \text { the study dealt specifically with planimetry measurements from digital pho- } \\ & \text { tographs ... concordance between the investigator and the digital planimetry } \\ & \text { provided independent confirmation of the primary efficacy endpoint of com- } \\ & \text { plete wound healing." }\end{aligned}$

Comment: assessment of healing seems to have had a blinded component

Incomplete outcome data Low risk Comment: no evidence of incomplete outcome data

(attrition bias)

All outcomes

\begin{tabular}{ll}
\hline Other bias $\quad$ Unclear risk $\quad$ Potential funding bias; no evidence of other bias \\
\hline
\end{tabular}

Blume 2008

\begin{tabular}{|c|c|}
\hline Methods & 2-arm RCT undertaken in the USA \\
\hline \multirow[t]{10}{*}{ Participants } & 342 adults; 341 randomised; ITT 335 \\
\hline & $\begin{array}{l}\text { Inclusion criteria: stage } 2 \text { or } 3 \text { (Wagner's scale) calcaneal, dorsal or planter foot ulcer; ulcer } \geq 2 \mathrm{~cm}^{2} \text { in } \\
\text { area after debridement; adequate blood perfusion (various tests and cut-offs reported) }\end{array}$ \\
\hline & $\begin{array}{l}\text { Exclusion criteria: recognised active Charcot disease; ulcers resulting from electrical, chemical or ra- } \\
\text { diation burns; collagen vascular disease; ulcer malignancy; untreated osteomyelitis or cellulitis; un- } \\
\text { controlled hyperglycaemia; inadequate lower extremity perfusion; pregnant or nursing mothers; or ul- } \\
\text { cer treatment within } 30 \text { days of trial start with normothermic or hyperbaric oxygen therapy, corticos- } \\
\text { teroids, immunosuppressive drugs, chemotherapy, recombinant or autologous growth factor prod- } \\
\text { ucts, skin and dermal substitutes; or use of any enzymic debridement treatment. }\end{array}$ \\
\hline & Key baselines covariates: \\
\hline & Wound area $\left(\mathrm{cm}^{2}\right)$ : \\
\hline & Group A: 13.5 (SD 18.2) \\
\hline & Group B: 11.0 (SD 12.7) \\
\hline & Wound duration (months) \\
\hline & Group A: 6.6 (SD 10.8) \\
\hline & Group B: 6.9 (SD 12.2) \\
\hline
\end{tabular}

Interventions

Group A ( $n=172)$ : NPWT (V.A.C. system) applied according to manufacturer's instructions, but no information provided about the pressure applied or the cycle (e.g. constant/cyclical, etc.). Treatment continued until wound closure, or until there was sufficient granulation tissue formation for healing by primary and secondary intention.

Group B ( $n=169)$ : advanced moist wound therapy dressings used according to guidelines/local protocols - noted as being predominantly hydrogels and alginates.

All participants received: assessment and debridement of ulcers within 2 days of randomisation; offloading therapy as deemed necessary 
Blume 2008 (Continued)

Outcomes

Primary review outcomes: number of wounds completely healed (defined as $100 \%$ re-epithelialisation without drainage or dressing requirement and INCLUDED closure via surgery where the decision for surgical closure was made by treating clinician); time to wound healing; amputation

Secondary review outcomes: other adverse events (serious and non-serious)

Notes Follow-up: 112 days (16 weeks)

Outcome assessment: participants examined weekly for the first 4 weeks and then every other day until day 112, or ulcer closure by any means. Participants achieving closure were followed up at 3 and 9 months

Funding: study funded by $\mathrm{KCl}$ - manufacturers of the V.A.C. intervention.

\section{Risk of bias}

\begin{tabular}{lll}
\hline Bias & Authors' judgement & Support for judgement \\
\hline $\begin{array}{l}\text { Random sequence genera- } \\
\text { tion (selection bias) }\end{array}$ & Low risk & $\begin{array}{l}\text { Quote: "randomization was accomplished by generating blocks of numbers } \\
\text { through http://www.randomizer.org." } \\
\text { Comment: adequate methodology }\end{array}$ \\
\hline $\begin{array}{l}\text { Allocation concealment } \\
\text { (selection bias) }\end{array}$ & Low risk & $\begin{array}{l}\text { Quote: "numbers were assigned to a treatment group and sealed in opaque } \\
\text { envelopes containing black paper labelled with treatment and patient ID. En- } \\
\text { velopes were sequentially numbered before clinical trial site distribution. At } \\
\text { patient randomisation, treatment was assigned on the basis of the next se- } \\
\text { quentially labelled envelope." }\end{array}$ \\
& $\begin{array}{l}\text { Comment: adequate methodology } \\
\end{array}$
\end{tabular}

\begin{tabular}{|c|c|c|}
\hline $\begin{array}{l}\text { Blinding of participants } \\
\text { and personnel (perfor- } \\
\text { mance bias) } \\
\text { All outcomes }\end{array}$ & Unclear risk & $\begin{array}{l}\text { Comment: it is understandably not possible to blind participants and investi- } \\
\text { gators to whether or not they receive NPWT. However, given this, it is impor- } \\
\text { tant that any decision-making that might be affected by performance bias is } \\
\text { recognised and blinding is introduced where possible. We note that unblind- } \\
\text { ed health professionals were able to make decisions about undertaking clo- } \\
\text { sure surgery that could then have resulted more wounds being closed (and } \\
\text { classed as healed) or amputated in } 1 \text { group compared with the other. As a re- } \\
\text { sult of this, we classed the risk of bias for this domain as unclear. }\end{array}$ \\
\hline
\end{tabular}

Blinding of outcome as- Unclear risk sessment (detection bias) All outcomes
Quote: "blinded photographic evaluation was conducted."

Comment: while the main report has no discussion of blinded outcome assessment, it is mentioned in the conference abstract describing the study. However as with Armstrong 2005, we noted that unblinded health professionals in 1 group were able to make decisions about undertaking closure surgery that could then have resulted more wounds being closed (and classed as healed) or amputated. As a result of this, we classed the risk of bias for this domain as unclear.

$\begin{array}{ll}\begin{array}{l}\text { Incomplete outcome data } \\ \text { (attrition bias) }\end{array} & \begin{array}{l}\text { Comment: } 3 \text { participants were excluded from analysis in each arm as they } \\ \text { did not receive the trial treatment allocated. There were relatively low num- } \\ \text { All outcomes }\end{array} \\ \text { bers of exclusions, although ideally data on these participants would have } & \text { been included in the RCT report. Additionally, } 31 \% \text { of participants in the NPWT } \\ \text { group and } 25 \% \text { in the dressing group were classed as being 'discontinued' for } & \text { reasons that included adverse events, ineffective treatment and death. It is } \\ \text { not clear whether participants who were discontinued for reasons other than } & \text { death were also censored from the analysis, rather than being followed up. } \\ \text { If discontinuation did result in censoring in this open trial it may have intro- } & \text { duced bias. }\end{array}$


Blume 2008 (Continued)

Other bias Unclear risk Potential funding bias; no evidence of other bias

Dalla-Paola 2010

\begin{tabular}{|c|c|}
\hline Methods & 2-arm RCT undertaken in Italy \\
\hline \multirow[t]{8}{*}{ Participants } & 130 adults. \\
\hline & $\begin{array}{l}\text { Inclusion criteria: people presenting with infected open amputations or surgical dehiscence of minor } \\
\text { amputations of level II-III A-B according to the University of Texas Diabetic Wound Classification }\end{array}$ \\
\hline & $\begin{array}{l}\text { Exclusion criteria: people with bleeding wounds or untreated osteomyelitis. In those cases of recent } \\
\text { debridement of the wound a minimum 24-h period was awaited before applying a V.A.C. dressing. }\end{array}$ \\
\hline & Key baselines covariates: \\
\hline & Wound area $\left(\mathrm{cm}^{2}\right)$ : not reported \\
\hline & Wound level University of Texas: \\
\hline & Group A: II: $n=20 ;$ III: $n=45$ \\
\hline & Group B: II: $n=22 ;$ III: $n=43$ \\
\hline \multirow[t]{2}{*}{ Interventions } & Group A ( $n=65)$ : V.A.C. therapy (V2) following surgical debridement \\
\hline & $\begin{array}{l}\text { Group B }(n=65) \text { : advanced dressings (control group, } C 2 \text { ) following surgical debridement (dressings } \\
\text { were changed } 3 \text { times per week and during every dressing change the wound bed was inspected. Con- } \\
\text { trol group received advanced dressings such as alginate, hydrofibre, silver-dressing or polyurethanes. } \\
\text { The choice of dressing mostly depended on the amount of exudate and presence of infection.) }\end{array}$ \\
\hline \multirow[t]{2}{*}{ Outcomes } & $\begin{array}{l}\text { Primary review outcomes: number of wounds completely healed (further); amputation (after follow-up } \\
\text { period) }\end{array}$ \\
\hline & $\begin{array}{l}\text { Secondary review outcomes: number of wounds closed or covered with surgery; time to closure or cov- } \\
\text { erage surgery }\end{array}$ \\
\hline \multirow[t]{3}{*}{ Notes } & Follow-up period: end of therapy defined as complete coverage of the wound with epithelial tissue \\
\hline & Funding: not reported \\
\hline & Only Study II included in this review \\
\hline
\end{tabular}

\section{Risk of bias}

\begin{tabular}{lll}
\hline Bias & Authors' judgement & Support for judgement \\
\hline $\begin{array}{l}\text { Random sequence genera- } \\
\text { tion (selection bias) }\end{array}$ & Low risk & $\begin{array}{l}\text { Quote: "randomization was performed using a computerized randomization } \\
\text { procedure." } \\
\text { Comment: adequate methodology }\end{array}$ \\
\hline $\begin{array}{l}\text { Allocation concealment } \\
\text { (selection bias) }\end{array}$ & Unclear risk & Not reported \\
\hline $\begin{array}{l}\text { Blinding of participants } \\
\text { and personnel (perfor- } \\
\text { mance bias) } \\
\text { All outcomes }\end{array}$ & Unclear risk & $\begin{array}{l}\text { Comment: it is understandably not possible to blind participants and investi- } \\
\text { gators to whether or not they receive NPWT. However, given this, it is impor- } \\
\text { tant that any decision-making that might be affected by performance bias is } \\
\text { recognised and blinding is introduced where possible. We noted that unblind- }\end{array}$ \\
\hline
\end{tabular}


Dalla-Paola 2010 (Continued)

ed health professionals were able to make decisions about undertaking closure surgery that could then have resulted in more wounds being closed (and classed as healed) or amputated in 1 group compared with the other. As a result of this, we classed the risk of bias for this domain as unclear.

Blinding of outcome as- Unclear risk
sessment (detection bias)

Quote: "clinicians (non-blinded, participating in the study) evaluated the All outcomes wound bed and made a subjective estimation of the depth of the wound and of the quality of the wound bed." "A photographic documentation was carried out upon enrolment in the study, during the intermediate phase and at the end of the therapy. A planimetry of superficial wounds was done to evaluate the dimensions of ulcerated wounds." "Presence and quantity of granulation tissue was also documented and microbiological examinations (after wound debridement, based on wound biopsies) were repeated. All patients with clinical signs of infection, after microbiological examination, were treated with targeted antibiotic therapy."

Comment: as a result of this, we classed the risk of bias for this domain as unclear.

Incomplete outcome data Low risk Comment: no evidence of incomplete outcome data

(attrition bias)

All outcomes

Other bias Low risk No evidence of other risk of bias

\section{Karatepe 2011}

\begin{tabular}{ll}
\hline Methods & 2-arm RCT undertaken in Turkey \\
\hline Participants & 67 adults \\
& Inclusion criteria: diabetic foot ulcers \\
& Exclusion criteria: not reported \\
& Key baselines covariates: \\
& Wound area (cm ${ }^{2}$ ): \\
& Group A: 35.7 (SD 6.4) \\
Group B: 29.7 (SD 5.2) & Wound duration (weeks): \\
Group A: 11.3 (SD 9.2) \\
Group B: 8.8 (SD 7.2)
\end{tabular}

Group B ( $n=37)$ : conventional wound care treatment (described as daily wound care, debridement and treatment of gangrenous tissue where required and use of sterilised gauze dressing).

Clinical measures included standard diabetic treatment, daily wound care including antiseptic bath, debridement, toe removal for gangrene when necessary and wound care with conventional methods or V.A.C.

Outcomes Primary review outcomes: time to healing


Notes Follow-up: final SF-36 form completed 1 month after wound healing (mean in 4th month of study).

Outcome assessment: healing time calculated as the time from hospital admission to re-epithelisation.

Table 2 titled as "Duration of granulation" but the table content presented "time to healing."

Funding: not reported

\section{Risk of bias}

Bias Authors' judgement Support for judgement

Random sequence genera- Low risk tion (selection bias)

Quote: "randomisation of the patients was arranged by the free use web based system (http://www.tufts.edul gdall/PLAN.HTM)."

Comment: classed as an adequate method

\begin{tabular}{lll}
\hline $\begin{array}{l}\text { Allocation concealment } \\
\text { (selection bias) }\end{array}$ & Unclear risk & Not reported \\
\hline $\begin{array}{l}\text { Blinding of participants } \\
\text { and personnel (perfor- } \\
\text { mance bias) }\end{array}$ & Unclear risk & $\begin{array}{l}\text { Not possible to blind participants and investigators to whether or not they re- } \\
\text { ceive NPWT }\end{array}$ \\
\begin{tabular}{l} 
All outcomes \\
\hline
\end{tabular}
\end{tabular}

$\begin{array}{ll}\text { Blinding of outcome as- } & \text { Unclear risk }\end{array}$

All outcomes

\begin{tabular}{l}
\hline Incomplete outcome data Unclear risk Not reported \\
(attrition bias) \\
All outcomes
\end{tabular}

\begin{tabular}{ll}
\hline Other bias $\quad$ Low risk $\quad$ No evidence of other risk of bias \\
\hline
\end{tabular}

Lavery 2014

Methods 2-arm RCT undertaken in the USA

Participants

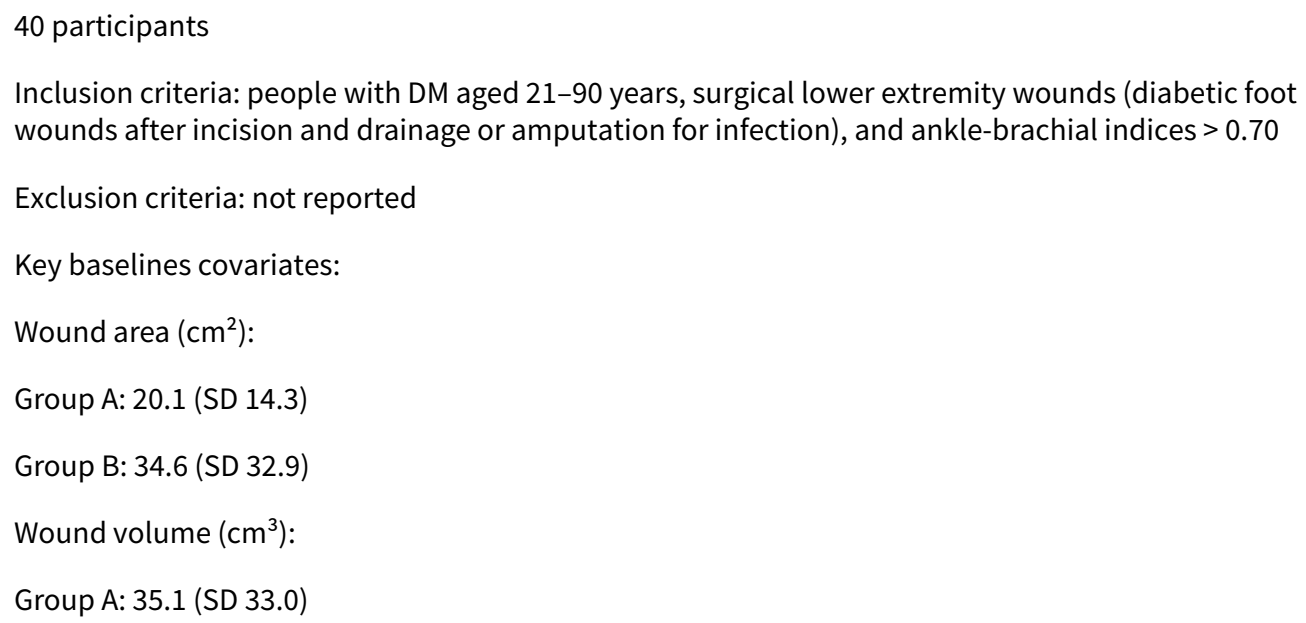


Lavery 2014 (Continued)

Group B: 65.3 (SD 69.9)

History of amputation:

Group A: 65\%

Group B: $65 \%$

Wound duration: not reported

$\begin{array}{ll}\text { Interventions } & \text { Group A }(n=20): 75 \text { mmHg continuous pressure with a silicone-coated dressing (Engenex with Bio- } \\ & \text { Dome Technology; ConvaTec, Skillman, NJ) } \\ & \text { Group B }(n=20): 125 \mathrm{mmHg} \text { continuous pressure with a polyurethane foam dressing (V.A.C. with Granu- } \\ & \text { Foam dressing; Kinetic Concepts, Inc., San Antonio, TX) }\end{array}$

Outcomes

Primary review outcomes: no review relevant outcome reported

Secondary review outcomes: number of wounds closed or covered with surgery; adverse events (we used data from Table 1 in the paper - 3 vs 2; however, discrepancy between table and text which suggests 3 vs 1)

\begin{tabular}{ll}
\hline Notes & Follow-up: 4 weeks \\
& Both NPWT devices were changed 3 times per week.
\end{tabular}

\section{Risk of bias}

\begin{tabular}{lll}
\hline Bias & Authors' judgement & Support for judgement \\
\hline $\begin{array}{l}\text { Random sequence genera- } \\
\text { tion (selection bias) }\end{array}$ & Low risk & $\begin{array}{l}\text { Quote: "randomised from a computer-generated list" } \\
\text { Comment: classed as an adequate method }\end{array}$ \\
\hline $\begin{array}{l}\text { Allocation concealment } \\
\text { (selection bias) }\end{array}$ & Unclear risk & Not reported \\
\hline $\begin{array}{l}\text { Blinding of participants } \\
\text { and personnel (perfor- } \\
\text { mance bias) }\end{array}$ & Unclear risk & $\begin{array}{l}\text { Comment: it is understandably not possible to blind participants and investi- } \\
\text { All outcomes }\end{array}$ \\
$\begin{array}{l}\text { gators to whether or not they receive NPWT. However, given this, it is impor- } \\
\text { tant that any decision-making that might be affected by performance bias is } \\
\text { recognised and blinding is introduced where possible. We noted that unblind- } \\
\text { ed health professionals were able to make decisions about undertaking clo- } \\
\text { sure surgery that could then have resulted in more wounds being closed (and } \\
\text { classed as healed) or amputated in } 1 \text { group compared with the other. As a re- } \\
\text { sult of this, we classed the risk of bias for this domain as unclear. }\end{array}$
\end{tabular}

\begin{tabular}{lll}
$\begin{array}{l}\text { Blinding of outcome as- } \\
\text { sessment (detection bias) } \\
\text { All outcomes }\end{array}$ & Unclear risk & Not reported \\
\hline $\begin{array}{l}\text { Incomplete outcome data } \\
\text { (attrition bias) } \\
\text { All outcomes }\end{array}$ & Low risk & Comment: no evidence of incomplete outcome data \\
\hline Other bias & Low risk & No evidence of other risk of bias
\end{tabular}


Mody 2008

Methods 2-arm RCT undertaken in India

Participants

48 participants (recruited from inpatient wards), 15 of whom were reported to have DM and a foot ulcer. Data for these 15 participants only were presented

Inclusion criteria: people admitted to general surgery, physical medicine and rehabilitation wards and referred by the surgical consultants for care of an acute or chronic extremity, sacral or abdominal wound that could not be treated with primary closure

Exclusion criteria: ischaemic wounds; or wounds: in anatomical locations where an adequate seal around the wound site could not be obtained; with exposed bowel or blood vessels; with necrotic tissue that could not be debrided; with communicating fistulae; with malignancy; with recent grafts; or presence of osteomyelitis; or receiving therapeutic anticoagulation

Key baselines covariates (foot ulcers in people with DM only):

Wound area $\left(\mathrm{cm}^{2}\right)$ :

Group A: 25.7 (SD 9.7)

Group B: 48.1 (SD 53.5)

Wound duration (days):

Group A: 8.5 (SD 8.3)

Group B: 5.2 (SD 2.3)

Interventions

Group A ( $n=6)$ : locally constructed (homemade) device: a sterilised, porous packing material obtained from a local source was cut to fit the wound. A 14-French suction catheter was tunnelled into the packing material, which then was placed into the wound cavity. A sterile adhesive plastic drape (Dermincise, Vygon, UK) was cut to overlap the surrounding skin and applied over the packing material, forming an airtight seal. Tubing was used to attach the free end of the suction catheter to a wall suction canister. The TNP timer was placed in circuit between the wall suction apparatus and the wall suction canister

The TNP timer, constructed from local electronics, was designed to cycle wall suction intermittently using a simple timed switch and a system of valves. For the study protocol, the timer was set to cycle for 2 minutes on, followed by 5 minutes off. Wall suction pressure was set at $125 \mathrm{mmHg}$. In sensitive wounds, suction was reduced to a tolerable level (usually $50-100 \mathrm{mmHg}$ ) until it could be comfortably increased. For oedematous wounds, the suction was kept on a continuous setting until oedema had been reduced and an intermittent regimen could be followed. The dressing was changed every 2 days unless otherwise scheduled by the treating physician. Wounds were debrided as required to keep the wound bed free of necrotic tissue. Participants receiving NPWT who no longer required hospitalisations for their primary diagnosis, or could not afford to remain in the hospital, remained in the study with conventional wound dressings in the outpatient setting, but outcomes were analysed in the original treatment groups.

Group B ( $n=9)$ : saline-soaked gauze and dry pads used to cover the wound. Dressing changes typically performed twice daily; frequency adjusted according to the judgement of the treating physician.

Wounds in both treatment groups were debrided before dressing application.

Outcomes

Primary review outcomes: number of wounds completely healed (satisfactory healing defined as complete wound closure by secondary intention or wound readiness for delayed primary closure as determined by the study investigator and treating surgeon)

Secondary review outcomes: number of wounds closed or covered with surgery

Notes

Participants were followed until wound closure or being lost to follow-up for a mean of 26.3 days (SD

18.5) in the control and 33.1 days (SD 37.3) in the treatment group.

\section{Risk of bias}

Negative pressure wound therapy for treating foot wounds in people with diabetes mellitus (Review) 
Mody 2008 (Continued)

\section{Bias Authors' judgement Support for judgement}

Random sequence genera- Low risk tion (selection bias)
Quote: "wounds that met inclusion and exclusion criteria were assessed for size (in a manner that allowed blinding) and then block-randomized using a concealed computer-generated table in a 1-to-2 ratio of TNP closure versus conventional wound dressing."

Comment: adequate method
Quote: "following enrolment, wound size was assessed using computer-aided measurements of digital photographs and block-randomized to the study arms using a concealed allocation table."

Comment: unclear how allocation concealment was conducted

Blinding of participants Unclear risk Not reported

and personnel (perfor-

mance bias)

All outcomes

Blinding of outcome as- $\quad$ Unclear risk $\quad$ Not reported
sessment (detection bias)
All outcomes

\begin{tabular}{lll}
$\begin{array}{l}\text { Incomplete outcome data } \\
\text { (attrition bias) } \\
\text { All outcomes }\end{array}$ & Low risk & Seems that participants were analysed in groups as randomised \\
\hline Other bias & Low risk & No evidence of other risk of bias \\
\hline
\end{tabular}

\section{Nain 2011}

Methods 2-arm RCT undertaken in India

Participants 30 participants

Inclusion criteria: age group 20-75 years, ulcer area $50-200 \mathrm{~cm}^{2}$, diagnosis of DM made by American Diabetes Association Criteria

Exclusion criteria: aged $<20$ years or $>75$ years; obvious septicaemia; osteomyelitis; wounds resulting from venous insufficiency; malignant disease in a wound; people being treated with corticosteroids, immunosuppressive drugs or chemotherapy; any other serious pre-existing cardiovascular, pulmonary and immunological disease.

Key baselines covariates: not reported evacuation tube embedded in the foam was connected to a fluid collection canister contained within a portable vacuum/suction machine. Subatmospheric (negative) pressure was applied within a range of $-50 \mathrm{mmHg}$ to $-125 \mathrm{mmHg}$ intermittently 3 times a day. NPWT dressings were changed when required. Subsequently, the control group received twice daily saline-moistened gauze dressings.

Group B: twice daily dressing changes with saline-moistened gauze

Cointerventions: wounds underwent initial sharp debridement to remove necrotic tissue and slough as far as possible. Standard antibiotic regimens were administered to all participants which consisted of broad-spectrum antibiotics initially and later according to the culture sensitivity report. 
Nain 2011 (Continued)

Outcomes
Primary review outcomes: number of wounds completely healed (complete healing defined as 100\% wound closure with re-epithelialisation or scab with no wound drainage present and no dressing required; complete responders: complete healing of lower limb ulcers)

Secondary review outcomes: no review relevant outcome reported

Notes Follow-up: 8 weeks

Funding: not reported

\section{Risk of bias}

\begin{tabular}{|c|c|c|}
\hline Bias & Authors' judgement & Support for judgement \\
\hline \multirow[t]{2}{*}{$\begin{array}{l}\text { Random sequence genera- } \\
\text { tion (selection bias) }\end{array}$} & Unclear risk & $\begin{array}{l}\text { Quote: "patients were randomly divided into two groups - study group and } \\
\text { control group." }\end{array}$ \\
\hline & & Comments: not reported how sequence for randomisation was generated. \\
\hline $\begin{array}{l}\text { Allocation concealment } \\
\text { (selection bias) }\end{array}$ & Unclear risk & Not reported \\
\hline $\begin{array}{l}\text { Blinding of participants } \\
\text { and personnel (perfor- } \\
\text { mance bias) } \\
\text { All outcomes }\end{array}$ & Unclear risk & $\begin{array}{l}\text { Not possible to blind participants and investigators to whether or not they re- } \\
\text { ceive NPWT. }\end{array}$ \\
\hline $\begin{array}{l}\text { Blinding of outcome as- } \\
\text { sessment (detection bias) } \\
\text { All outcomes }\end{array}$ & Unclear risk & Not reported \\
\hline \multirow{2}{*}{$\begin{array}{l}\text { Incomplete outcome data } \\
\text { (attrition bias) } \\
\text { All outcomes }\end{array}$} & High risk & $\begin{array}{l}\text { Quote: "the patients who underwent below knee amputation were excluded } \\
\text { from this analysis." }\end{array}$ \\
\hline & & $\begin{array}{l}\text { Comment: surely this is attrition bias. We do not know how many people un- } \\
\text { derwent amputation (it was unclear what the } 80 \% \text { vs } 60 \% \text { refer to. In the text it } \\
\text { said that } 9 \text { wounds in the A group as } 60 \% \text { at } 4 \text { weeks). }\end{array}$ \\
\hline Other bias & Unclear risk & Not reported \\
\hline
\end{tabular}

Novinščak 2010

\begin{tabular}{ll}
\hline Methods & 3-arm RCT undertaken in Croatia \\
\hline Participants & 27 adult inpatients \\
& $\begin{array}{l}\text { Inclusion criteria: complicated diabetic ulcer (Wagner 2-5) managed to international guidelines for } \\
\text { treatment protocol (confirmed with the author that these were all foot wounds) }\end{array}$ \\
& Exclusion criteria: revascularisation, reconstruction and amputation procedures were not considered \\
in this study. & Key baselines covariates: not reported \\
& Wound duration (months): not reported \\
\hline
\end{tabular}

Interventions

Group A $(n=7)$ : NPWT 
Novinščak 2010 (Continued)

Group B ( $\mathrm{n}=12)$ : moist dressings

Group C $(n=8)$ : classic gauze

Surgical debridement, off-loading, comorbidity treatment and appropriate wound care were performed.

\begin{tabular}{|c|c|c|}
\hline Outcomes & \multicolumn{2}{|c|}{$\begin{array}{l}\text { Primary review outcome: healing rate (author defined as wound closure - personal contact) } \\
\text { Secondary review outcomes: no review relevant outcome reported }\end{array}$} \\
\hline Notes & \multicolumn{2}{|c|}{ Follow-up: 2 months, extracted from abstract only } \\
\hline \multicolumn{3}{|l|}{ Risk of bias } \\
\hline Bias & Authors' judgement & Support for judgement \\
\hline $\begin{array}{l}\text { Random sequence genera- } \\
\text { tion (selection bias) }\end{array}$ & Unclear risk & Not reported \\
\hline $\begin{array}{l}\text { Allocation concealment } \\
\text { (selection bias) }\end{array}$ & Unclear risk & Not reported \\
\hline $\begin{array}{l}\text { Blinding of participants } \\
\text { and personnel (perfor- } \\
\text { mance bias) } \\
\text { All outcomes }\end{array}$ & Unclear risk & Not reported \\
\hline $\begin{array}{l}\text { Blinding of outcome as- } \\
\text { sessment (detection bias) } \\
\text { All outcomes }\end{array}$ & Unclear risk & Not reported \\
\hline $\begin{array}{l}\text { Incomplete outcome data } \\
\text { (attrition bias) } \\
\text { All outcomes }\end{array}$ & Unclear risk & Not reported \\
\hline Other bias & Unclear risk & Not reported \\
\hline
\end{tabular}

\section{Vaidhya 2015}

\begin{tabular}{ll}
\hline Methods & 2-arm RCT undertaken in India \\
\hline Participants & 60 participants \\
& Inclusion criteria: people with ulcers on dorsum of foot of size $>10 \mathrm{~cm}^{2}$. Adequate blood circulation was \\
& assessed by doing lower limb arterial Doppler. \\
& Exclusion criteria: people with osteomyelitis, peripheral vascular disease or malignancy \\
& Key baselines covariates: not reported
\end{tabular}

Interventions

Group A: NPWT dressing (a usual suction machine generating pressure of -80 to $-150 \mathrm{mmHg}$, Ryle's tube, piece of foam cut according to size and shape of ulcer, and adhesive transparent dressing (OpSite by Smith \& Nephews, UK). The suction was applied 30 minutes on and 30 minutes off.)

Group B: conventional dressing (cleaning with povidine iodine solution with or without hydrogen peroxide and applying moist gauze to wound and dressing closed by cotton bandage) 
All participants were given medical therapy for DM and antibiotics given according to culture and sensitivity patterns. All foot ulcers were surgically debrided prior to initiation of NPWT or conventional treatment. In the NPWT group, dressings were changed every $48-72 \mathrm{~h}$. In the control group, conventional dressings were applied at the time of surgical debridement and changed twice a day thereafter. Participants with failure of dressings were treated with other methods of dressing.

Outcomes Primary review outcomes: amputation (data for alternative therapy or amputation)

Secondary review outcomes: number of wounds closed or covered with surgery

Notes Follow-up: end point of study was when wound was ready for either skin grafting or secondary suturing.

Funding: not reported

\section{Risk of bias}

\begin{tabular}{lll}
\hline Bias & Authors' judgement & Support for judgement \\
\hline $\begin{array}{l}\text { Random sequence genera- } \\
\text { tion (selection bias) }\end{array}$ & Unclear risk & $\begin{array}{l}\text { Quote: "sixty patients were randomised into either the experimental NPWT } \\
\text { group or conventional dressing group (control)." } \\
\text { Comment: method of sequence generation not reported }\end{array}$ \\
\hline $\begin{array}{l}\text { Allocation concealment } \\
\text { (selection bias) }\end{array}$ & Unclear risk & Not reported \\
\hline $\begin{array}{l}\text { Blinding of participants } \\
\text { and personnel (perfor- } \\
\text { mance bias) }\end{array}$ & Unclear risk & $\begin{array}{l}\text { Comment: it is understandably not possible to blind participants and investi- } \\
\text { gatl outcomes } \\
\text { tant that any decision-making that might be affected by performance bias is } \\
\text { recognised and blinding is introduced where possible. We noted that unblind- } \\
\text { ed health professionals were able to make decisions about undertaking clo- } \\
\text { sure surgery that could then have resulted more wounds being closed (and } \\
\text { classed as healed) or amputated in 1 group compared with the other. As a re- } \\
\text { sult of this, we classed the risk of bias for this domain as unclear. }\end{array}$ \\
\hline
\end{tabular}

Blinding of outcome as- Unclear risk Not reported
sessment (detection bias) All outcomes

Incomplete outcome data Low risk Comment: no evidence of incomplete outcome data
(attrition bias)

All outcomes

Other bias Low risk No evidence of other risk of bias

\section{Zhang 2017}

\begin{tabular}{ll}
\hline Methods & 2-arm RCT undertaken in China \\
\hline Participants & 40 participants \\
& $\begin{array}{l}\text { Inclusion criteria: clinical diagnosis of type } 2 \text { DM, wound was consistent with the diagnosis of a chron- } \\
\text { ic wound, } 2 \leq \text { Wagner grade } \leq 4, \text { continuous existence of the diabetic foot lesion for a minimum of } 1 \\
\text { month. }\end{array}$ \\
& $\begin{array}{l}\text { Exclusion criteria: refusal to give written informed consent; aged < } 18 \text { years; pregnancy; presence of ex- } \\
\text { pected non-compliance with the requirements of the study estimated by investigator at time point of }\end{array}$
\end{tabular}


inclusion; necrotic tissue that could not be debrided; malignancy of the wound; severe heart disease, heart failure, unstable angina pectoris, myocardial infarction or severe systemic infection; severe renal insufficiency, with a serum creatinine level > $106 \mu \mathrm{mol} / \mathrm{L}$; liver dysfunction, with alanine aminotransferase levels $>125 \mathrm{U} / \mathrm{L}$ or glutamic-oxalacetic transaminase level $>87.5 \mathrm{U} / \mathrm{L}$; application of immunosuppressive agents and growth factors; poor compliance, death or unable to complete the course of treatment (during treatment); contraindications for surgery or people did not agree to having surgery.

Key baselines covariates:

Wound area and wound duration not reported

Interventions
Group A: vacuum sealing drainage group: wounds cleaned and disinfected by repeatedly washing with
sterilised physiological saline, hydrogen peroxide and iodine solution and then covered with nega-
tive-pressure material according to the shape and size after debridement; dressing changed every 7
days. Negative pressure was maintained at -120 to $-400 \mathrm{mmHg}$
Group B: routine dressing: $0.5 \%$ dilute iodoform gauze and Vaseline gauze dressing, changed every oth-
er day.

Outcomes Primary review outcomes: number of wounds completely healed (described as "cured"); amputation Secondary review outcomes: no review relevant outcome reported

$\begin{array}{ll}\text { Notes } & \begin{array}{l}\text { Infiltration of the wound surface, granulation tissue growth and epithelium of the wound surface were } \\ \text { observed every } 7 \text { days for } 1 \text { month. } \\ \text { Funding: Science and Technology Grant }\end{array}\end{array}$

\section{Risk of bias}

\begin{tabular}{|c|c|c|}
\hline Bias & Authors' judgement & Support for judgement \\
\hline $\begin{array}{l}\text { Random sequence genera- } \\
\text { tion (selection bias) }\end{array}$ & Unclear risk & Not reported \\
\hline $\begin{array}{l}\text { Allocation concealment } \\
\text { (selection bias) }\end{array}$ & Unclear risk & Not reported \\
\hline $\begin{array}{l}\text { Blinding of participants } \\
\text { and personnel (perfor- } \\
\text { mance bias) } \\
\text { All outcomes }\end{array}$ & Unclear risk & $\begin{array}{l}\text { Comment: it is understandably not possible to blind participants and investi- } \\
\text { gators to whether or not they receive NPWT. However, given this, it is impor- } \\
\text { tant that any decision-making that might be affected by performance bias is } \\
\text { recognised and blinding is introduced where possible. We noted that unblind- } \\
\text { ed health professionals were able to make decisions about undertaking clo- } \\
\text { sure surgery that could then have resulted in more wounds being closed (and } \\
\text { classed as healed) or amputated in } 1 \text { group compared with the other. As a re- } \\
\text { sult of this, we classed the risk of bias for this domain as unclear. }\end{array}$ \\
\hline
\end{tabular}

\begin{tabular}{lll}
\hline $\begin{array}{l}\text { Blinding of outcome as- } \\
\text { sessment (detection bias) } \\
\text { All outcomes }\end{array}$ & Unclear risk & Not reported \\
\hline $\begin{array}{l}\text { Incomplete outcome data } \\
\text { (attrition bias) }\end{array}$ & Low risk & Comment: no evidence of incomplete outcome data \\
All outcomes & &
\end{tabular}

Other bias Low risk No evidence of other risk of bias




\begin{tabular}{|c|c|}
\hline Methods & 2-arm RCT undertaken in China \\
\hline \multirow[t]{10}{*}{ Participants } & 60 participants \\
\hline & $\begin{array}{l}\text { Inclusion criteria: duration of DM } 10-20 \text { years; mean fasting blood glucose at admission } \geq 10 \mathrm{mmol} / \mathrm{L} \text {; } \\
\text { diabetic foot by Wagner grading method of } \geq 2 \text {; diabetic foot ulcers distributed in the distal end of the } \\
\text { toe, toe plantar joints, heel, ankle and } 1 / 3 \text { lower leg }\end{array}$ \\
\hline & $\begin{array}{l}\text { Exclusion criteria: DM not diagnosed; cancerous ulcer or ulcer malignant, osteomyelitis; taking certain } \\
\text { uncommon drugs, chemotherapy, dialysis; difficult to control high blood sugar (glycosylated haemo- } \\
\text { globin }>12 \% \text { ) }\end{array}$ \\
\hline & Key baselines covariates: \\
\hline & Wound area $\left(\mathrm{cm}^{2}\right)$ : \\
\hline & Group A: 39.9 (SD 19.8) \\
\hline & Group B: 40.4 (SD 20.4) \\
\hline & Wound duration (days) \\
\hline & Group A: 51.4 (SD 36.3) \\
\hline & Group B: 52.6 (SD 27.6) \\
\hline \multirow[t]{3}{*}{ Interventions } & $\begin{array}{l}\text { Group A: vacuum sealing drainage group, conventional treatment combined with the vacuum sealing } \\
\text { drainage technology }\end{array}$ \\
\hline & $\begin{array}{l}\text { Group B: traditional treatment group, regulating blood sugar level, dressing and traditional debride- } \\
\text { ment }\end{array}$ \\
\hline & Cointerventions: all participants received blood sugar control and debridement \\
\hline \multirow[t]{2}{*}{ Outcomes } & $\begin{array}{l}\text { Primary review outcomes: number of wounds completely healed (defined as cured wound: no amputa- } \\
\text { tion is needed); amputation }\end{array}$ \\
\hline & Secondary review outcomes: number of wounds closed or covered with surgery; wound recurrence \\
\hline \multirow[t]{3}{*}{ Notes } & Follow-up: not specified for wound healing; ulcer recurrence was observed in 6-10 months \\
\hline & $\begin{array}{l}\text { Outcome assessment: healing time calculated only for cured wounds (no amputation needed); prepa- } \\
\text { ration time described as time for skin/flap grafting }\end{array}$ \\
\hline & Funding: not reported \\
\hline
\end{tabular}

\section{Risk of bias}

\begin{tabular}{lll}
\hline Bias & Authors' judgement & Support for judgement \\
\hline $\begin{array}{l}\text { Random sequence genera- } \\
\text { tion (selection bias) }\end{array}$ & Unclear risk & Not reported \\
\hline $\begin{array}{l}\text { Allocation concealment } \\
\text { (selection bias) }\end{array}$ & Unclear risk & Not reported \\
\hline $\begin{array}{l}\text { Blinding of participants } \\
\text { and personnel (perfor- } \\
\text { mance bias) } \\
\begin{array}{l}\text { All outcomes } \\
\text { Unclear risk }\end{array}\end{array}$ & $\begin{array}{l}\text { Comment: it is understandably not possible to blind participants and investi- } \\
\text { gators to whether or not they receive NPWT. However, given this, it is impor- } \\
\text { tant that any decision-making that might be affected by performance bias is } \\
\text { recognised and blinding is introduced where possible. We noted that unblind- } \\
\text { ed health professionals were able to make decisions about undertaking clo- } \\
\text { sure surgery that could then have resulted more wounds being closed (and }\end{array}$ \\
\hline
\end{tabular}


Zhu 2014 (Continued)

classed as healed) or amputated in 1 group compared with the other. As a result of this, we classed the risk of bias for this domain as unclear.

\begin{tabular}{ll}
\hline Blinding of outcome as- & Unclear risk
\end{tabular}

Incomplete outcome data Low risk Comment: no evidence of incomplete outcome data
(attrition bias)

All outcomes

Other bias Low risk No evidence of other risk of bias

DM: diabetes mellitus; h: hour; ITT: intention-to-treat population; n: number of participants; NPWT: negative pressure wound therapy; RCT: randomised controlled trial; SD: standard deviation; SF-36: 36-item Short Form; TNP: topical negative pressure (synonym for NPWT).

Characteristics of excluded studies [ordered by study ID]

\begin{tabular}{|c|c|}
\hline Study & Reason for exclusion \\
\hline Armstrong 2012 & Included multiple wounds types. Unable to obtain diabetic foot wound data separately \\
\hline Braakenburg 2005 & Included multiple wounds types. Unable to obtain diabetic foot wound data separately \\
\hline Chong 2011 & Randomised crossover trial; no relevant outcome reported \\
\hline Eginton 2003 & $\begin{array}{l}\text { Due to focus on biochemical and related outcomes and the very short follow-up, we considered } \\
\text { that relevant outcomes were not measured (they were not reported). }\end{array}$ \\
\hline Etoz 2007 & Not an RCT, as participants allocated using alternation \\
\hline Foo 2004 & $\begin{array}{l}\text { Due to focus on biochemical and related outcomes and the very short follow-up, we considered } \\
\text { that relevant outcomes were not measured (they were not reported). }\end{array}$ \\
\hline Formosa 2015 & Not an RCT \\
\hline Gonzalez 2017 & Included multiple wound types. Unable to obtain diabetic foot wound data separately \\
\hline Lone 2014 & Not an RCT, as participants allocated using odd and even numbers (quasi-randomised study) \\
\hline Maggio 2010 & $\begin{array}{l}\text { Treatment with NPWT was not the only systematic difference between groups (intervention group } \\
\text { receiving NPWT also received autologous fibroblasts and skin grafting) }\end{array}$ \\
\hline McCallon 2000 & $\begin{array}{l}\text { Not an RCT, as participants allocated using alternation. Coin flipped for first participant and then } \\
\text { participants allocated by alternation }\end{array}$ \\
\hline Moghazy 2015 & Not an RCT, as "stratified sequential allocation method" used \\
\hline Mouës 2004 & Not a diabetic foot wound study population \\
\hline Perez 2010 & Included multiple wound types. Unable to obtain diabetic foot wound data separately \\
\hline Rahmanian-Schwarz 2012 & Included multiple wound types. Unable to obtain diabetic foot wound data separately \\
\hline Ravari 2013 & The investigators described a non-random component in the sequence generation process. \\
\hline
\end{tabular}




\begin{tabular}{|c|c|}
\hline Study & Reason for exclusion \\
\hline Riaz 2010 & $\begin{array}{l}\text { Included wounds in people with diabetes in regions other than the foot (legs and back). Unable to } \\
\text { obtain diabetic foot wound data separately }\end{array}$ \\
\hline Sajid 2015 & $\begin{array}{l}\text { Due to focus on biochemical and related outcomes and the very short follow-up, we considered } \\
\text { that relevant outcomes were not measured (they were not reported). }\end{array}$ \\
\hline Sepulveda 2009 & $\begin{array}{l}\text { Due to focus on biochemical and related outcomes and the very short follow-up, we considered } \\
\text { that relevant outcomes were not measured (they were not reported). }\end{array}$ \\
\hline Sun 2007 & Crossover design and no relevant outcome reported \\
\hline Sun 2015 & NPWT was not the only difference between trial arms. \\
\hline Tuncel 2013 & Included multiple wounds types. Unable to obtain diabetic foot wound data separately \\
\hline Ugurlar 2017 & The investigators described a non-random component in the sequence generation process. \\
\hline Wang 2016 & $\begin{array}{l}\text { Due to focus on biochemical and related outcomes and the very short follow-up, we considered } \\
\text { that relevant outcomes were not measured (they were not reported). }\end{array}$ \\
\hline Yang 2014 & $\begin{array}{l}\text { Due to focus on biochemical and related outcomes and the very short follow-up, we considered } \\
\text { that relevant outcomes were not measured (they were not reported). }\end{array}$ \\
\hline Yang 2017a & $\begin{array}{l}\text { Due to focus on biochemical and related outcomes and the very short follow-up, we considered } \\
\text { that relevant outcomes were not measured (they were not reported). }\end{array}$ \\
\hline Yang 2017b & $\begin{array}{l}\text { Due to focus on biochemical and related outcomes and the very short follow-up, we considered } \\
\text { that relevant outcomes were not measured (they were not reported). }\end{array}$ \\
\hline Zhang 2014 & $\begin{array}{l}\text { Due to focus on biochemical and related outcomes and the very short follow-up, we considered } \\
\text { that relevant outcomes were not measured (they were not reported). }\end{array}$ \\
\hline
\end{tabular}

NPWT: negative pressure wound therapy; RCT: randomised controlled trial.

Characteristics of ongoing studies [ordered by study ID]

ACTRN12612000885897

Trial name or title

Methods

Participants
A pilot randomised controlled trial of negative pressure wound therapy (NPWT) in hospital in the home (HITH) to treat post-operative foot wounds

\section{RCT}

Men and women aged > 18 years; postoperative foot amputation to the transmetatarsal level of foot $\geq 5 \mathrm{~cm}^{2}$ to $\leq 20 \mathrm{~cm}^{2}$ measured by digital planimetry

\begin{tabular}{ll}
\hline Interventions & NPWT vs standard care \\
\hline Outcomes & $\begin{array}{l}\text { Proportion of wounds healed; time to healing; frequency of treatment; wound recurrence; re- } \\
\text { sources used/costs; recruitment rates; pain and health-related quality of life }\end{array}$ \\
\hline Starting date & 17 August 2012 \\
\hline Contact information & carolina.weller@monash.edu \\
\hline
\end{tabular}


ACTRN12612000885897 (Continued)
Notes
Not yet recruiting

\section{ChicTR-TRC-12002700}

\begin{tabular}{ll}
\hline Trial name or title & $\begin{array}{l}\text { A prospective multicenter assessment of Foryou NPWT security and effectiveness in promoting the } \\
\text { healing of diabetic foot ulcer }\end{array}$ \\
\hline Methods & RCT \\
\hline Participants & $\begin{array}{l}\text { People with type } 1 \text { or type } 2 \text { DM and with DFUs, including amputation wounds, were considered } \\
\text { suitable for NPWT by the author of this study }\end{array}$ \\
\hline Interventions & NPWT vs advanced wound dressing treatment \\
\hline Outcomes & Change in wound area; complete healing rate \\
\hline Starting date & 1 August 2012 \\
\hline Contact information & yaomingxue@126.com \\
\hline Notes & Recruitment status not updated \\
\hline
\end{tabular}

\section{DRKS00000059}

\begin{tabular}{ll}
\hline Trial name or title & Treatment of diabetic foot wounds by vacuum-assisted closure \\
\hline Methods & RCT \\
\hline Participants & Men and women aged $>18$ years with diabetic foot wounds \\
\hline Interventions & NPWT vs standard conventional moist wound therapy \\
\hline Outcomes & Time until complete (100\%) wound closure \\
\hline Starting date & 1 August 2009 \\
\hline Contact information & $\begin{array}{l}\text { Private Universität Witten/Herdecke GmbH Institut für Forschung in der Operativen Medizin, Ost- } \\
\text { merheimer Str. 200, 51109 Cologne, Germany }\end{array}$ \\
\hline Notes & Recruiting suspended before start date \\
\hline
\end{tabular}

\section{ISRCTN64926597}

\begin{tabular}{ll}
\hline Trial name or title & Comparing treatments for diabetic foot ulcers \\
\hline Methods & RCT \\
\hline Participants & Adults aged $\geq 18$ years with DM and a foot ulcer \\
\hline Interventions & Group 1: TAU
\end{tabular}


ISRCTN64926597 (Continued)

$$
\begin{aligned}
& \text { Group 2: TAU + HD } \\
& \text { Group 3: TAU + HD + NPWT } \\
& \text { Group 4: TAU + HD + DCD } \\
& \text { Group 5: TAU + HD + DCD + NPWT }
\end{aligned}
$$

\begin{tabular}{ll}
\hline Outcomes & Reduction in index ulcer area size; time to healing \\
\hline Starting date & April 2017 \\
\hline Contact information & r.m.gilberts@leeds.ac.uk \\
\hline Notes & Recruitment status: recruiting \\
& Overall trial end date: 31 March 2022 \\
\hline
\end{tabular}

DCD: decellularised dermal allograft; DM: diabetes mellitus; DFU: diabetic foot ulcer; HD: hydrosurgical debridement; NPWT: negative pressure wound therapy; RCT: randomised controlled trial; TAU: treatment as usual.

\section{DATA AND ANALYSES}

Comparison 1. Negative pressure wound therapy (NPWT) compared with dressings in postoperative wounds

\begin{tabular}{lllll}
\hline Outcome or subgroup title & No. of studies & $\begin{array}{l}\text { No. of partici- } \\
\text { pants }\end{array}$ & Statistical method & Effect size \\
\hline $\begin{array}{l}\text { 1 Proportion of wounds } \\
\text { healed }\end{array}$ & 1 & 162 & Risk Ratio (M-H, Fixed, 95\% Cl) & $1.44[1.03,2.01]$ \\
\hline 2 Time to healing & 1 & 162 & Hazard Ratio (Fixed, 95\% Cl) & $1.91[1.21,2.99]$ \\
\hline 3 Amputations & 2 & 292 & Risk Ratio (M-H, Fixed, 95\% Cl) & $0.38[0.14,1.02]$ \\
\hline $\begin{array}{l}4 \text { Number of wounds closed } \\
\text { or covered with surgery }\end{array}$ & 1 & 130 & Risk Ratio (M-H, Fixed, 95\% Cl) & $1.02[0.95,1.09]$ \\
\hline 5 Adverse events & 1 & 162 & Risk Ratio (M-H, Fixed, 95\% Cl) & $0.96[0.72,1.28]$ \\
\hline
\end{tabular}

Analysis 1.1. Comparison 1 Negative pressure wound therapy (NPWT) compared with dressings in postoperative wounds, Outcome 1 Proportion of wounds healed.

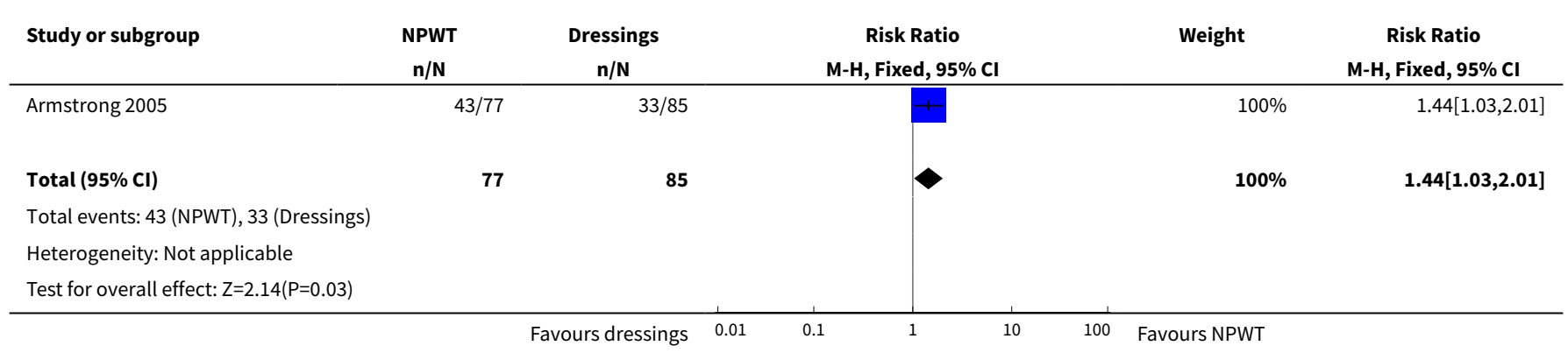


Analysis 1.2. Comparison 1 Negative pressure wound therapy (NPWT) compared with dressings in postoperative wounds, Outcome 2 Time to healing.

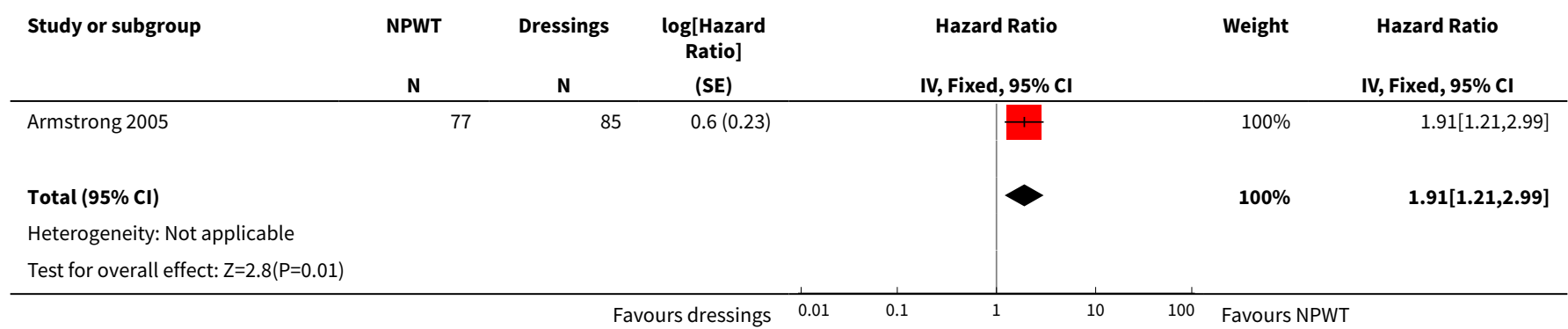

Analysis 1.3. Comparison 1 Negative pressure wound therapy (NPWT) compared with dressings in postoperative wounds, Outcome 3 Amputations.

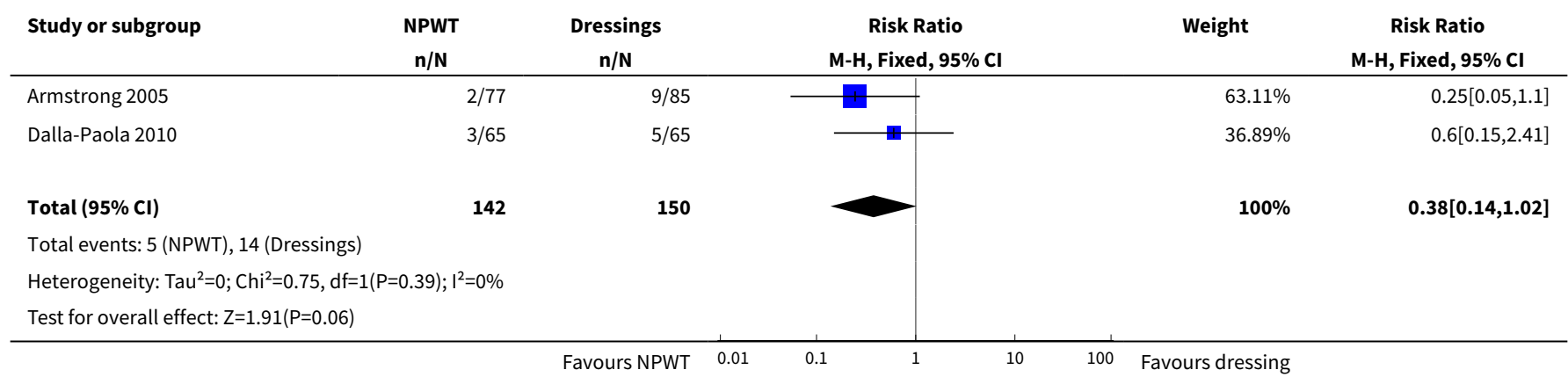

Analysis 1.4. Comparison 1 Negative pressure wound therapy (NPWT) compared with dressings in postoperative wounds, Outcome 4 Number of wounds closed or covered with surgery.

\begin{tabular}{|c|c|c|c|c|c|}
\hline Study or subgroup & $\begin{array}{c}\text { NPWT } \\
\mathrm{n} / \mathrm{N}\end{array}$ & $\begin{array}{c}\text { Dressing } \\
\mathrm{n} / \mathrm{N}\end{array}$ & $\begin{array}{c}\text { Risk Ratio } \\
\text { M-H, Fixed, 95\% Cl }\end{array}$ & Weight & $\begin{array}{c}\text { Risk Ratio } \\
\text { M-H, Fixed, } 95 \% \mathrm{Cl}\end{array}$ \\
\hline Dalla-Paola 2010 & $63 / 65$ & $62 / 65$ & & $100 \%$ & $1.02[0.95,1.09]$ \\
\hline Total $(95 \% \mathrm{Cl})$ & 65 & 65 & 1 & $100 \%$ & $1.02[0.95,1.09]$ \\
\hline \multicolumn{6}{|c|}{ Total events: 63 (NPWT), 62 (Dressing) } \\
\hline \multicolumn{6}{|c|}{ Heterogeneity: Not applicable } \\
\hline
\end{tabular}


Analysis 1.5. Comparison 1 Negative pressure wound therapy (NPWT) compared with dressings in postoperative wounds, Outcome 5 Adverse events.

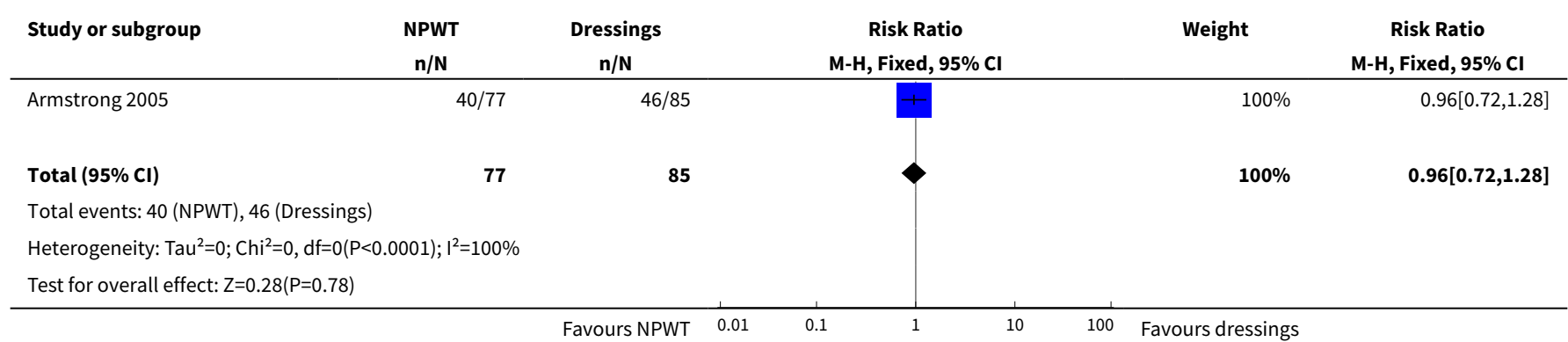

\section{Comparison 2. NPWT compared with dressings in diabetic foot ulcers}

\begin{tabular}{|c|c|c|c|c|}
\hline Outcome or subgroup title & No. of studies & $\begin{array}{l}\text { No. of partici- } \\
\text { pants }\end{array}$ & Statistical method & Effect size \\
\hline 1 Proportion of wounds healed & 5 & 486 & Risk Ratio (IV, Fixed, 95\% CI) & $1.40[1.14,1.72]$ \\
\hline 1.1 Advanced dressings & 1 & 341 & Risk Ratio (IV, Fixed, 95\% CI) & $1.49[1.11,2.01]$ \\
\hline 1.2 Basic contact dressings & 2 & 45 & Risk Ratio (IV, Fixed, 95\% CI) & $1.34[0.83,2.16]$ \\
\hline 1.3 Anti-microbial dressings & 2 & 100 & Risk Ratio (IV, Fixed, 95\% CI) & $1.32[0.93,1.87]$ \\
\hline 2 Amputations & 3 & 441 & Risk Ratio (M-H, Fixed, 95\% Cl) & $0.33[0.15,0.70]$ \\
\hline $\begin{array}{l}3 \text { Number of wounds closed or } \\
\text { covered with surgery }\end{array}$ & 3 & 129 & Risk Ratio (M-H, Fixed, 95\% Cl) & $1.02[0.85,1.24]$ \\
\hline 4 Wound recurrence & 1 & 60 & Risk Ratio (M-H, Fixed, 95\% Cl) & $0.5[0.10,2.53]$ \\
\hline
\end{tabular}

Analysis 2.1. Comparison 2 NPWT compared with dressings in diabetic foot ulcers, Outcome 1 Proportion of wounds healed.

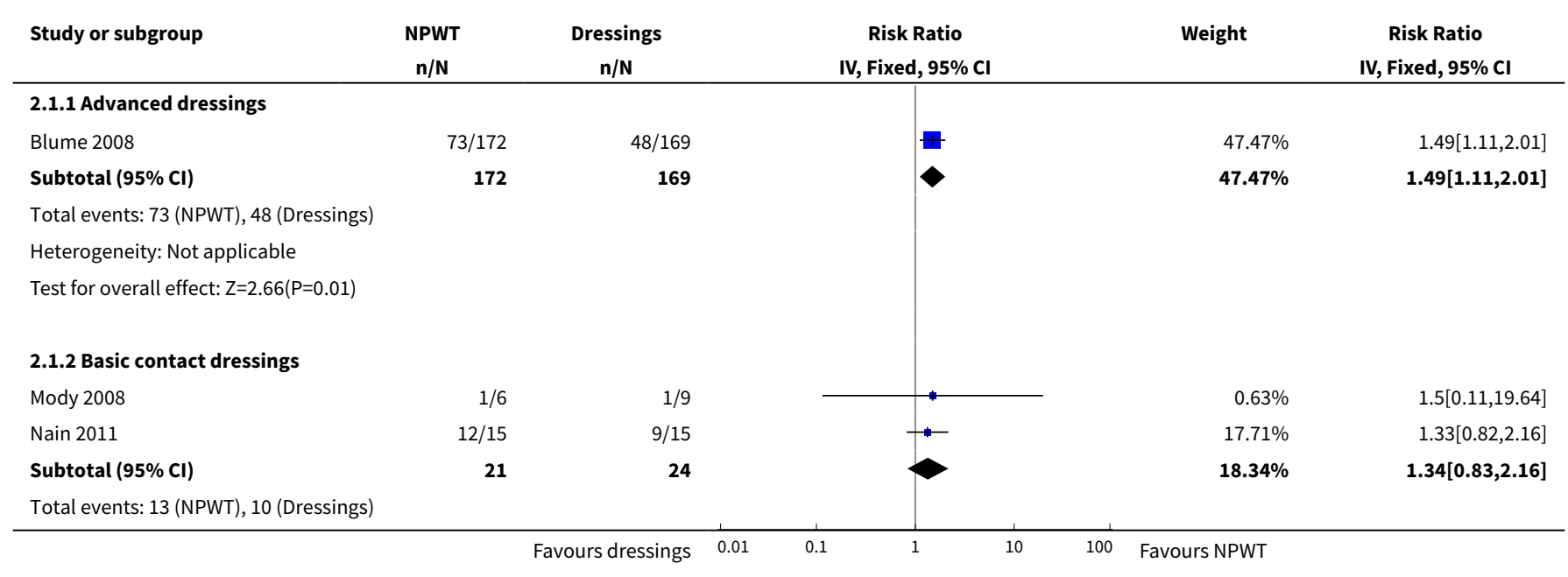




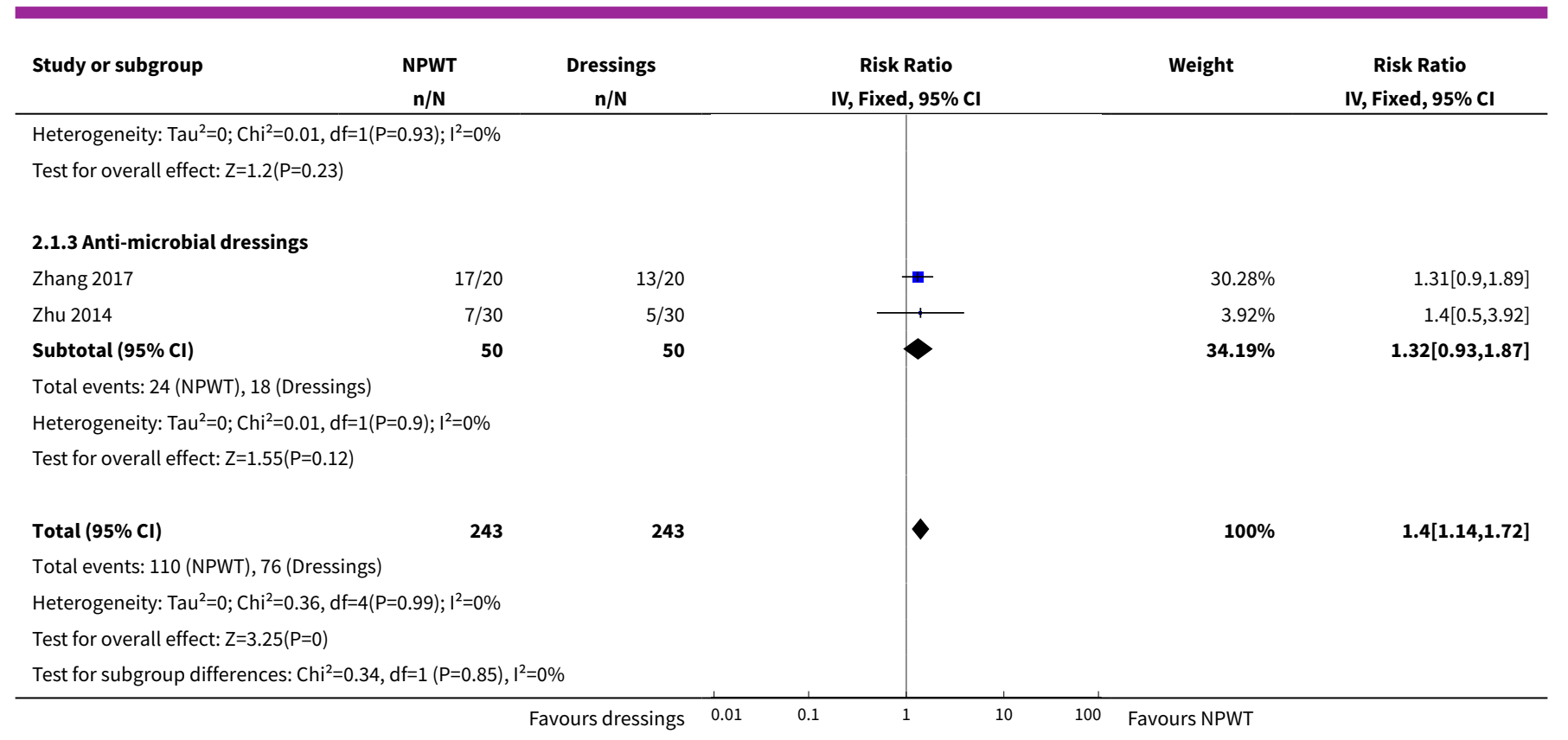

\section{Analysis 2.2. Comparison 2 NPWT compared with dressings in diabetic foot ulcers, Outcome 2 Amputations.}

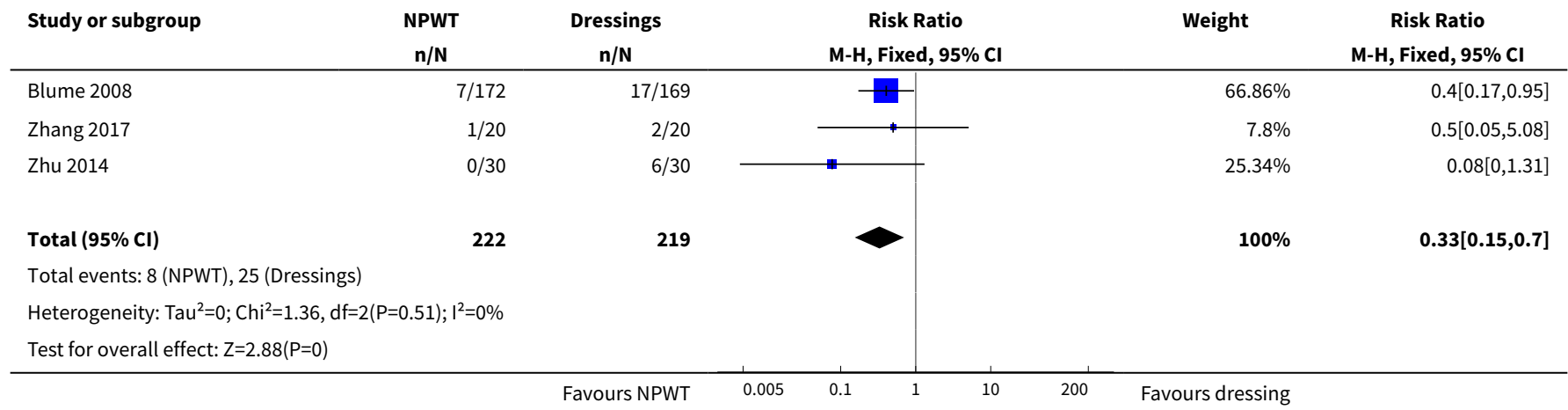

Analysis 2.3. Comparison 2 NPWT compared with dressings in diabetic foot ulcers, Outcome 3 Number of wounds closed or covered with surgery.

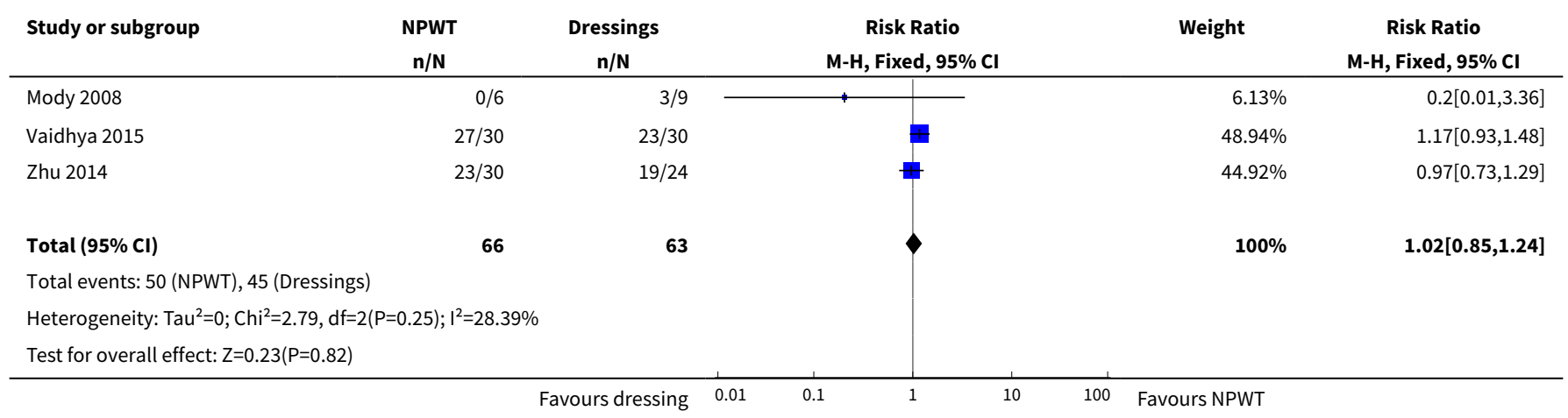


Analysis 2.4. Comparison 2 NPWT compared with dressings in diabetic foot ulcers, Outcome 4 Wound recurrence.

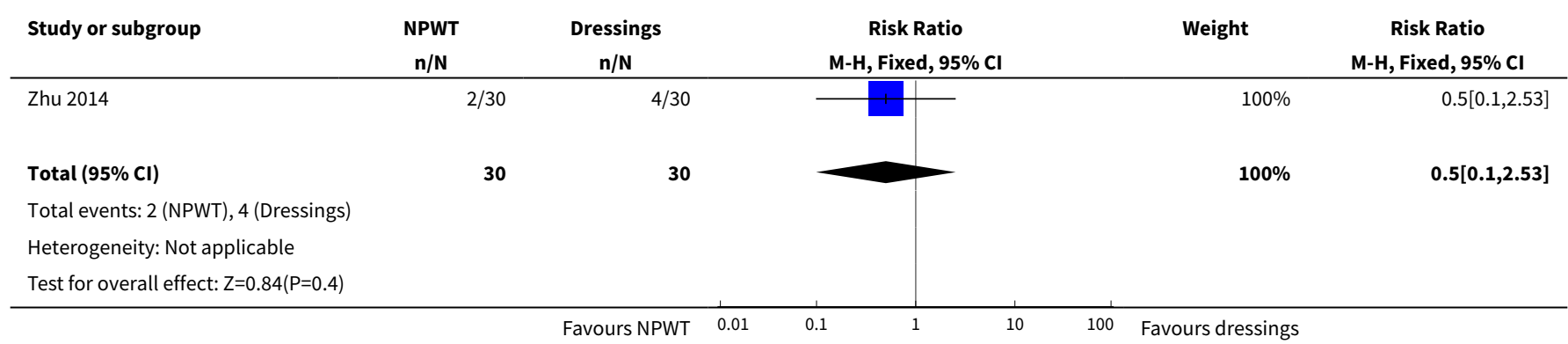

\section{Comparison 3. Low compared with high pressure of NPWT in diabetic foot ulcers}

\begin{tabular}{lllll}
\hline Outcome or subgroup title & No. of studies & $\begin{array}{l}\text { No. of partici- } \\
\text { pants }\end{array}$ & Statistical method & Effect size \\
\hline $\begin{array}{l}1 \text { Number of wounds closed or cov- } \\
\text { ered with surgery }\end{array}$ & 1 & 40 & Risk Ratio (M-H, Fixed, 95\% Cl) & $0.83[0.47,1.47]$ \\
\hline 2 Adverse events & 1 & 40 & Risk Ratio (M-H, Fixed, 95\% Cl) & $1.5[0.28,8.04]$ \\
\hline
\end{tabular}

Analysis 3.1. Comparison 3 Low compared with high pressure of NPWT in diabetic foot ulcers, Outcome 1 Number of wounds closed or covered with surgery.

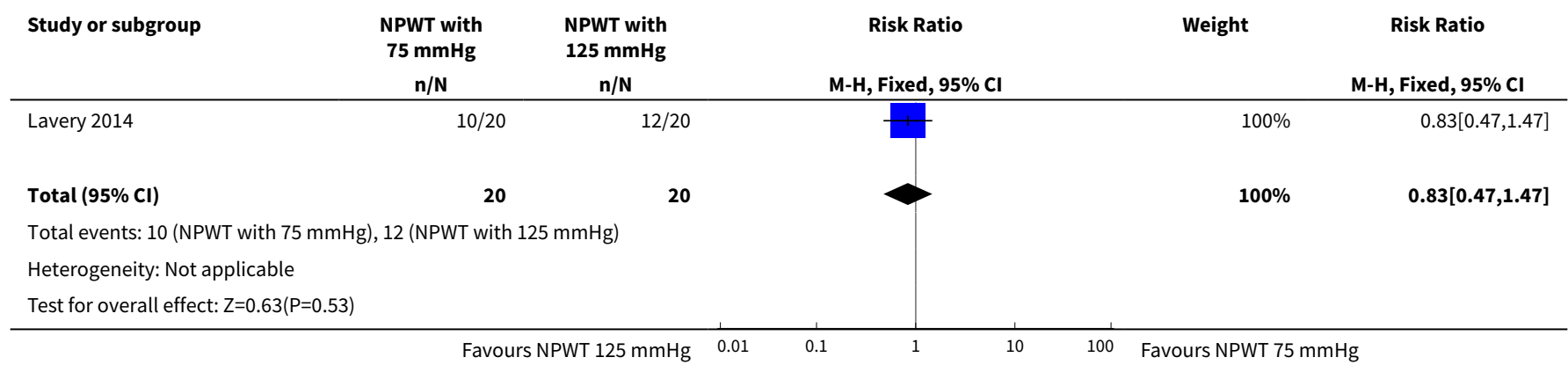

\section{Analysis 3.2. Comparison 3 Low compared with high pressure} of NPWT in diabetic foot ulcers, Outcome 2 Adverse events.

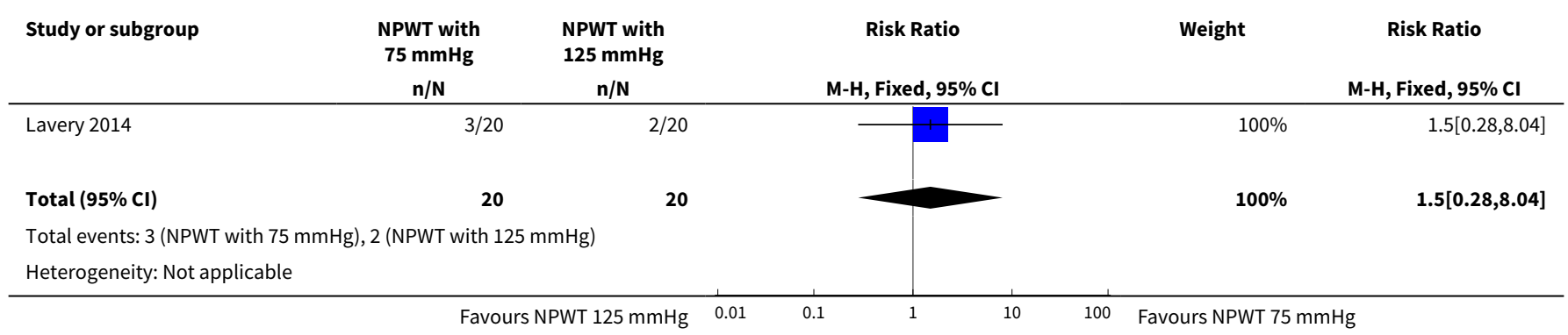




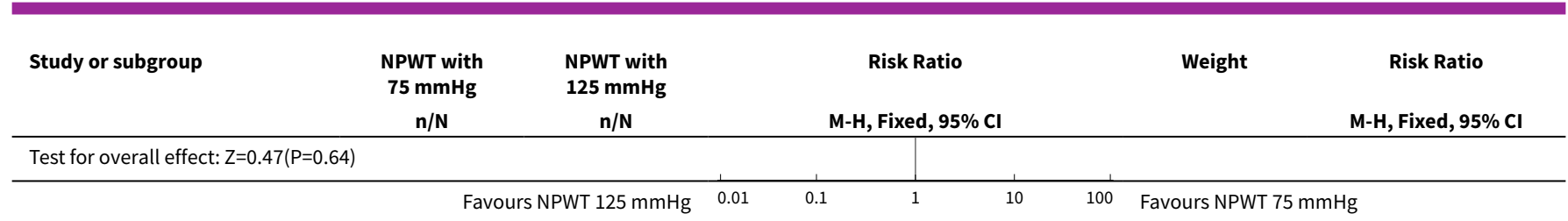




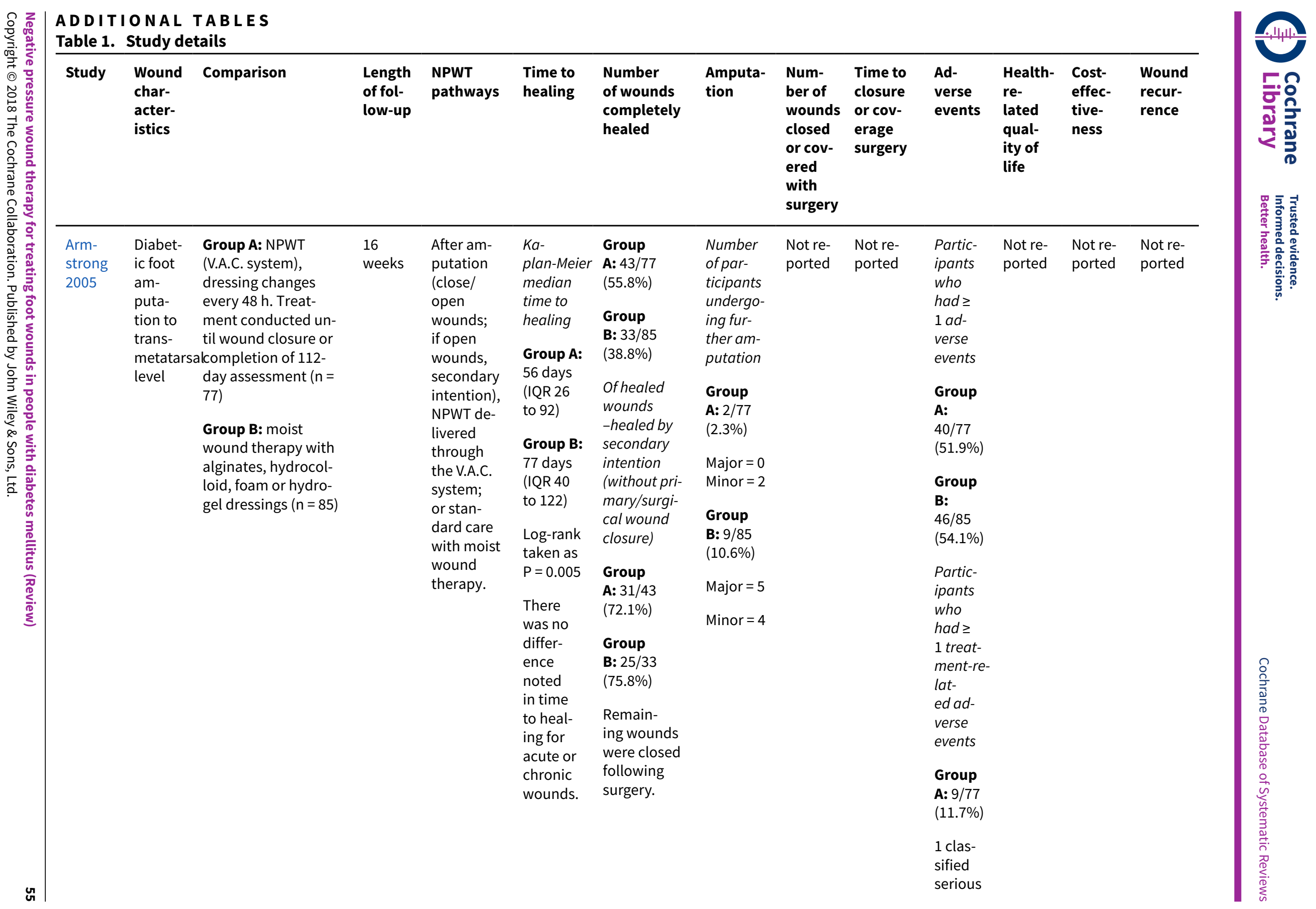




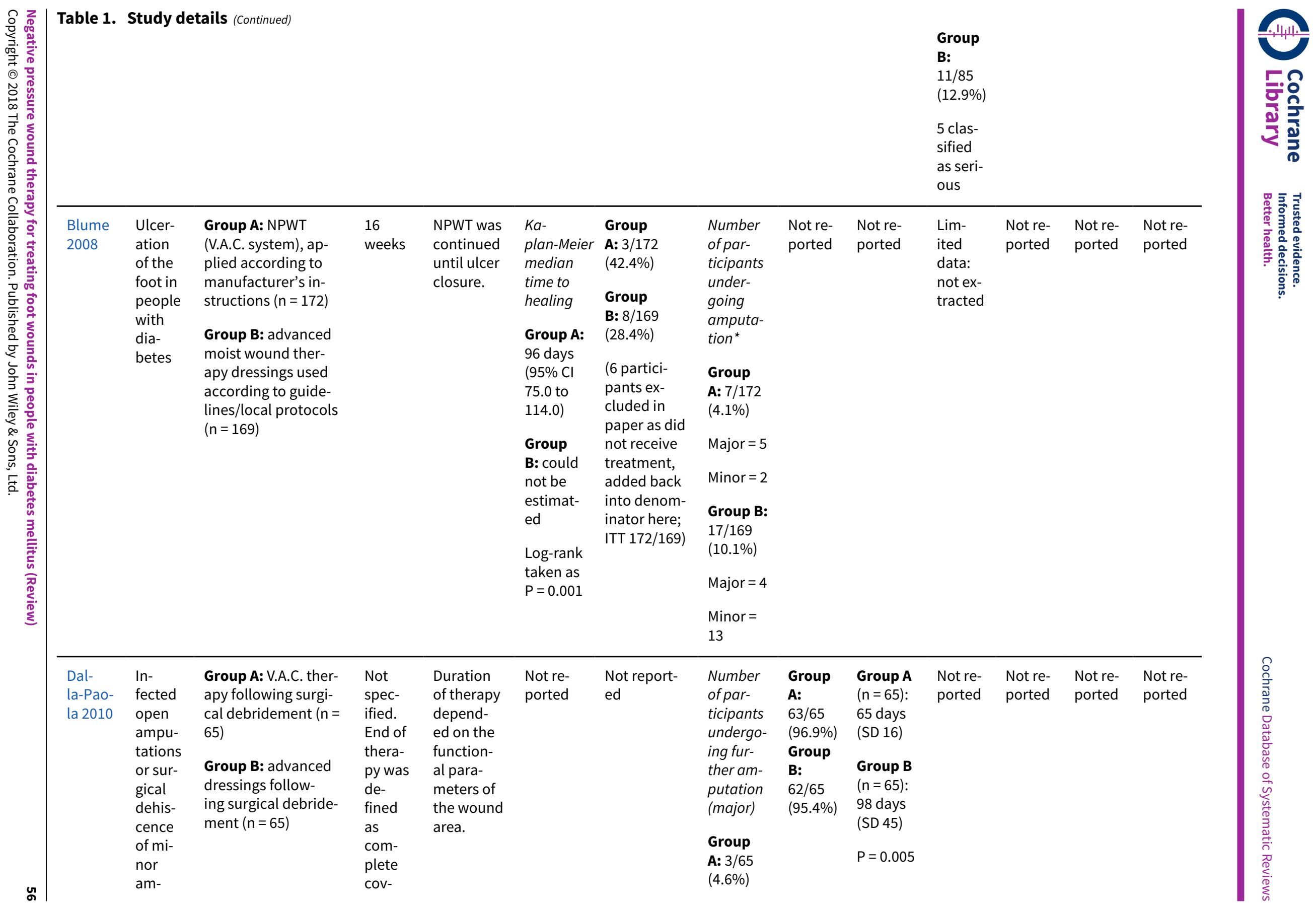




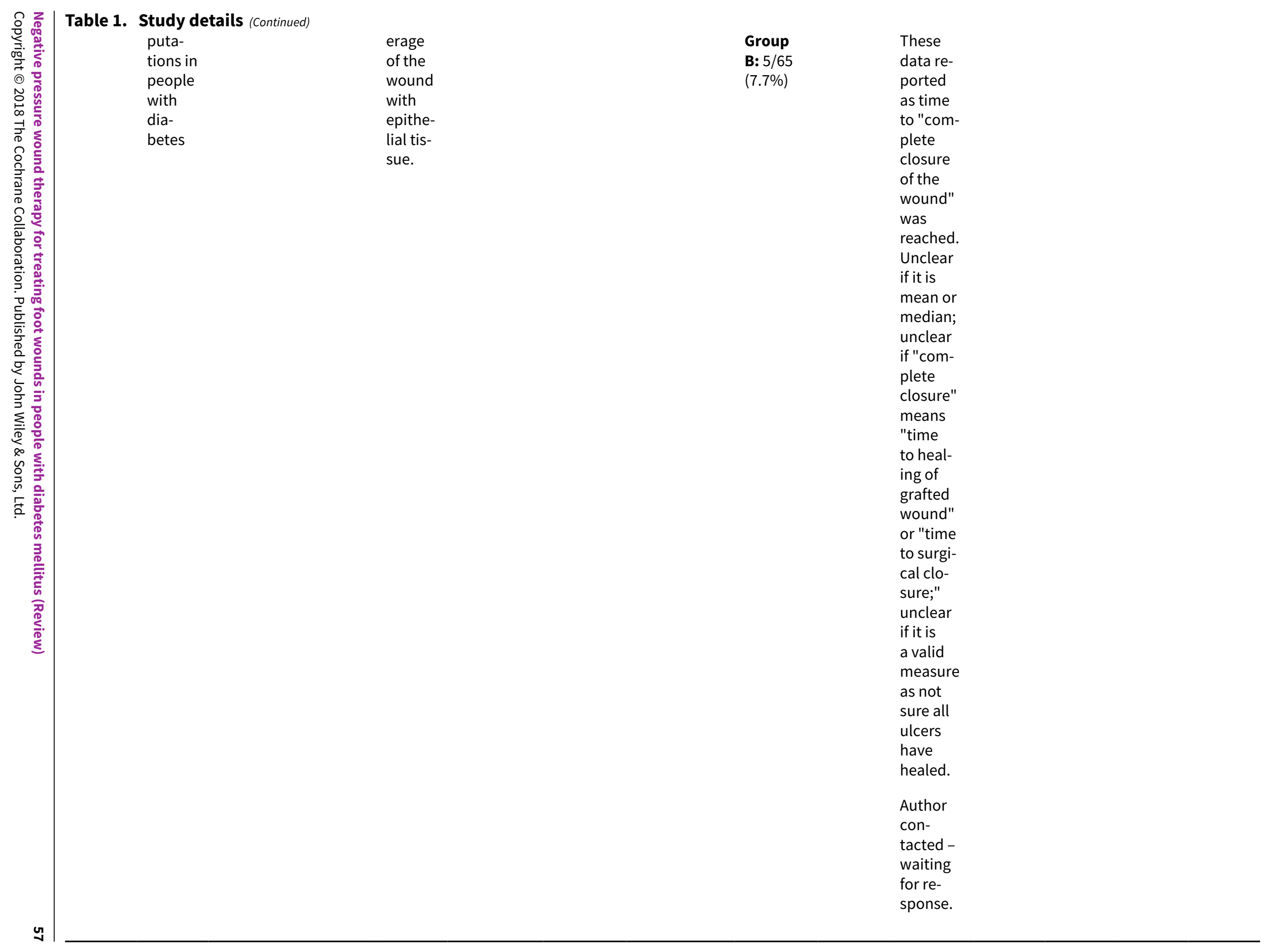




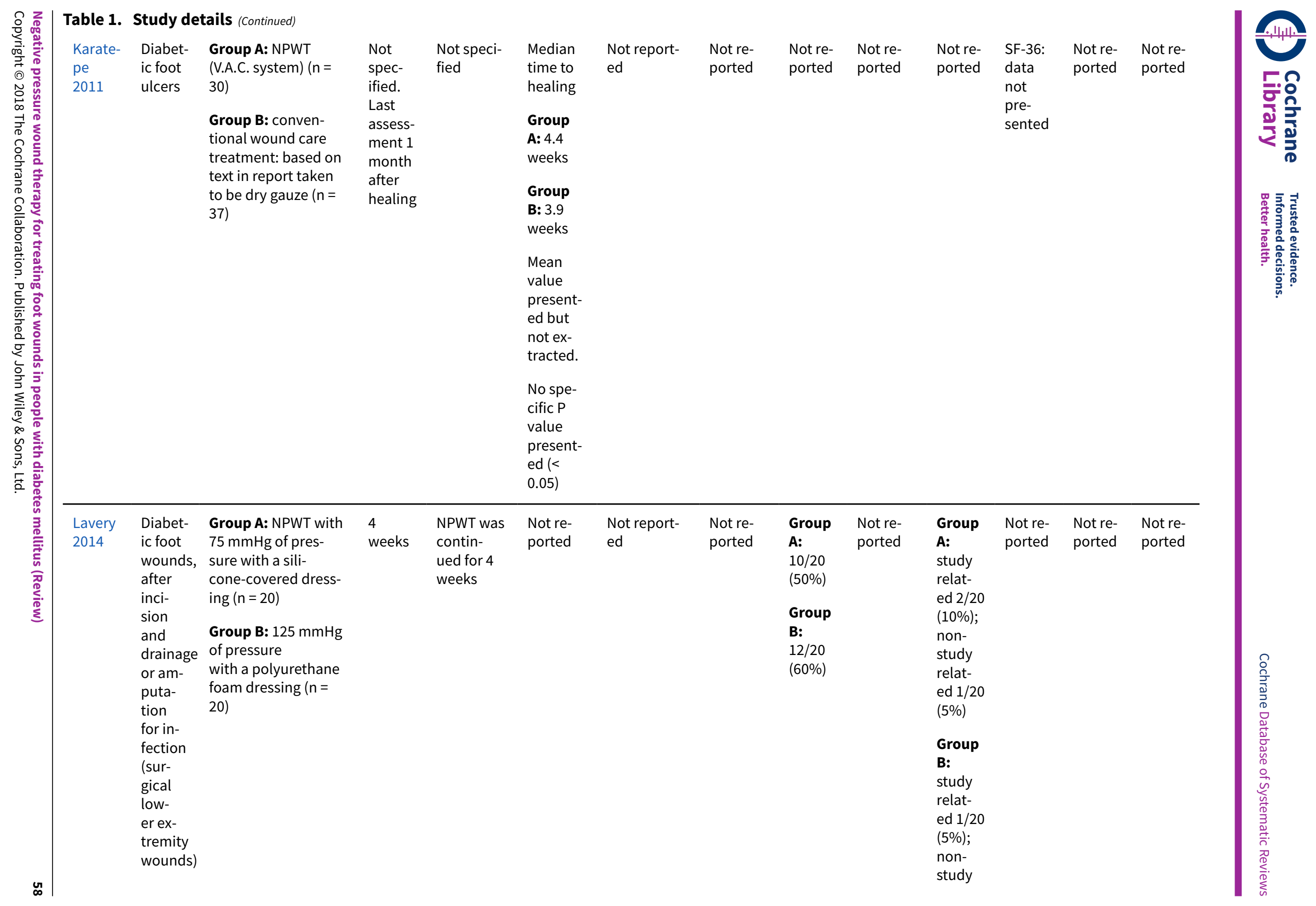




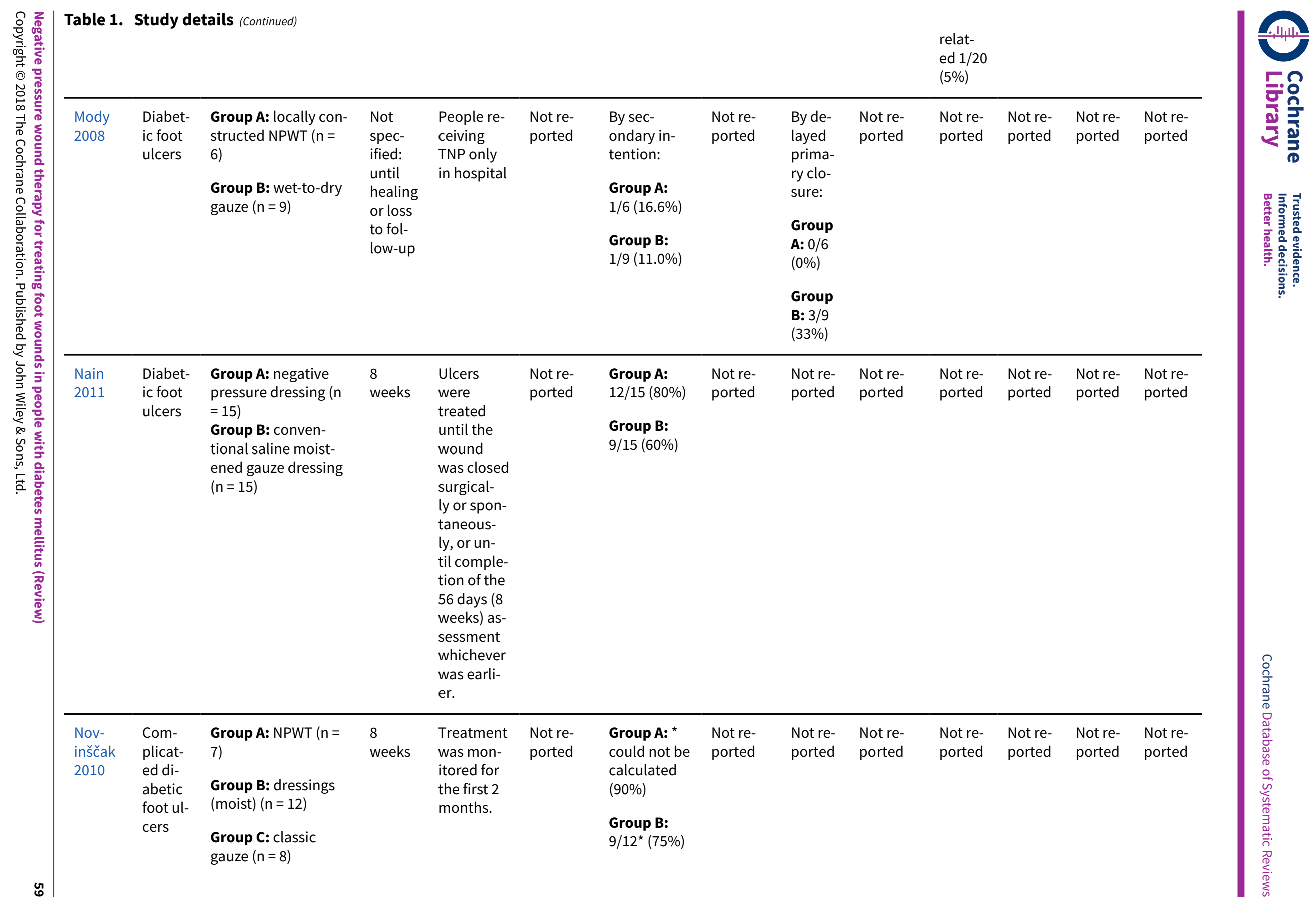




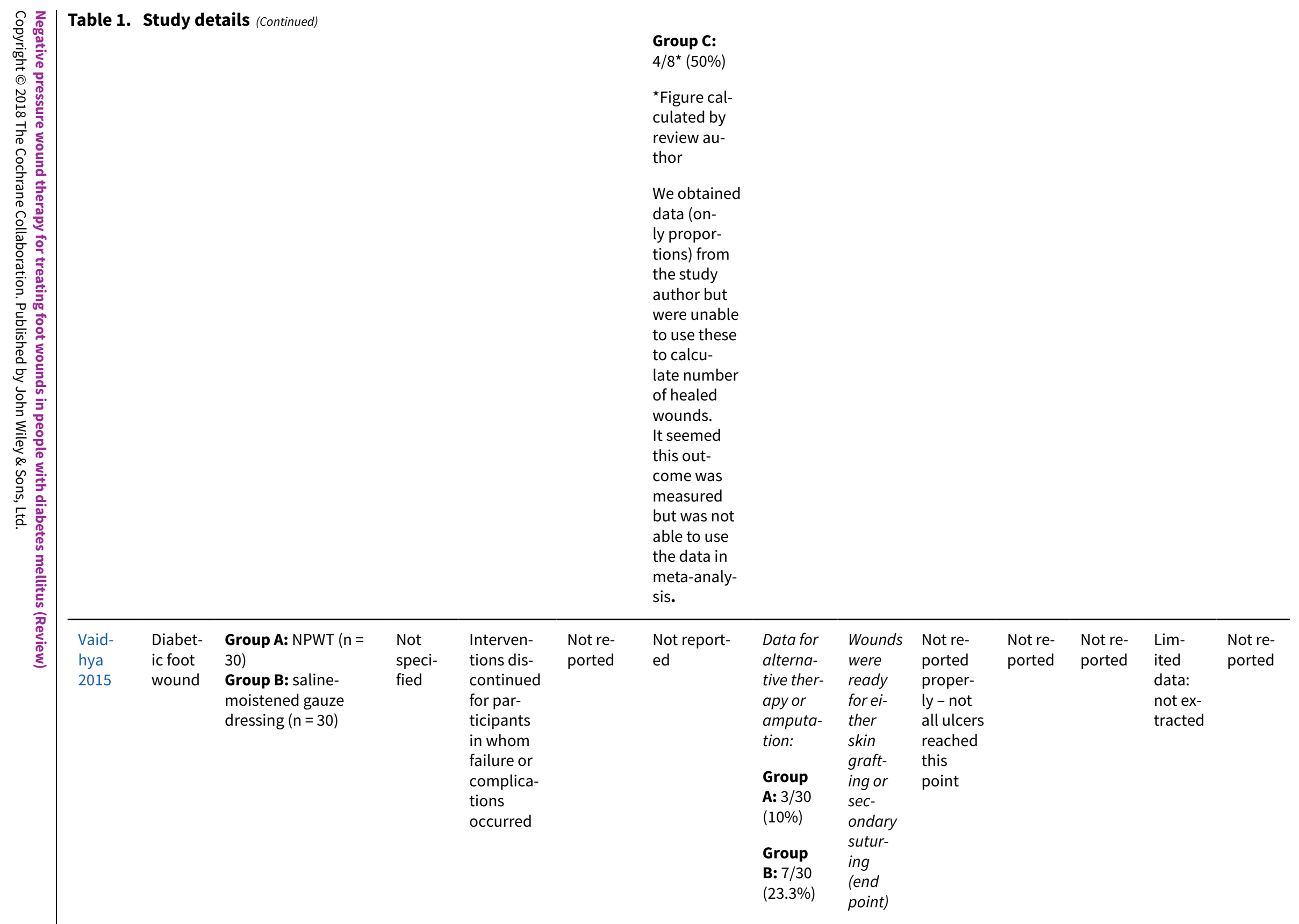




\begin{tabular}{|c|c|c|c|c|c|c|c|c|c|c|c|c|c|}
\hline & & & & & & & & $\begin{array}{l}\text { Group } \\
\text { A: } \\
27 / 30 \\
(90 \%) \\
\text { Group } \\
\text { B: } \\
23 / 30 \\
(67.7 \%)\end{array}$ & & & & & \\
\hline $\begin{array}{l}\text { Zhang } \\
2017\end{array}$ & $\begin{array}{l}\text { Chron- } \\
\text { ic dia- } \\
\text { betic } \\
\text { ulcers }\end{array}$ & $\begin{array}{l}\text { Group A: vacuum } \\
\text { sealing drainage }(n= \\
20) \\
\text { Group B: gauze } \\
\text { dressing }(n=20)\end{array}$ & $\begin{array}{l}\text { Not re- } \\
\text { ported }\end{array}$ & $\begin{array}{l}\text { Interven- } \\
\text { tions were } \\
\text { adminis- } \\
\text { tered in } \\
\text { hospital }\end{array}$ & $\begin{array}{l}\text { Not re- } \\
\text { ported }\end{array}$ & $\begin{array}{l}\text { Group A: } \\
17 / 20(85 \%) \\
\text { Group B: } \\
13 / 20(65 \%)\end{array}$ & $\begin{array}{l}\text { Group } \\
\text { A: } 1 / 20 \\
(5 \%) \\
\text { Group } \\
\text { B: } 2 / 20 \\
(10 \%)\end{array}$ & $\begin{array}{l}\text { Not re- } \\
\text { ported }\end{array}$ & $\begin{array}{l}\text { Not re- } \\
\text { ported }\end{array}$ & $\begin{array}{l}\text { Not re- } \\
\text { ported }\end{array}$ & $\begin{array}{l}\text { Not re- } \\
\text { ported }\end{array}$ & $\begin{array}{l}\text { Not re- } \\
\text { ported }\end{array}$ & $\begin{array}{l}\text { Not re- } \\
\text { ported }\end{array}$ \\
\hline $\begin{array}{l}\text { Zhu } \\
2014\end{array}$ & $\begin{array}{l}\text { Diabet- } \\
\text { ic foot } \\
\text { wounds }\end{array}$ & $\begin{array}{l}\text { Group A: vacuum } \\
\text { sealing drainage ( }= \\
\text { 30) } \\
\text { Group B: tradition- } \\
\text { al treatment (povi- } \\
\text { done/lipid dressing) } \\
(n=30)\end{array}$ & $\begin{array}{l}\text { Not re- } \\
\text { ported } \\
\text { Fol- } \\
\text { low-up } \\
\text { to } 6-10 \\
\text { months } \\
\text { for } \\
\text { wounds } \\
\text { recur- } \\
\text { rence }\end{array}$ & $\begin{array}{l}\text { Vacuum } \\
\text { sealing } \\
\text { drainage } \\
\text { admin- } \\
\text { istered } \\
\text { when nec- } \\
\text { essary } \\
\text { at sever- } \\
\text { al time } \\
\text { points }\end{array}$ & $\begin{array}{l}\text { Not re- } \\
\text { ported } \\
\text { proper- } \\
\text { ly - not } \\
\text { all ulcers } \\
\text { healed }\end{array}$ & $\begin{array}{l}\text { Group A: } \\
7 / 30(23 \%) \\
\text { Group B: } \\
5 / 30(17 \%)\end{array}$ & $\begin{array}{l}\text { Group A: } \\
0 \\
\text { Group } \\
\text { B: } 6 / 30 \\
(20 \%)\end{array}$ & $\begin{array}{l}\text { Of } \\
\text { healed } \\
\text { wounds } \\
\text { by sec- } \\
\text { ondary } \\
\text { surgery } \\
\text { (skin/ } \\
\text { flap } \\
\text { graft- } \\
\text { ing): } \\
\text { Group } \\
\text { A: } \\
\text { 23/30 } \\
\text { Group } \\
\text { B: } \\
\text { 19/24 }\end{array}$ & $\begin{array}{l}\text { Not re- } \\
\text { ported } \\
\text { proper- } \\
\text { ly-not } \\
\text { all ulcers } \\
\text { reached } \\
\text { this } \\
\text { point }\end{array}$ & $\begin{array}{l}\text { Not re- } \\
\text { ported }\end{array}$ & $\begin{array}{l}\text { Not re- } \\
\text { ported }\end{array}$ & $\begin{array}{l}\text { Not re- } \\
\text { ported }\end{array}$ & $\begin{array}{l}\text { Group } \\
\text { A: } 2 \\
\text { Group } \\
\text { B: } 4 \\
\text { Fol- } \\
\text { low-up } \\
\text { time: } \\
6-10 \\
\text { months }\end{array}$ \\
\hline
\end{tabular}

h: hour; IQR: interquartile range; ITT: intention to treat; n: number of participants; NPWT: negative pressure wound therapy; SF-36: 36-item Short Form; TNP: topical negative pressure. 


\section{A P PEN DICES}

\section{Appendix 1. Search strategies}

\section{Cochrane Wounds Specialised Register}

1 MESH DESCRIPTOR Foot Ulcer EXPLODE ALL AND INREGISTER 2 MESH DESCRIPTOR Diabetic Foot EXPLODE ALL AND INREGISTER

3 (diabet* near3 ulcer ${ }^{\star}$ ) AND INREGISTER

4 (diabet $^{*}$ near3 (foot or feet)) AND INREGISTER

5 (diabet* $^{\star}$ near3 wound $^{\star}$ ) AND INREGISTER

6 (diabet* near3 defect* ${ }^{\star}$ ) AND INREGISTER

7 MESH DESCRIPTOR Amputation EXPLODE ALL AND INREGISTER

8 MESH DESCRIPTOR Amputation Stumps EXPLODE ALL AND INREGISTER

9 (diabetic near3 amputat ${ }^{\star}$ ) AND INREGISTER

10 MESH DESCRIPTOR Debridement EXPLODE ALL AND INREGISTER

11 debrid $^{\star}$ or slough* or deslough* AND INREGISTER

12 \#1 OR \#2 OR \#3 OR \#4 OR \#5 OR \#6 OR \#7 OR \#8 OR \#9 OR \#10 OR \#11

13 MESH DESCRIPTOR Negative-Pressure Wound Therapy EXPLODE ALL AND INREGISTER

14 MESH DESCRIPTOR Suction EXPLODE ALL AND INREGISTER

15 MESH DESCRIPTOR Vacuum EXPLODE ALL AND INREGISTER

16 MESH DESCRIPTOR Drainage EXPLODE ALL AND INREGISTER

17 (negative pressure or negative-pressure or TNP) AND INREGISTER

18 (sub-atmospheric or subatmospheric) AND INREGISTER

19 ((seal* ${ }^{\star}$ next surface $\left.{ }^{\star}\right)$ or (seal ${ }^{\star}$ next aspirat $\left.\left.{ }^{\star}\right)\right)$ AND INREGISTER

20 (wound near2 suction*) AND INREGISTER

21 ((foam next suction) or (suction next dressing $)$ ) AND INREGISTER

22 (vacuum assisted or vacuum-assisted or VAC) AND INREGISTER

23 ((vacuum next therapy) or (vacuum next dressing ${ }^{\star}$ ) or (vacuum next seal ${ }^{\star}$ ) or (vacuum next closure) or (vacuum next compression) or (vacuum next pack ${ }^{\star}$ ) or (vacuum next drainage) or (suction* next drainage)) AND INREGISTER

24 \#13 OR \#14 OR \#15 OR \#16 OR \#17 OR \#18 OR \#19 OR \#20 OR \#21 OR \#22 OR \#23

$25 \# 12$ AND \#24

\section{The Cochrane Central Register of Controlled Clinical Trials (CENTRAL)}

\#1 MeSH descriptor: [Foot Ulcer] explode all trees \#2 MeSH descriptor: [Diabetic Foot] explode all trees

\#3 (diabet* near/3 ulcer $\left.{ }^{\star}\right)$ :ti,ab,kw

\#4 (diabet* near/5 (foot or feet)):ti,ab,kw

\#5 (diabet* near/5 wound $\left.{ }^{\star}\right): t i, a b, k w$

\#6 (diabet ${ }^{\star}$ near/3 defect $\left.{ }^{\star}\right): t i, a b, k w$

\#7 MeSH descriptor: [Amputation] explode all trees

\#8 MeSH descriptor: [Amputation Stumps] explode all trees

\#9 (diabetic near/3 amputat $\left.{ }^{\star}\right): t i, a b, k w$

\#10 MeSH descriptor: [Debridement] explode all trees

\#11 (debrid* or slough* or deslough $\left.{ }^{\star}\right): t i, a b, k w$

$\# 12$ \#1 or \#2 or \#3 or \#4 or \#5 or \#6 or \#7 or \#8 or \#9 or \#10 or \#11

\#13 MeSH descriptor: [Negative-Pressure Wound Therapy] explode all trees

\#14 MeSH descriptor: [Suction] explode all trees

\#15 MeSH descriptor: [Vacuum] explode all trees

\#16 MeSH descriptor: [Drainage] explode all trees

\#17 ("negative pressure" or negative-pressure or TNP):ti,ab,kw

\#18 (sub-atmospheric or subatmospheric):ti,ab,kw

\#19 ((seal ${ }^{\star}$ next surface ${ }^{\star}$ ) or (seal ${ }^{\star}$ next aspirat $\left.\left.{ }^{\star}\right)\right):$ ti,ab,kw

\#20 (wound near/2 suction*):ti,ab,kw

\#21 ((foam next suction) or (suction next dressing )):ti,ab,kw

\#22 (vacuum assisted or vacuum-assisted or VAC):ti,ab,kw

\#23 ((vacuum next therapy) or (vacuum next dressing ${ }^{\star}$ ) or (vacuum next seal ${ }^{\star}$ ) or (vacuum near closure) or (vacuum next compression) or (vacuum next pack*) or (vacuum next drainage) or (suction next drainage)):ti,ab,kw

$\# 24 \# 13$ or \#14 or \#15 or \#16 or \#17 or \#18 or \#19 or \#20 or \#21 or \#22 or \#23

$\# 25 \# 12$ and \#24

Negative pressure wound therapy for treating foot wounds in people with diabetes mellitus (Review) 


\section{Ovid MEDLINE}

1 exp Foot Ulcer/

2 exp Diabetic Foot/

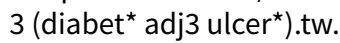

4 (diabet ${ }^{\star}$ adj3 (foot or feet)).tw.

5 (diabet $^{\star}$ adj3 wound $\left.^{\star}\right)$.tw.

6 (diabet $^{\star}$ adj3 defect $\left.{ }^{\star}\right)$.tw.

7 exp Amputation/

8 exp Amputation Stumps/

9 (diabetic adj3 amputat*).tw.

10 exp Debridement/

11 (debrid* or slough* or deslough*).tw.

12 or $/ 1-11$

13 exp Negative-Pressure Wound Therapy/

14 exp Suction/

15 exp Vacuum/

16 exp Drainage/

17 (negative pressure or negative-pressure or TNP).tw.

18 (sub-atmospheric or subatmospheric).tw.

$19\left(\left(\right.\right.$ seal $^{\star}$ adj surface $\left.{ }^{\star}\right)$ or $\left(\right.$ seal $^{\star}$ adj aspirat $\left.\left.{ }^{\star}\right)\right)$. tw.

20 (wound adj2 suction*).tw.

21 ((foam adj suction) or (suction adj dressing $\left.\left.{ }^{\star}\right)\right)$.tw.

22 (vacuum assisted closure or VAC).tw.

23 ((vacuum adj therapy) or (vacuum adj dressing ${ }^{\star}$ ) or (vacuum adj seal ${ }^{\star}$ ) or (vacuum adj closure) or (vacuum adj compression) or (vacuum adj pack ${ }^{\star}$ ) or (vacuum adj drainage) or (suction* adj drainage)).tw.

24 or/13-23

2512 and 24

26 randomized controlled trial.pt.

27 controlled clinical trial.pt.

28 randomi?ed.ab.

29 placebo.ab.

30 clinical trials as topic.sh.

31 randomly.ab.

32 trial.ti.

33 or $/ 26-32$

34 exp animals/ not humans.sh.

3533 not 34

3625 and 35

\section{Ovid Embase}

1 exp foot ulcer/

2 exp diabetic foot/

3 (diabet $^{\star}$ adj3 ulcer $\left.^{\star}\right)$.tw.

4 (diabet* ${ }^{\star}$ adj3 (foot or feet)).tw.

5 (diabet $^{\star}$ adj3 wound $\left.{ }^{\star}\right)$.tw.

6 (diabet* adj3 defect $\left.{ }^{\star}\right)$.tw.

7 exp amputation/

8 exp amputation stump/

9 (diabetic adj3 amputat ${ }^{\star}$ ).tw.

10 exp debridement/

11 (debrid* $^{\star}$ or slough* or deslough ${ }^{\star}$ ).tw.

12 or/1-11

13 exp vacuum assisted closure/

14 exp suction drainage/

15 exp vacuum/

16 exp wound drainage/

17 (negative pressure or negative-pressure or TNP).tw.

18 (sub-atmospheric or subatmospheric).tw.

19 ((seal ${ }^{\star}$ adj surface $\left.{ }^{\star}\right)$ or $\left(\right.$ seal $^{\star}$ adj aspirat $\left.\left.{ }^{\star}\right)\right)$. tw.

20 (wound adj2 suction*).tw. 
21 ((foam adj suction) or (suction adj dressing $\left.\left.{ }^{\star}\right)\right)$. tw.

22 (vacuum assisted closure or VAC).tw.

23 ((vacuum adj therapy) or (vacuum adj dressing ${ }^{\star}$ ) or (vacuum adj seal*) or (vacuum adj closure) or (vacuum adj compression) or (vacuum $\operatorname{adj~pack}^{\star}$ ) or (vacuum adj drainage) or (suction* adj drainage)).tw.

24 or/13-23

2512 and 24

26 Randomized controlled trials/

27 Single-Blind Method/

28 Double-Blind Method/

29 Crossover Procedure/

30 (random $^{\star}$ or factorial ${ }^{\star}$ or crossover ${ }^{\star}$ or cross over ${ }^{\star}$ or cross-over $^{\star}$ or placebo ${ }^{\star}$ or assign ${ }^{\star}$ or allocat ${ }^{\star}$ or volunteer ${ }^{\star}$ ).ti,ab.

31 (doubl* $^{\star}$ adj blind*).ti,ab.

32 (singl $^{\star}$ adj blind $\left.{ }^{\star}\right)$.ti,ab.

33 or/26-32

34 exp animals/ or exp invertebrate/ or animal experiment/ or animal model/ or animal tissue/ or animal cell/ or nonhuman/

35 human/ or human cell/

36 and/34-35

3734 not 36

3833 not 37

3925 and 38

\section{EBSCO CINAHL Plus}

S39 S25 AND S38

S38 S26 OR S27 OR S28 OR S29 OR S30 OR S31 OR S32 OR S33 OR S34 OR S35 OR S36 OR S37

$\mathrm{S} 37 \mathrm{TI}$ allocat* ${ }^{\star}$ andom* or AB allocat* ${ }^{\star}$ random*

S36 MH "Quantitative Studies"

S35 TI placebo* or AB placebo*

S34 MH "Placebos"

S33 TI random* allocat* or AB random* allocat ${ }^{\star}$

S32 MH "Random Assignment"

S31 TI randomi?ed control ${ }^{\star}$ trial $^{\star}$ or $\mathrm{AB}$ randomi?ed control ${ }^{\star}$ trial $^{*}$

S30 AB ( singl* or doubl* or trebl* or tripl ${ }^{*}$ ) and AB ( blind ${ }^{\star}$ or mask ${ }^{*}$ )

S29 TI ( singl* or doubl* or trebl* or tripl ${ }^{\star}$ ) and TI ( blind ${ }^{\star}$ or mask ${ }^{\star}$ )

S28 TI clinic* N1 trial* or AB clinic* N1 trial*

S27 PT Clinical trial

S26 MH "Clinical Trials+"

S25 S12 AND S24

S24 S13 OR S14 OR S15 OR S16 OR S17 OR S18 OR S19 OR S20 OR S21 OR S22 OR S23

S23 AB ( ((vacuum therapy) or (vacuum dressing $\left.{ }^{\star}\right)$ or (vacuum seal ${ }^{\star}$ ) or (vacuum closure) or (vacuum compression) or (vacuum pack $\left.{ }^{\star}\right)$ or (vacuum drainage) or (suction* drainage)) ) OR TI ( ((vacuum therapy) or (vacuum dressing ${ }^{\star}$ ) or (vacuum seal*) or (vacuum closure) or (vacuum compression) or (vacuum pack*) or (vacuum drainage) or (suction* drainage)))

S22 TI ( (vacuum assisted or vacuum-assisted or VAC) ) OR AB ( (vacuum assisted or vacuum-assisted or VAC) )

$\mathrm{S} 21 \mathrm{TI}$ ( ((foam $\mathrm{n} 1$ suction) or (suction $\mathrm{n} 1$ dressing $\left.\left.{ }^{\star}\right)\right)$ ) OR AB ( ((foam $\mathrm{n} 1$ suction) or (suction $\mathrm{n} 1$ dressing $\left.\left.{ }^{\star}\right)\right)$ )

$\mathrm{S} 20 \mathrm{TI}$ (wound $\mathrm{n} 2$ suction*) OR AB (wound $\mathrm{n} 2$ suction*)

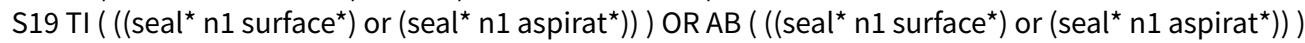

S18 TI ( (sub-atmospheric or subatmospheric) ) OR AB ( (sub-atmospheric or subatmospheric))

S17 TI ( (negative pressure or negative-pressure or TNP) ) OR AB ( (negative pressure or negative-pressure or TNP))

S16 (MH "Drainage+")

S15 (MH "Vacuum")

S14 (MH "Suction+")

S13 (MH "Negative Pressure Wound Therapy")

S12 S1 OR S2 OR S3 OR S4 OR S5 OR S6 OR S7 OR S8 OR S9 OR S10 OR S11

S11 TI ( debrid* or slough* or deslough*) OR AB ( debrid* or slough* or deslough* )

S10 (MH "Debridement+")

S9 TI (diabetic n3 amputat*) OR AB (diabetic n3 amputat*)

S8 (MH "Amputation Stumps")

S7 (MH "Amputation+")

S6 TI (diabet ${ }^{\star} n 3$ defect $\left.^{\star}\right)$ OR AB (diabet ${ }^{\star} n 3$ defect $\left.^{\star}\right)$

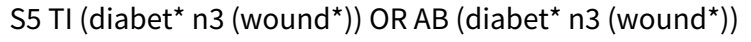

S4 TI ( (diabet* n3 (foot or feet)) ) OR AB ( (diabet* n3 (foot or feet)) )

S3 TI (diabet ${ }^{\star}$ n3 ulcer $\left.{ }^{\star}\right)$ OR AB (diabet ${ }^{\star}$ n3 ulcer ${ }^{\star}$ ) 
S2 (MH "Diabetic Foot")

S1 (MH "Foot Ulcer+")

US National Institutes of Health Ongoing Trials Register (ClinicalTrials.gov)

(diabetic OR diabetes OR "foot ulcer") AND ("negative pressure" OR NPWT OR TNP OR vacuum assisted OR VAC)

World Health Organization International Clinical Trials Registry Platform

(diabetic OR diabetes OR "foot ulcer") AND ("negative pressure" OR NPWT OR TNP OR vacuum assisted OR VAC)

\section{Appendix 2. Cochrane tool for assessing risk of bias}

\section{Was the allocation sequence randomly generated?}

\section{Low risk of bias}

The investigators describe a random component in the sequence generation process such as: referring to a random number table; using a computer random number generator; coin tossing; shuffling cards or envelopes; throwing dice; drawing of lots.

\section{High risk of bias}

The investigators describe a non-random component in the sequence generation process. Usually, the description would involve some systematic, non-random approach, for example: sequence generated by odd or even date of birth; sequence generated by some rule based on date (or day) of admission; sequence generated by some rule based on hospital or clinic record number.

\section{Unclear}

Insufficient information about the sequence generation process is provided to permit a judgement of low or high risk of bias.

\section{Was the treatment allocation adequately concealed?}

\section{Low risk of bias}

Participants and investigators enrolling participants could not foresee assignment because one of the following, or an equivalent method, was used to conceal allocation: central allocation (including telephone, web-based, and pharmacy-controlled randomisation); sequentially numbered drug containers of identical appearance; sequentially numbered, opaque, sealed envelopes.

\section{High risk of bias}

Participants or investigators enrolling participants could possibly foresee assignments and thus introduce selection bias, such as allocation based on: use of an open random allocation schedule (e.g. a list of random numbers); assignment envelopes without appropriate safeguards (e.g. envelopes were unsealed, non-opaque, or not sequentially numbered); alternation or rotation; date of birth; case record number; any other explicitly unconcealed procedure.

\section{Unclear}

Insufficient information is provided to permit a judgement of low or high risk of bias. This is usually the case if the method of concealment is not described, or not described in sufficient detail to allow a definitive judgement, for example if the use of assignment envelopes is described, but it is unclear whether envelopes were sequentially numbered, opaque, and sealed.

\section{Blinding: was knowledge of the allocated interventions adequately prevented during the study?}

\section{Low risk of bias}

Any one of the following:

- No blinding, but the review authors judge that the outcome and the outcome measurement are not likely to be influenced by lack of blinding.

- Blinding of participants and key study personnel ensured, and unlikely that the blinding could have been broken.

- Either participants or some key study personnel were not blinded, but outcome assessment was blinded, and the non-blinding of others unlikely to introduce bias.

\section{High risk of bias}

Any one of the following:

- No blinding or incomplete blinding, and the outcome or outcome measurement is likely to be influenced by lack of blinding.

- Blinding of key study participants and personnel attempted, but likely that the blinding could have been broken.

- Either participants or some key study personnel were not blinded, and the non-blinding of others likely to introduce bias.

Negative pressure wound therapy for treating foot wounds in people with diabetes mellitus (Review) 


\section{Unclear}

Either of the following:

- Insufficient information to permit judgement of low or high risk of bias.

- The study did not address this outcome.

\section{Were incomplete outcome data adequately addressed?}

\section{Low risk of bias}

Any one of the following:

- No missing outcome data.

- Reasons for missing outcome data are unlikely to be related to true outcome (for survival data, censoring unlikely to be introducing bias).

- Missing outcome data are balanced in numbers across intervention groups, with similar reasons for missing data across groups.

- For dichotomous outcome data, the proportion of missing outcomes compared with the observed event risk is not enough to have a clinically relevant impact on the intervention effect estimate.

- For continuous outcome data, a plausible effect size (difference in means or standardised difference in means) among missing outcomes is not enough to have a clinically relevant impact on the observed effect size.

- Missing data have been imputed using appropriate methods.

\section{High risk of bias}

Any one of the following:

- Reasons for missing outcome data are likely to be related to the true outcome, with either an imbalance in numbers or reasons for missing data across intervention groups.

- For dichotomous outcome data, the proportion of missing outcomes compared with the observed event risk is enough to induce clinically relevant bias in the intervention effect estimate.

- For continuous outcome data, a plausible effect size (difference in means or standardised difference in means) among missing outcomes is enough to induce a clinically relevant bias in the observed effect size.

- 'As-treated' analysis done with a substantial departure of the intervention received from that assigned at randomisation.

- Potentially inappropriate application of simple imputation.

\section{Unclear}

Either of the following:

- Insufficient reporting of attrition/exclusions to permit a judgement of low or high risk of bias (e.g. number randomised not stated, no reasons for missing data provided).

- The study did not address this outcome.

\section{Are reports of the study free of suggestion of selective outcome reporting?}

\section{Low risk of bias}

Either of the following:

- The study protocol is available and all of the study's prespecified (primary and secondary) outcomes that are of interest in the review have been reported in the prespecified way.

- The study protocol is not available, but it is clear that the published reports include all expected outcomes, including those that were prespecified (convincing text of this nature may be uncommon).

\section{High risk of bias}

Any one of the following:

- Not all of the study's prespecified primary outcomes have been reported.

- One or more primary outcomes is/are reported using measurements, analysis methods, or subsets of the data (e.g. subscales) that were not prespecified.

- One or more reported primary outcomes was/were not prespecified (unless clear justification for their reporting is provided, such as an unexpected adverse effect).

- One or more outcomes of interest in the review is/are reported incompletely so that they cannot be entered in a meta-analysis.

- The study report fails to include results for a key outcome that would be expected to have been reported for such a study.

Negative pressure wound therapy for treating foot wounds in people with diabetes mellitus (Review) 


\section{Unclear}

Insufficient information is provided to permit a judgement of low or high risk of bias. It is likely that the majority of studies will fall into this category.

\section{Other sources of potential bias}

\section{Low risk of bias}

The study appears to be free of other sources of bias.

\section{High risk of bias}

There is at least one important risk of bias. For example, the study:

- had a potential source of bias related to the specific study design used; or

- has been claimed to have been fraudulent; or

- had some other problem.

\section{Unclear}

There may be a risk of bias, but there is either:

- insufficient information to assess whether an important risk of bias exists; or

- insufficient rationale or evidence that an identified problem will introduce bias.

\section{WHAT'S NEW}

\begin{tabular}{lll}
\hline Date & Event & Description \\
\hline 30 January 2018 & $\begin{array}{l}\text { New citation required and conclusions } \\
\text { have changed }\end{array}$ & $\begin{array}{l}\text { Six additional studies included in the review and conclusions } \\
\text { changed. }\end{array}$ \\
\hline 23 January 2018 & Amended & $\begin{array}{l}\text { Two studies previously awaiting classification have been moved } \\
\text { to excluded studies. }\end{array}$ \\
\hline 23 January 2018 & New search has been performed & $\begin{array}{l}\text { First update: new search. GRADE assessment of certainty of the } \\
\text { evidence undertaken and methodology updated. ZL joined the } \\
\text { author team. }\end{array}$ \\
\hline
\end{tabular}

\section{H I S T O R Y}

Protocol first published: Issue 1, 2013

Review first published: Issue 10, 2013

\begin{tabular}{lll}
\hline Date & Event & Description \\
\hline 3 June 2014 & Amended & Edits to table labels \\
\hline
\end{tabular}

\section{CONTRIBUTIONSOF AUTHORS}

Zhenmi Liu: co-ordinated the review update; extracted data; checked the quality of data extraction; analysed or interpreted data; undertook and checked quality assessment; performed statistical analysis; checked the quality of the statistical analysis; produced the first draft of the review update; contributed to writing or editing the review update; advised on the review update; secured funding; performed previous work that was the foundation of the current review update; wrote to study authors, experts and companies; performed economic analysis; performed translations; approved the final review update prior to submission; and is a guarantor of the review update. 
Jo Dumville: conceived the review; designed and co-ordinated the review update; extracted data; checked the quality of data extraction; analysed or interpreted data; undertook and checked quality assessment; checked the quality of the statistical analysis; contributed to writing or editing the review update; advised on the review update; secured funding; performed previous work that was the foundation of the current review update and approved the final review update prior to submission.

Robert Hinchliffe: co-ordinated the review update; advised on the review update; performed previous work that was the foundation of the current review update and approved the final review update prior to submission.

Nicky Cullum: co-ordinated the review update; advised on the review update; performed previous work that was the foundation of the current review update and approved the final review update prior to submission.

Fran Game: co-ordinated the review update; advised on the review update; performed previous work that was the foundation of the current review update and approved the final review update prior to submission.

Nikki Stubbs: co-ordinated the review update; advised on the review update and performed previous work that was the foundation of the current review update.

Michael Sweeting: co-ordinated the review update; advised on the review update and performed previous work that was the foundation of the current review update.

Frank Peinemann: co-ordinated the review update; advised on the review update and performed previous work that was the foundation of the current review update.

\section{Contributions of editorial base}

Joan Webster (Editor): edited the review and the update, advised on methodology, interpretation and content and approved the final version for publication.

Sally Bell-Syer and Gill Rizzello (Managing Editors): co-ordinated the editorial process. Advised on interpretation and content. Edited the review and the update respectively.

Ruth Foxlee and Naomi Shaw (Information Specialists): designed and edited the search strategy, edited the methods section and ran the searches for the review and update respectively.

Rachel Richardson (Methodologist): edited the review.

Ursula Gonthier (Editorial Assistant): edited the Plain language summary and the reference sections.

\section{DECLARATIONSOF INTEREST}

Zhenmi Liu: my employment at the University of Manchester was supported by a grant from the National Institute for Health Research (NIHR) UK (NIHR Systematic Review Fellowships).

Jo Dumville: received research funding from the National Institute for Health Research (NIHR) UK for the production of systematic reviews focusing on high priority Cochrane Reviews in the prevention and treatment of wounds. This research was co-funded by the NIHR Manchester Biomedical Research Centre and partly funded by the National Institute for Health Research Collaboration for Leadership in Applied Health Research and Care (NIHR CLAHRC) Greater Manchester.

Robert Hinchliffe: none known.

Nicky Cullum: received research funding from the National Institute for Health Research (NIHR) UK for wounds-related research and systematic reviews focusing on high priority Cochrane Reviews in the prevention and treatment of wounds. This research was co-funded by the NIHR Manchester Biomedical Research Centre and partly funded by the National Institute for Health Research Collaboration for Leadership in Applied Health Research and Care (NIHR CLAHRC) Greater Manchester.

Fran Game: grant funding was provided to Derby Teaching Hospitals NHS FT for a researcher led, NHS sponsored trial into a device for wound healing for the diabetic foot by the manufacturer of the device, Reapplix ApS Denmark. Grant funding was also provided to Derby Teaching Hospitals NHS FT for an investigator led, NHS sponsored trial into wound healing, using Omnigen by the manufacturers of the product, NuVision.

Nikki Stubbs: has received payments for Cogora, a healthcare marketing agency and expenses for conference attendance. She has received funding from pharmaceutical companies to support non product-related training and education events in the UK National Health Service that were unrelated to the subject matter of this systematic review.

Michael Sweeting: none known. 
Frank Peinemann: none known.

\section{SOURCES OF SUPPORT}

\section{Internal sources}

- Division of Nursing, Midwifery and Social Work, School of Health Sciences, Faculty of Biology, Medicine and Health, University of Manchester, UK, UK.

\section{External sources}

- National Institute for Health Research (NIHR), UK.

This project was supported by the NIHR, via Cochrane Infrastructure and Cochrane Programme Grant funding (NIHR Cochrane Programme Grant 13/89/08 - High Priority Cochrane Reviews in Wound Prevention and Treatment) to Cochrane Wounds. The views and opinions expressed herein are those of the authors and do not necessarily reflect those of the Systematic Reviews Programme, the NIHR, the NHS or the Department of Health.

- NIHR Manchester Biomedical Research Centre (BRC), UK.

This research was co-funded by the NIHR Manchester BRC. The views expressed in this publication are those of the authors and not necessarily those of the NHS, the National Institute for Health Research or the Department of Health.

- National Institute for Health Research Collaboration for Leadership in Applied Health Research and Care (NIHR CLAHRC), Greater Manchester, UK.

Nicky Cullum and Jo Dumville's work on this project was partly funded by the NIHR CLAHRC, Greater Manchester. The funder had no role in the decision to publish, or preparation of the manuscript. However, the review may be considered to be affiliated to the work of the NIHR CLAHRC Greater Manchester. The views expressed herein are those of the authors and not necessarily those of the NHS, NIHR or the Department of Health.

- National Institute for Health Research (NIHR) Systematic Review Fellowships (NIHR-RMFI-2015-06-52 Zhenmi Liu), UK.

\section{DIFFERENCES BETWEEN PROTOCOLANDREVIEW}

We have populated sections of the 'Methods' and 'Discussion' which were previously not available in the older version of Review Manager as follows: Assessment of reporting biases; Overall completeness and applicability of evidence.

Description of the condition: we added additional information to the 'Background' section.

Types of outcome measures: we removed 'change (and rate of change) in wound size' as this is not 'complete wound healing.' We also made a post hoc decision to assess 'cost-effectiveness' rather than 'resource use.' This is an important outcome from both clinical and practical perspective and negative pressure wound therapy (NPWT) is used widely but very expensive. We also added 'number of wounds closed or covered with surgery' and 'time to closure or coverage surgery' as secondary outcomes as they are clinically relevant outcomes, differing from the outcome of 'complete wound healing.'

Summary of findings: we decided to downgrade when the 'Risk of bias' assessment for selection bias or blinding was unclear. We also added these outcomes: number of wounds closed or covered with surgery; adverse events; cost-effectiveness and wound recurrence to the 'Summary of findings' tables.

Due to the new included studies which included various types of dressings, we carried out a post hoc subgroup analysis based on the type of dressings.

\section{N DEX TERMS}

\section{Medical Subject Headings (MeSH)}

*Amputation; *Bandages [statistics \& numerical data]; *Wound Healing; Debridement; Diabetic Foot [ ${ }^{*}$ surgery]; Negative-Pressure Wound Therapy [adverse effects] [*methods] [statistics \& numerical data]; Randomized Controlled Trials as Topic

\section{MeSH check words}

Humans 